Aus der Poliklinik für Präventive Zahnmedizin, Parodontologie und Kariologie

(Prof. Dr. med. dent. A. Wiegand)

im Zentrum Zahn-, Mund- und Kieferheilkunde

der Medizinischen Fakultät der Universität Göttingen

\title{
In-vitro-Studie zum Einfluss verschiedener Immunsuppressiva auf Ge- samt- und Lebendzellzahl, Zelldurchmesser und Menge an Prokollagen Typ I gingivaler Fibroblasten
}

\author{
INAUGURAL-DISSERTATION \\ zur Erlangung des Doktorgrades \\ für Zahnheilkunde \\ der Medizinischen Fakultät der \\ Georg-August-Universität zu Göttingen
}

vorgelegt von

Lisa Sievers

aus Kassel

Göttingen 2016 
Dekan: $\quad$ Prof. Dr. rer. nat. H.K. Kroemer

Referent: $\quad$ PD Dr. Dirk Ziebolz

Ko-Referent/in: Prof. Dr. Cornelia Sabine Seitz

Drittreferent/in: $\quad$ Prof. Dr. Detlef Haase

Datum der mündlichen Prüfung: 03.07.2017 
Hiermit erkläre ich, die Dissertation mit dem Titel „In-vitro-Studie zum Einfluss verschiedener Immunsuppressiva auf Gesamt- und Lebendzellzahl, Zelldurchmesser und Menge an Prokollagen Typ I gingivaler Fibroblasten“ eigenständig angefertigt und keine anderen als die von mir angegebenen Quellen und Hilfsmittel verwendet zu haben.

Göttingen, den 19.12.2016

Lisa Sievers 


\section{Inhaltsverzeichnis}

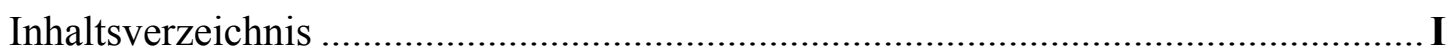

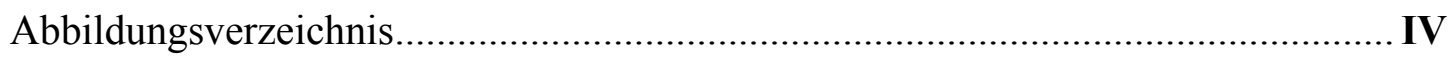

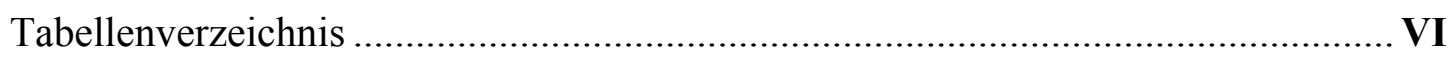

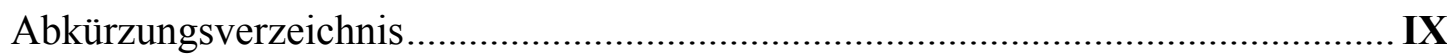

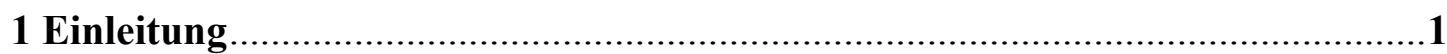

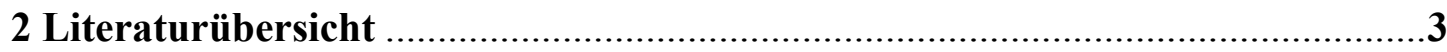

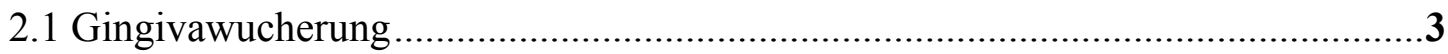

2.1.1 Definition und Ätiologie der Gingivawucherung ................................................3

2.1.2 Die medikamentös-induzierte Gingivawucherung ..........................................4

2.1.2.1 Medikamentös-induzierte Gingivawucherung durch die Einnahme von

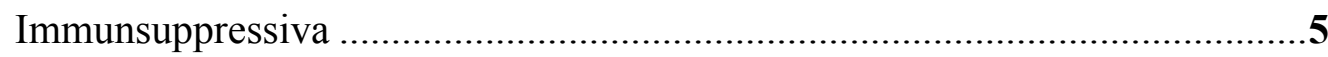

2.1.2.2 Epidemiologie der medikamentös-induzierten Gingivawucherung ..................7

2.1.2.3 Therapieansätze bei der medikamentös-induzierten Gingivawucherung ..........7

2.2 Organtransplantation: Immunsuppressiva und ihre Wirkungsweise ......................9

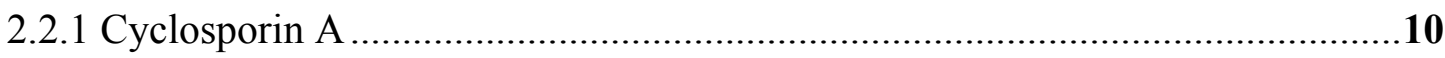

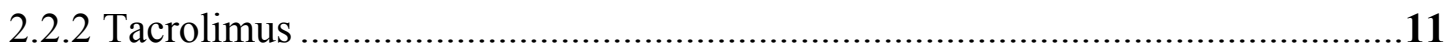

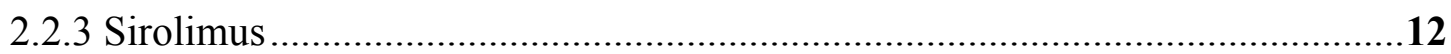

2.3 Überblick zur aktuellen Studienlage...........................................................13

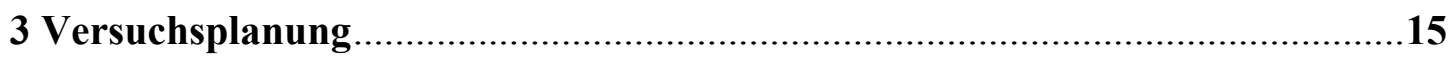

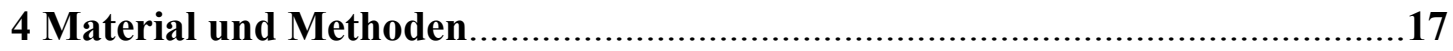

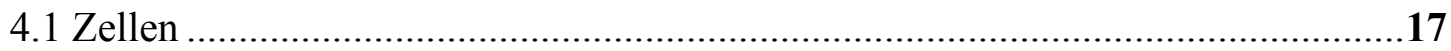

4.1.1 Zellkultur zur Bereitstellung der 3T3-Zelllinie ...........................................18

4.2 Immunsuppressiva und deren Aufbereitung .....................................................20

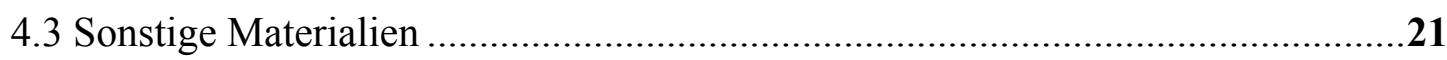

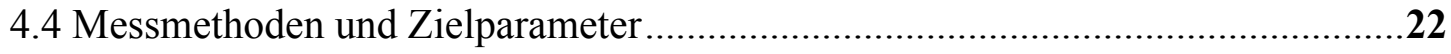

4.4.1 Elektrisch basierte Zellzahlbestimmung mittlels CASY ${ }^{\circledR}$.................................22

4.4.2 CellTiter-Blue ${ }^{\circledR}$ Cell Viability Assay .............................................................23

4.4.3 Messung der Menge an Prokollagen Typ I (Mouse Procollagen Type I

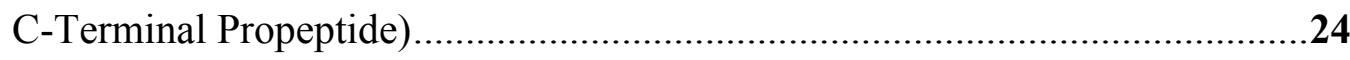

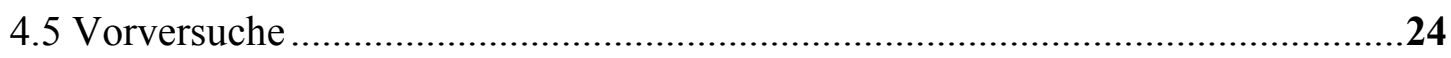

4.5.1 Vorversuche zur Bestimmunng der Ausgangszellzahl ...................................24 
4.5.2 Vorversuche zur Bestimmunng der Konzentration der Immunsuppressiva .......25

4.5.3 Vorversuche zur Messung der Prokollagen Typ I Menge .................................28

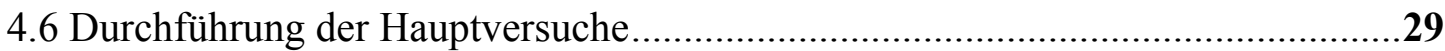

4.6.1 Bestimmung der Parameter: Gesamt- und Lebendzellzahl, Zelldurchmesser .....30

4.6.2 Bestimmung des Parameters: Prokollagen Typ I..............................................31

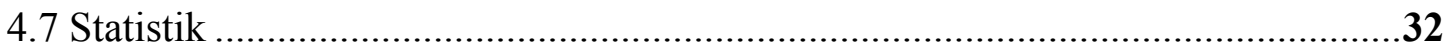

5 Ergebnisse

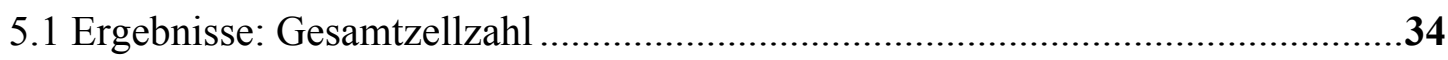

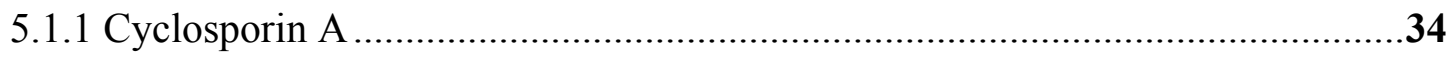

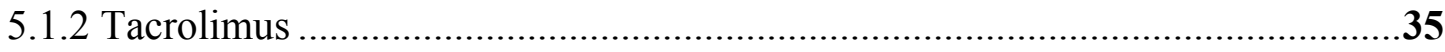

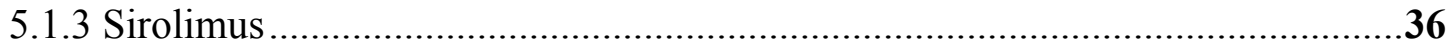

5.1.4 Konzentrationsvergleich der Konzentration 15 ng/Well und Konzentrationsvergleich der mittleren Konzentration der Immunsuppressiva .........................38

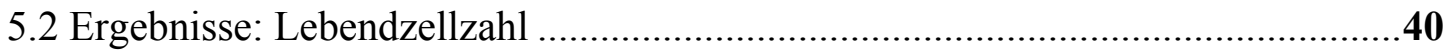

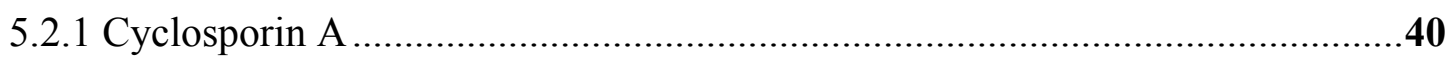

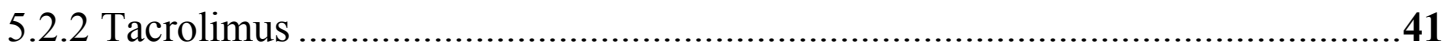

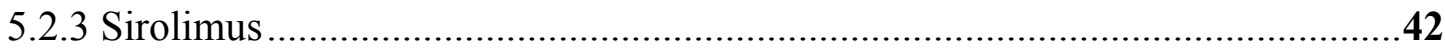

5.2.4 Konzentrationsvergleich der Konzentration 15 ng/Well und Konzentrationsvergleich der mittleren Konzentration der Immunsuppressiva ........................44

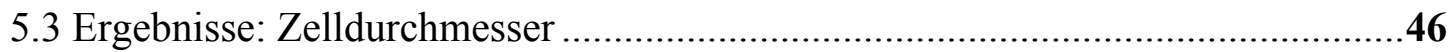

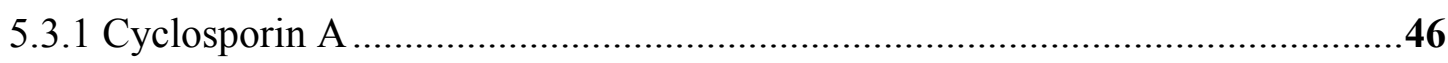

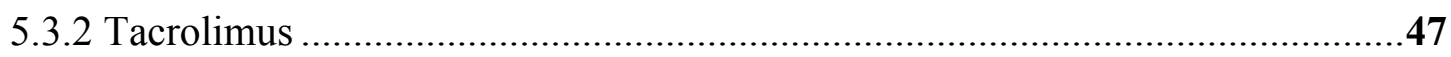

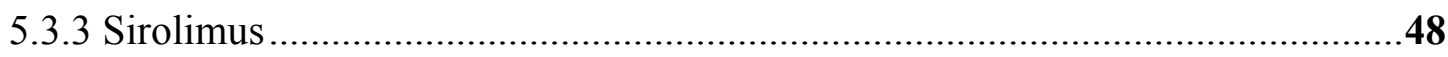

5.3.4 Konzentrationsvergleich der Konzentration 15 ng/Well und Konzentrationsvergleich der mittleren Konzentration der Immunsuppressiva ........................49

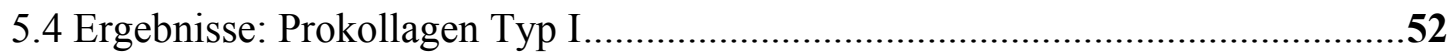

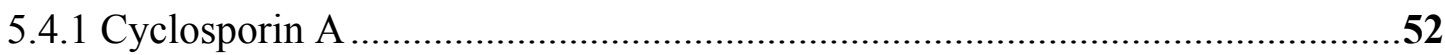

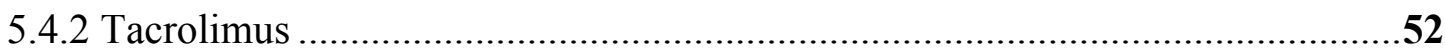

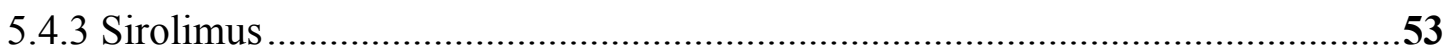

5.4.4 Konzentrationsvergleich der Konzentration 15 ng/Well und Konzentrationsvergleich der mittleren Konzentration der Immunsuppressiva .........................54

5.4.5 Statistische Auswertung der Menge an Prokollagen Typ I...............................55

5.5 Fotografische Dokumentation der behandelten Zellen .......................................55

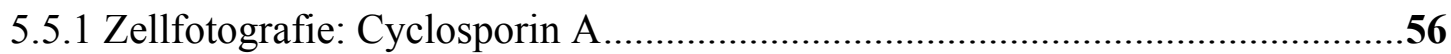

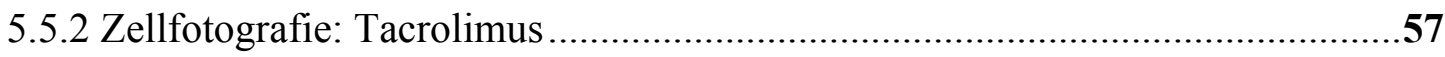




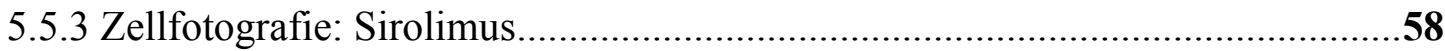

5.6 Zusammenfassung der wichtigsten Ergebnisse ..............................................59

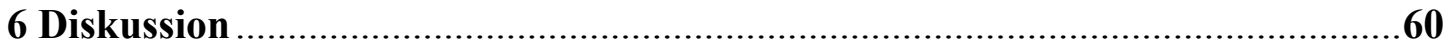

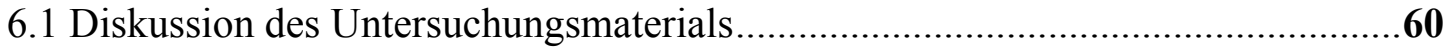

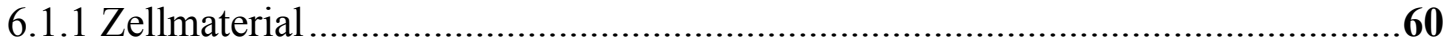

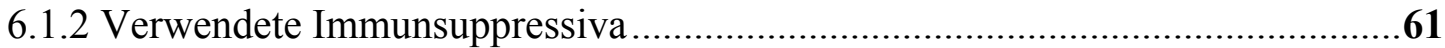

6.2 Diskussion der Untersuchungsmethoden .....................................................63

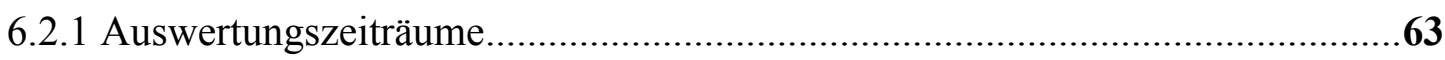

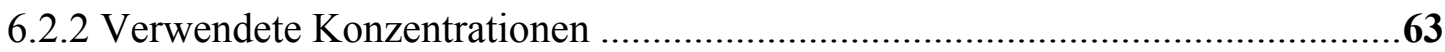

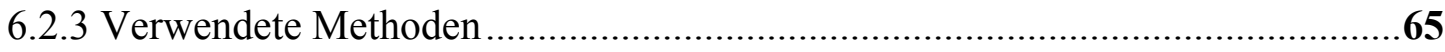

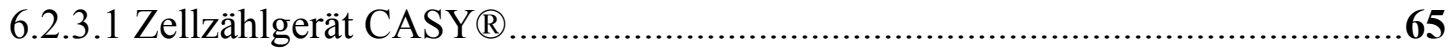

6.2.3.2 Mouse Procollagen Type I C-Terminal Propeptide ELISA.............................65

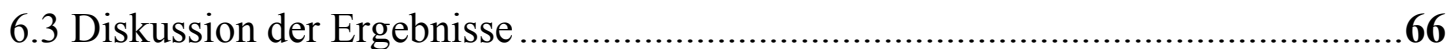

6.3.1 Gesamt- und Lebendzellzahl ....................................................................66

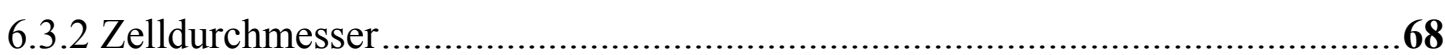

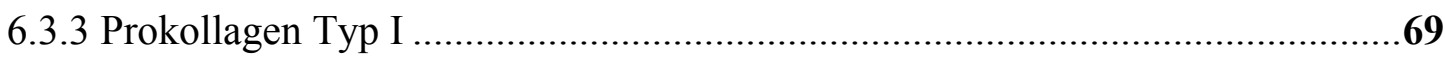

6.3.4 Interpretation der Ergebnisse im Kontext des multifaktoriellen Modells...........71

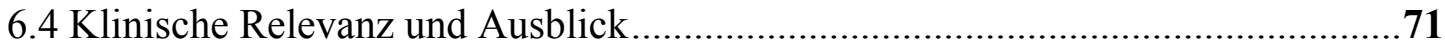

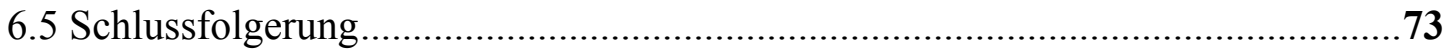

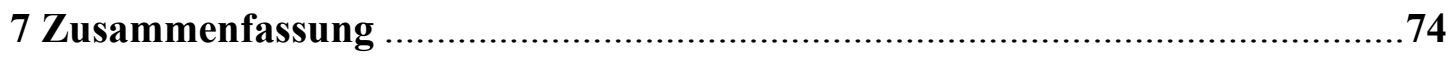

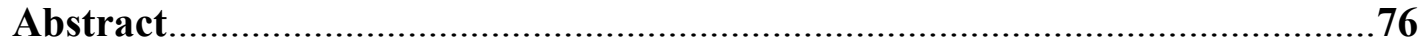

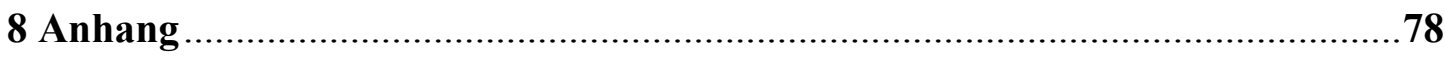

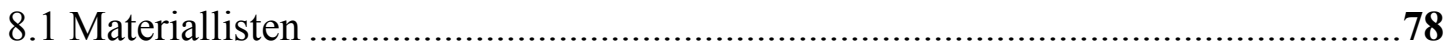

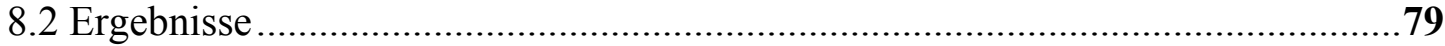

8.2.1 Ergebnisse: Gesamt- und Lebendzellzahl ...........................................................79

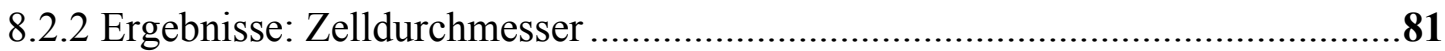

8.2.3 Ergebnisse: Prokollagen Typ I..............................................................83

8.2.4 Angabe der allgemeinen statistischen Auswertung aller Parameter...................84

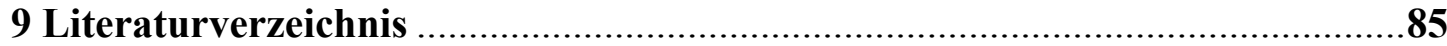




\section{Abbildungsverzeichnis}

Abbildung 1:

23-jährige Patientin, Zustand nach NTx, Immunsuppression mit Cyclosporin A;

mit freundlicher Genehmigung von Prof. R. Mausberg, Universität Göttingen

Abbildung 2:

Immortalisierte Zellpopulation von 3T3-Zellen; Fotografie aus eigenem

Bestand, aufgenommen mit Axiovert 200M (Zeiss, Göttingen, Deutschland)

Abbildung 3:

Wachstumskurve der ermittelten Lebendzellzahl mithilfe des

Zellzählgerätes $C A S Y{ }^{\circledR}$ (Ausgangszellzahl von $2 \times 10^{4}$ Zellen)

Abbildung 4:

Wachstumskurve der ermittelten Ausgangszellzahl von $2 \times 10^{4}$ Zellen

mithilfe des Proliferationsassays CellTiter-Blue ${ }^{\circledR}$ Cell Viability Assay

Abbildung 5:

Vorversuch zur Konzentrationsfindung: Gesamtzellzahl (x10 $\left.{ }^{4}\right)$

Abbildung 6:

Vorversuch zur Konzentrationsfindung: Lebendzellzahl (x10 $)$

Abbildung 7:

Vorversuch zur Konzentrationsfindung: Zelldurchmesser $(\mu \mathrm{m})$

Abbildung 8:

Vorversuch zur Bestimmung der Prokollagen Typ I Menge (ng/ml) aus dem

Überstand mithilfe des PICP ELISAs

Abbildung 9:

Versuchsablauf der Studie

Abbildung 10:

Darstellung der Gesamtzellzahl (x $10^{4}$ Zellen) über einen Auswertungszeitraum bis 72 Stunden: Behandlung mit CSA

Abbildung 11:

Darstellung der Gesamtzellzahl (x $10^{4}$ Zellen) über einen Auswertungszeitraum bis 72 Stunden: Behandlung mit TCR

Abbildung 12 :

Darstellung der Gesamtzellzahl (x $10^{4}$ Zellen) über einen Auswertungszeitraum bis 72 Stunden: Behandlung mit SIR

Abbildung 13:

Darstellung der Gesamtzellzahl (x $10^{4}$ Zellen): Konzentrationsvergleich

$15 \mathrm{ng} /$ Well der Immunsuppressiva

Abbildung 14:

Darstellung der Gesamtzellzahl (x $10^{4}$ Zellen): Konzentrationsvergleich der mittleren Konzentration der Immunsuppressiva

Abbildung 15:

Darstellung der Lebendzellzahl (x $10^{4}$ Zellen) über einen Auswertungszeitraum bis 72 Stunden: Behandlung mit CSA 
Abbildung 16:

Darstellung der Lebendzellzahl (x $10^{4}$ Zellen) über einen Auswertungszeitraum bis 72 Stunden: Behandlung mit TCR

Abbildung 17:

Darstellung der Lebendzellzahl (x $10^{4}$ Zellen) über einen Auswertungszeitraum bis 72 Stunden: Behandlung mit SIR

Abbildung 18:

Darstellung der Lebendzellzahl (x $10^{4}$ Zellen): Konzentrationsvergleich

$15 \mathrm{ng} /$ Well der Immunsuppressiva

Abbildung 19:

Darstellung der Lebendzellzahl (x $10^{4}$ Zellen): Konzentrationsvergleich der mittleren Konzentration der Immunsuppressiva

Abbildung 20:

Darstellung des Zelldurchmessers $(\mu \mathrm{m})$ über einen Auswertungszeitraum

von 72 Stunden: Behandlung mit CSA

Abbildung 21:

Darstellung des Zelldurchmessers $(\mu \mathrm{m})$ über einen Auswertungszeitraum von 72 Stunden: Behandlung mit TCR

Abbildung 22:

Darstellung des Zelldurchmessers $(\mu \mathrm{m})$ über einen Auswertungszeitraum von 72 Stunden: Behandlung mit SIR

Abbildung 23:

Darstellung des Zelldurchmessers ( $\mu \mathrm{m})$ : Konzentrationsvergleich 15 ng/Well der Immunsuppressiva

Abbildung 24:

Darstellung des Zelldurchmessers $(\mu \mathrm{m})$ : Konzentrationsvergleich der mittleren

Konzentration der Immunsuppressiva

Abbildung 25:

Darstellung der Prokollagen Typ I Menge (ng/ml): Behandlung mit CSA

Abbildung 26:

Darstellung der Prokollagen Typ I Menge (ng/ml): Behandlung mit TCR

Abbildung 27:

Darstellung der Prokollagen Typ I Menge (ng/ml): Behandlung mit SIR

Abbildung 28:

Darstellung der Prokollagen Typ I Menge (ng/ml): Konzentrationsvergleich

$15 \mathrm{ng} /$ Well der Immunsuppressiva

Abbildung 29:

Darstellung der Prokollagen Typ I Menge (ng/ml): Konzentrationsvergleich der mittleren Konzentration der Immunsuppressiva.

Abbildung 30-34:

Fotografische Darstellung der Zellen unter Einwirkung von CSA

Abbildung 35-39:

Fotografische Darstellung der Zellen unter Einwirkung von TCR

Abbildung 40-44:

Fotografische Darstellung der Zellen unter Einwirkung von SIR 


\section{Tabellenverzeichnis}

Tabelle 1:

Überblick - Prävalenz der medikamentös-induzierten Gingivawucherung ...................7

Tabelle 2:

Überblick - aktuelle Studienlage (2010 - 2015)....................................................14

Tabelle 3:

Überblick - Immunsuppressiva (CSA: Cyclosporin A, TCR: Tacrolimus,

SIR: Sirolimus)

Tabelle 4:

Angabe der Konzentrationen (ng/Well) für die Hauptversuche

Tabelle 5:

Angabe der Standards (ng/ml) zur Durchführung des ELISAs

Tabelle 6:

p-Werte der statistischen Auswertung der Gesamtzellzahl: Behandlung mit CSA.....35

Tabelle 7:

p-Werte der statistischen Auswertung der Gesamtzellzahl: Behandlung mit TCR......36

Tabelle 8:

p-Werte der statistischen Auswertung der Gesamtzellzahl: Behandlung mit SIR .......37

Tabelle 9:

p-Werte der statistischen Auswertung: Konzentrationsvergleich von

Sirolimus nach 48 und 72 Stunden Einwirkzeit

Tabelle 10:

p-Werte der statistischen Auswertungen der Gesamtzellzahlmessung beider

Konzentrationsvergleiche der Immunsuppressiva

Tabelle 11:

p-Werte der statistischen Auswertungen der Gesamtzellzahl: Konzentrationsvergleiche der Immunsuppressiva zu den Auswertungszeitpunkten 48 und 72

Stunden

Tabelle 12:

p-Werte der statistischen Auswertung der Lebendzellzahl: Behandlung mit CSA .....41

Tabelle 13:

p-Werte der statistischen Auswertung der Lebendzellzahl: Behandlung mit TCR .....42

Tabelle 14:

p-Werte der statistischen Auswertung der Lebendzellzahl: Behandlung mit SIR

Tabelle 15:

p-Werte der statistischen Auswertung der Lebendzellzahl:

Konzentrationsvergleich von Sirolimus nach 48 und 72 Stunden Einwirkzeit

Tabelle 16:

p-Werte der statistischen Auswertungen der Lebendzellzahlmessung beider

Konzentrationsvergleiche der Immunsuppressiva

Tabelle 17:

p-Werte der statistischen Auswertungen der Lebendzellzahl: Konzentrationsvergleiche der Immunsuppressiva zu den Auswertungszeitpunkten 48 und 72 Stunden 
Tabelle 18:

p-Werte der statistischen Auswertung des Zelldurchmessers: Behandlung mit CSA

Tabelle 19:

p-Werte der statistischen Auswertung des Zelldurchmessers: Behandlung mit TCR

Tabelle 20:

p-Werte der statistischen Auswertung des Zelldurchmessers: Behandlung mit SIR

Tabelle 21:

p-Werte der statistischen Auswertung der Menge an Prokollgen Typ I

Tabelle 22:

Übersicht - Studien zu Cyclosporin A (unter Angabe der verwendeten Dosen) .64

Tabelle 23:

Übersicht - Studien zu Tacrolimus (unter Angabe der verwendeten Dosen)

Tabelle 24:

Angabe der verwendeten Materialen bei Durchführung der Zellkultur .78

Tabelle 25:

Angabe der verwendeten Materialien im Bezug auf das Zellzählgerät $C A S Y \circledR$ 78

Tabelle 26:

Angabe der verwendeten Immunsuppressiva 78

Tabelle 27:

Angabe der verwendeten Methoden

Tabelle 28:

Mediane der Gesamt- und Lebendzellzahl (x 104): Behandlung mit CSA.

Tabelle 29:

Mediane der Gesamt- und Lebendzellzahl (x 10 $0^{4}$ : Behandlung mit

TCR

Tabelle 30:

Mediane der Gesamt- und Lebendzellzahl (x 104): Behandlung mit

SIR

Tabelle 31:

Mediane der Gesamt- und Lebendzellzahl (x 10 ${ }^{4}$ ): Behandlung mit $15 \mathrm{ng} /$ Well

CSA, TCR und SIR

Tabelle 32:

Mediane der Gesamt- und Lebendzellzahl (x 10 $0^{4}$ ): Behandlung mit der mittleren Konzentration von CSA, TCR und SIR.

Tabelle 33:

Mediane des Zelldurchmessers $(\mu \mathrm{m})$ : Behandlung mit CSA

Tabelle 34:

Mediane des Zelldurchmessers $(\mu \mathrm{m})$ : Behandlung mit TCR

Tabelle 35:

Mediane des Zelldurchmessers $(\mu \mathrm{m})$ : Behandlung mit SIR 
Tabelle 36:

Mediane des Zelldurchmessers $(\mu \mathrm{m})$ : Konzentrationsvergleich $15 \mathrm{ng} / \mathrm{Well}$ der Immunsuppressiva

Tabelle 37:

Mediane des Zelldurchmessers $(\mu \mathrm{m})$ : Konzentrationsvergleich der mittleren

Konzentration der Immunsuppressiva

Tabelle 38:

Mediane der Menge an Prokollagen Typ I (ng/ml): Behandlung mit CSA .83

Tabelle 39:

Mediane der Menge an Prokollagen Typ I (ng/ml): Behandlung mit TCR

Tabelle 40:

Mediane der Menge an Prokollagen Typ I (ng/ml): Behandlung mit SIR

Tabelle 41:

Mediane der Menge an Prokollagen Typ I (ng/ml): Konzentrationsvergleich $15 \mathrm{ng} /$ Well der Immunsuppressiva

Tabelle 42:

Median der Menge an Prokollagen Typ I (ng/ml): Konzentrationsvergleich der mittleren Konzentration aller Immunsuppressiva

Tabelle 43:

p-Werte der globalen statistischen Auswertung der einzelnen Parameter aller Immunsuppressiva, Signifikanz bei $p<0,05$. 


\section{Abkürzungsverzeichnis}

BOP

Cas. Nr.

CSA

$\mathrm{CO}_{2}$

DDR1

DMEM

DMSO

DNA

DSO

EDTA

ELISA

et al.

Fa.

FKPB

FKS

GZ

HI

$\mathrm{IgE}$

IL-2

IL-6

JNK

LZ

MMP-1

MMP-10

mRNA

mTOR

NFTA

OD

PBI

PBS

PCR
Bleeding on Probing

Catalog number

Cyclosporin A

Kohlenstoffmonoxid

Discodin Domain Receptor 1

Dulbecco's modified Eagle Medium

Dimethylsulfoxid

Desoxyribonukleinsäure

Deutsche Stiftung für Organspende

Ethylendiamintetraacetat

Enzyme-linked-ImmunoabsorbentAssay

et alii

Firma

FK-Bindungsprotein

Fetales Kälberserum

Gesamtzellzahl

Hyperthrophieindex

Immunglobulin $\mathrm{E}$

Interleukin-2

Interleukin-6

C-Jun NH2-terminale Kinase

Lebendzellzahl

Matrixmetalloproteinase-1

Matrixmetalloproteinase-10

Messenger RNA

Mammalian target of Rapamycin

Nuclear factor of activated cells

Optische Dichte

Papillenblutungsindex

Phospore-buffered saline

Polymerase-Chain-Reaction 
PICP

PTEN

p-Wert

RNA

SIR

SPARC

ST

TCR

TGF- $\beta$

TIMP-1
Mouse Procollagen Type I C-Terminal

Propeptide

Phosphatase and Tensin Homolog

Signifikanzwert; Englisch: p-value

Ribonucleic acid

Sirolimus

Secreted protein, acidic, rich in cystein

Sondierungstiefe

Tacrolimus

Transforming growth factor $\beta$

Tissue inhibitor of

matrixmetalloproteinases-1 


\section{$1 \quad$ Einleitung}

Die Organtransplantation ist seit mehr als zwei Dekaden ein etabliertes und standardisiertes Verfahren in der Medizin (Hraský 2010). Nach aktuellen Erhebungen der Deutschen Stiftung für Organspende (DSO) wurden im Jahr 2015 insgesamt 3777 Organtransplantate in Deutschland verpflanzt (DSO Jahresbericht 2015). Derzeit warten 10.239 Patienten auf ein Spenderorgan (DSO Jahresbericht 2015). Dagegen ist die Anzahl der Organspender trotz vieler Informationskampagnen nach wie vor rückläufig. Gerade durch die abnehmende Zahl der verfügbaren Spenderorgane gewinnt deren Verträglichkeit beim Empfänger an Bedeutung. Um Abstoßungen erfolgreich verpflanzter Transplantate zu verhindern, sind die Patienten auf eine lebenslange Immunsupprimierung angewiesen (Hraský 2010).

Die Entdeckung von Azathioprin in den 1950er Jahren eröffnete der Transplantation in diesem Zusammenhang neue Wege (Szilinski 2009). Mediziner verfügen seitdem nicht nur über die Möglichkeit, ein Organ von einem Individuum zum anderen zu transplantieren, sie können nun auch die immunologische Abwehrreaktion des Empfängers auf das transplantierte Organ kontrollieren. Ende der 1970er Jahre bedeutete die Entdeckung des Immunsuppressivums Cyclosporin A wiederum einen enormen Fortschritt in der Transplantationsmedizin (Szilinski 2009). Dieses immunsupprimierende Medikament wirkt im Vergleich zu Azathioprin deutlich zielgerichteter auf Zellen des Immunsystems (Szilinski 2009). Mit der Zulassung noch potenterer und wenig toxischer Immunsuppressiva, wie Tacrolimus (im Jahr 1994) und Sirolimus (im Jahr 2001), ergeben sich in der Transplantationsmedizin insgesamt weitaus mehr therapeutische Optionen als zuvor.

Immunkompromittierte Patienten bedürfen auch in ihrer zahnmedizinischen Betreuung einer besonderen Aufmerksamkeit, da sie aus zahnärztlicher Sicht gewisse Risikopotentiale aufweisen. Wundheilungsstörungen und Infektionen, ausgelöst durch eine immunsuppressive Langzeittherapie, sind bei diesen Patienten keine Seltenheit (Little und Falace 1991). Vor allem das Immunsuppressivum Cyclosporin A zeigt als orale Nebenwirkung gingivale Wucherungen (Daley und Wysocki 1984, Dannewitz und Eickholz 2002a). Gingivawucherungen werden in der Literatur als multifaktoriell bedingtes Krankheitsbild beschrieben (Seymour und Smith 1991).

Einige Studien untersuchten daher die Ursache und Entstehung von Gingivawucherungen unter Einnahme verschiedener Immunsuppressiva (Dannewitz et al. 2009 und 2011, Castronovo et al. 2014, Pamuk et al. 2015, Staudinger et al. 2015). In der bisherigen Forschung fehlt es jedoch an Untersuchungen, die unterschiedliche Immunsuppressiva in verschiedenen Konzentrationen und Einwirkzeiten in einen direkten Vergleich miteinander stellen. 
Das Ziel der vorliegenden Studie war es daher, Wirkung und Potential der Immunsuppressiva Cyclosporin A, Tacrolimus und Sirolimus in unterschiedlichen Konzentrationen und Einwirkzeiten auf gingivale Fibroblasten zu untersuchen und dadurch mögliche Unterschiede der drei Immunsuppressiva feststellen zu können.

Als Untersuchungsparameter wurden Gesamt- und Lebendzellzahl, Zelldurchmesser und Menge an Prokollagen Typ I definiert, wobei dosis- und/oder zeitabhängige Effekte auf die verwendeten Zellen eruiert werden sollten.

Auf Basis bestehender Forschung lassen sich folgende Arbeitshypothesen ableiten:

Die singuläre Einwirkung von Immunsuppressiva auf die verwendeten Zellen zeigt sich in einer Zunahme der Untersuchungsparameter. Dieser Effekt ist dosis- und zeitabhängig, wobei er sich mit erhöhter Dosierung und Einwirkzeit der Immunsuppressiva verstärkt. Zudem werden Unterschiede zwischen den einzelnen Immunsuppressiva vermutet, da vornehmlich Cyclosporin A dafür bekannt ist, gingivale Wucherungen auszulösen. 


\section{$2 \quad$ Literaturübersicht}

\subsection{Gingivawucherung}

Gingivawucherungen zählen zu der Gruppe der gingivalen Erkrankungen. Dabei wird prinzipiell zwischen Plaque-induzierten und nicht Plaque-induzierten gingivalen Erkrankungen differenziert, wobei die Gingivawucherungen Bestandteil der Plaque-induzierten gingivalen Erkrankungen sind (Armitage 1999). Im Fokus der weiteren Betrachtung steht vor allem die medikamentösinduzierte Gingivawucherung als spezifische Untergruppe der Gingivawucherungen bei den Plaque-induzierten gingivalen Erkrankungen. Hierbei wird sowohl auf den Zusammenhang zwischen gingivaler Wucherung und der Einnahme von Immunsuppressiva als auch auf die Epidemiologie der medikamentös-induzierten Gingivawucherung eingegangen. Abschließend werden die wichtigsten Therapieansätze erläutert und ein Ausblick zum aktuellen Stand der Forschung gegeben.

\subsubsection{Definition und Ätiologie der Gingivawucherung}

Die Gingivawucherung ist durch eine abnorme Zunahme des gingivalen Gewebes definiert (AAOM 2015). Sie kann durch inflammatorische Zustände, unter Medikamenteneinnahme, durch hereditäre Faktoren und durch systemisch bedingte Ursachen entstehen (AAOM 2015). Unter einer Gingivawucherung versteht man nicht ausschließlich eine reine Zunahme der Zellzahl, sondern ebenfalls eine Zunahme von intrazellulären Kollagenfasern (Dannewitz und Eickholz 2002a). Daher ist der früher häufig verwendete Begriff Gingivahyperplasie nicht zutreffend.

Gingivawucherungen lassen sich durch eine Steigerung der zellulären und azellulären Bestandteile des Bindegewebes charakterisieren (Lang 2003). Die Gingiva kann generalisiert oder lokalisiert Wucherungen aufweisen (Dannewitz und Eickholz 2002a). In licht- und elektromikroskopischen Untersuchungen pathologisch veränderter Gingivaproben konnte ein mehrschichtiges, hyperplastisches Epithel mit kryptenförmigen Einziehungen und lokalisierten Ulzerationen beobachtet werden (Hannak und Hermann 1992). Es zeigte sich ebenfalls eine Zunahme von kollagenen Faserbündeln und Fibroblasten, die zwischen den Faserbündeln angeordnet waren (Yamasaki et al. 1987). Die Wucherung beschränkt sich auf die Gingiva und entsteht meist an der dentogingivalen Grenze (Lang 2003).

Das klinische Bild der Gingivawucherung wird seit der einheitlichen und international geltenden Klassifikation von Oak Brook (Armitage 1999) zu den Plaque-induzierten Erkrankungen gezählt (Dannewitz und Eickholz 2002a). Sie kann durch verschiedene Faktoren modifiziert werden. Hier spielen unter anderem genetische Faktoren, Allgemeinerkrankun- 
gen, entzündliche Genesen und die Einnahme von Medikamenten eine wichtige Rolle (Dannewitz und Eickholz 2002a). Vor allem die dauerhafte Einnahme von Immunsuppressiva (nachfolgend beschrieben) sowie Antikonvulsiva (z.B. Phenytoin) und Kalziumkanalblockern (z.B. Nifedipin, Amlodipin) kann eine medikamentös-induzierte Gingivawucherung bedingen (Ciancio 1996, Seymour 2003).

\subsubsection{Die medikamentös-induzierte Gingivawucherung}

Seymour und Smith (1991) gehen hinsichtlich der Ätiologie einer medikamentösinduzierten Gingivawucherung von einem multifaktoriellen Modell aus. Alter, Geschlecht, genetische Prädisposition, pharmakokinetische Variablen, parodontale Parameter und zusätzliche Medikation sind entscheidende Risikofaktoren, die laut der Autoren mit der Entwicklung und Ausprägung der gingivalen Wucherungen in Verbindung gebracht werden können (Seymour et al. 2000). Jedoch ist die Pathogenese der medikamentös-induzierten Gingivawucherung nach wie vor nicht vollumfänglich geklärt. Einige Riskofaktoren werden im Folgenden genauer erläutert.

Das Alter kann als wichtiger Risikofaktor herangezogen werden, insbesondere unter Medikation mit Cyclosporin A (Schulz et al. 1990, Hefti et al. 1994) und dem Antikonvulsivum Phenytoin (Daley et al. 1986). Hierbei ist jedoch zu beachten, dass sowohl Immunmodulatoren als auch Kalziumkanalblocker und Antikonvulsiva ihre medizinische Indikation in unterschiedlichen Altersgruppen finden (Seymour et al. 2000). Lediglich Immunsuppressiva wie Cyclosporin A sind bei einer breitgefächerten Altersgruppe indiziert (Seymour et al. 2000). Ellis et al. (1999) beschrieben einen geschlechtsspezifischen Zusammenhang, in dem Männer unter Medikation mit Kalziumkanalblockern etwa drei Mal häufiger eine Gingivawucherung entwickelten als Frauen.

Einige Untersuchungen zeigten einen Zusammenhang zwischen dem Mundhygienestatus der Patienten und dem Auftreten und Schweregrad gingivaler Wucherungen (Addy et al. 1983, Daley et al. 1986, Barclay et al. 1992, Aimetti et al. 2005).

In unterschiedlichen Studien wurde beobachtet, dass eine zusätzliche Medikation zur bereits bestehenden Einnahme von Immunsuppressiva eine gingivale Wucherung begünstigt. Die gleichzeitige Einnahme von Cyclosporin A und Nifedipin, einem Kalziumkanalblocker, wies einen negativen Einfluss auf Inzidenz und Ausprägung der gingivalen Wucherungen bei organtransplantierten Patienten auf (Slavin und Taylor 1987, Bökenkamp et al. 1994, Khoori et al. 2003).

Nachfolgend wird der Zusammenhang zwischen gingivalen Wucherungen und der Einnahme von Immunsuppressiva genauer erläutert. 


\subsubsection{Medikamentös-induzierte Gingivawucherung durch die Einnahme von Immunsuppressiva}

1983 wiesen Rateitschak-Plüss et al. in einer klinischen Studie auf erste gingivale Veränderungen durch die Gabe des Immunsuppressivums Cyclosporin A hin. Nachfolgend bestätigten Daley und Wysocki (1984) diesen Zusammenhang. Sie beschrieben die Bedeutung des Immunsuppressivums Cyclosporin A für Zahnärzte und formulierten einen Leitfaden für die Behandlung von Patienten mit gingivalen Wucherungen (Daley und Wysocki 1984). Vor allem in den ersten drei bis sechs Monaten nach Beginn der Einnahme war das Auftreten von interdentalen Wucherungen eminent, wobei besonders Kinder und Jugendliche betroffen waren (Daley und Wysocki 1984). Nach initialer Einnahme entsteht die Wucherung bevorzugt in der interdentalen Papille, wobei eine Dickenzunahme der keratinisierten Gingiva, wie in Abbildung 1 gezeigt, beschrieben wird (Hassell und Hefti 1991). Die Zahnfleischpapille füllt bei einem gesunden Erwachsenen normalerweise die Interdentalräume vollständig aus (Hassell und Jacoway 1980a). Bei einer Gingivawucherung ragt diese über den Interdentalraum hinaus und breitet sich weiter auf die marginale und befestigte Gingiva aus (Keller und Mohr 1988). Die medikamentös-induzierte gingivale Wucherung ist auf die befestigte Gingiva begrenzt, ohne das darunterliegende Parodontium negativ zu verändern (Marshall und Bartold 1999). Zudem wird die Wucherung als eine ödematös geschwollene, blumenkohlartig aussehende, gerötete Gingiva beschrieben (Adams und Davies 1984). Hierbei können entweder alle Kieferquadranten (Hassell und Jacoway 1980b) oder ausschließlich einzelne Papillen (Vogel et al. 1984) betroffen sein. Vor allem im anterior-vestibulären Segment scheint das klinische Bild einer solchen Gingivawucherung vermehrt aufzutreten (Tyldesley und Rotter 1984, Götze et al. 1990, Günay und Evers 1990, Hassell und Hefti 1991). Jedoch können die Wucherungen nach koronal extendieren und sich hierdurch störend auf Okklusion, Mastikation und Sprache auswirken (Marshall und Bartold 1999).
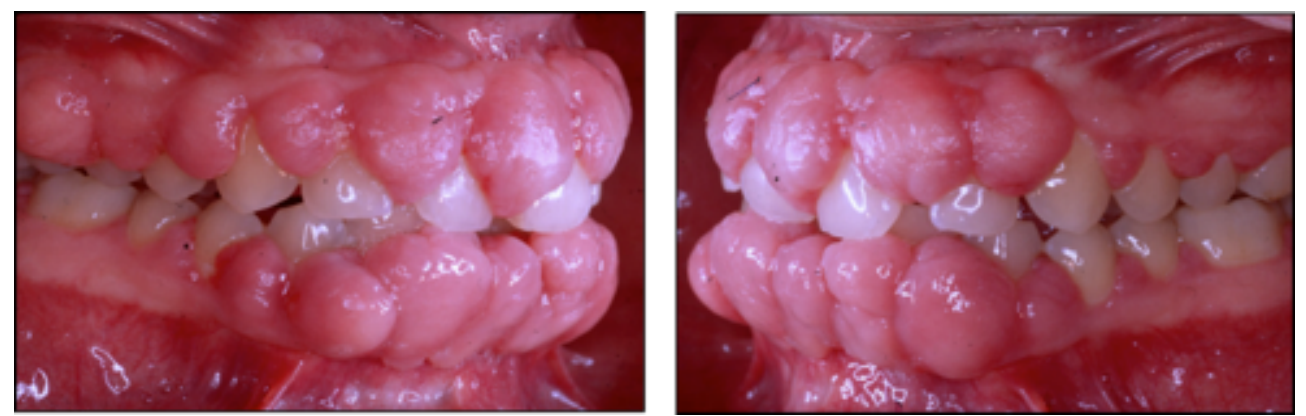

Abbildung 1: 23-jährige Patientin, Zustand nach NTx, Immunsuppression mit Cyclosporin A; mit freundlicher Genehmigung von Prof. Mausberg, Universität Göttingen 
Eine bereits bestehende Gingivitis oder Parodontitis wie auch insuffiziente konservierende und prothetische Versorgungen sind Kofaktoren, die das klinische Bild negativ beeinflussen (Seymour und Smith 1991). Zudem fiel eine Korrelation zwischen gingivalen Wucherungen und Patienten mit einer schlechten Mundhygiene auf (Daley und Wysocki 1984). Daher ist unumstritten, dass neben einer guten Mundhygiene bei transplantierten Patienten (Somacarrera et al. 1997, Cakir 1999) auch ein suffizient versorgtes Gebiss vor und nach der Transplantation von entscheidender Bedeutung ist.

Dannewitz et al. (2011) zeigten in ihrer Studie mit 36 unter Cyclosporin A immunsupprimierten Patienten, dass sowohl der Entzündungsgrad der Gingiva als auch die Konzentration von Cyclosporin A im Speichel negative Auswirkungen auf den Schweregrad der gingivalen Wucherungen ausüben. Zudem stellten sie einen Zusammenhang zwischen einer reduzierten Aktivität des Transkriptionsfaktors nuclear factor of activated cells (NFAT) und der Ausprägung gingivaler Wucherungen fest. Patienten mit Gingivawucherungen wiesen dabei eine signifikant reduzierte NFAT-Aktivität auf (Dannewitz et al. 2011).

Hinke (1994) untersuchte den Einfluss der Generik von Cyclosporin A auf Mischspeichel und Plaque an 29 immunsupprimierten Patienten. Sie zeigte, dass Cyclosporin A sowohl im Mischspeichel als auch in der Plaque vorhanden war. Der Zahnbelag fungierte als lokaler Cyclosporin A-Speicher mit einer Depotwirkung von 2962 ng/10 mg Plaque. Daher ist nicht auszuschließen, dass diesem Reservoir an Cyclosporin A eine entscheidende Bedeutung bei der Entstehung von Gingivawucherungen zukommt (Hinke 1994). Jedoch wird der Zusammenhang zwischen Ausmaß und Schweregrad der gingivalen Wucherungen sowie pharmakologischer Variablen, wie zum Beispiel Dosis oder Serumkonzentration, nach wie vor sehr kontrovers diskutiert (Seymour et al. 2000, Dannewitz et al. 2011).

Neue Immunsuppressiva, wie z.B. Tacrolimus, zeigen weniger oder gar keine Veränderungen der Gingiva (Jahn und Ender 2002, Ellis et al. 2004, Cota et al. 2008, Greenberg et al. 2008). Einige Studien zeigten wiederum unter Einnahme neuerer Immunsuppressiva eine signifikant erhöhte Epitheldicke, eine Zunahme des Bindegewebes und eine erhöhte Dichte an Fibroblasten (Nassar et al. 2008, Pamuk et al. 2013).

$\mathrm{Zu}$ den Immunsuppressiva der neuen Generation zählt ebenfalls das Medikament Sirolimus. Neben einigen Anwendungen von Sirolimus in Tiermodell-Studien und Daten zur Pharmakokinetik finden sich insbesondere für den Zusammenhang zwischen SirolimusEinnahme und dem Auftreten von gingivalen Wucherungen nur wenige Studien. Cota et al. (2008) beobachteten in ihrer Querschnittsstudie mit nierentransplantierten Patienten unter 
Sirolimus-Medikation ein erhebliches, aber kein signifikantes Auftreten gingivaler Wucherungen.

Das folgende Kapitel gibt Auskunft über die Epidemiologie der medikamentös-induzierten Gingivawucherung.

\subsubsection{Epidemiologie der medikamentös-induzierten Gingivawucherung}

Die medikamentös-induzierte Gingivawucherung wird, wie zuvor bereits erwähnt, vor allem mit Immunmodulatoren, Antikonvulsiva und Kalziumkanalblockern in Verbindung gebracht (Seymour 2003). Tabelle 1 gibt einen Überblick hinsichtlich der Prävalenz der einzelnen Medikamente und verweist auf dazugehörige Studien.

Tabelle 1: Überblick - Prävalenz der medikamentös-induzierten Gingivawucherung

\begin{tabular}{|c|c|c|c|}
\hline \multicolumn{2}{|l|}{ Medikament } & Autor & Prävalenz \\
\hline \multirow{7}{*}{$\begin{array}{l}\text { Immun- } \\
\text { suppresiva }\end{array}$} & \multirow[b]{2}{*}{ Cyclosporin A } & Dannewitz und Eickholz (2002a) & $25-30 \%$ \\
\hline & & $\begin{array}{l}\text { Dongari et al. (1993) } \\
\text { Pernu et al. (1992) } \\
\text { Somacarrera et al. (1994) }\end{array}$ & $8-61 \%$ \\
\hline & \multirow{3}{*}{ Tacrolimus } & Paixão et al. (2011) & $8,3 \%$ \\
\hline & & Ellis et al. (2004) & $14 \%$ \\
\hline & & $\begin{array}{l}\text { Greenberg et al. (2008) } \\
\text { James et al. (2001) }\end{array}$ & $0 \%$ \\
\hline & \multirow{2}{*}{ Sirolimus } & Cota et al. (2010) & $15,6 \%$ \\
\hline & & Groth et al. (1999) & $0 \%$ \\
\hline \multirow{6}{*}{$\begin{array}{l}\text { Kalziumkanal- } \\
\text { blocker }\end{array}$} & \multirow{3}{*}{ Nifedipin } & Barclay et al. (1992) & $10 \%$ \\
\hline & & Dannewitz und Eickholz (2002a) & $44 \%$ \\
\hline & & Fattore et al. (1991) & $83 \%$ \\
\hline & \multirow{3}{*}{ Amlodipin } & Ellis et al. (1999) & $1,7 \%$ \\
\hline & & Jorgensen (1997) & $3,3 \%$ \\
\hline & & Karnik et al. (2012) & $5,1 \%$ \\
\hline \multirow{2}{*}{ Antikonvulsiva } & \multirow{2}{*}{ Phenytoin } & $\begin{array}{l}\text { Angelopoulos und Goaz (1972) } \\
\text { Dannewitz und Eickholz (2002a) }\end{array}$ & $50 \%$ \\
\hline & & $\begin{array}{l}\text { Hassell (1981) } \\
\text { Thomason et al. (1992) }\end{array}$ & $13 \%$ \\
\hline
\end{tabular}

\subsubsection{Therapieansätze bei der medikamentös-induzierten Gingivawucherung}

Bis heute stellen gingivale Wucherungen sowohl für den betroffenen Patient als auch für den behandelnden Zahnarzt eine große Herausforderung in der Behandlung dar. Eine erste mögliche Maßnahme ist die Umstellung auf ein anderes Medikament, nach Rücksprache 
mit dem behandelnden Arzt. Unter Immunsuppression mit Cyclosporin A stellte sich Tacrolimus als geeignetes Alternativpräparat hinsichtlich der Prävention gingivaler Veränderungen heraus. Einige Studien zeigten einen Rückgang der Gingivawucherung und eine Verbesserung der Sondierungstiefen nach Umstellung der Medikation (Jahn und Ender 2002, Purschwitz et al. 2007). Wenn Patienten bereits zu Beginn ihrer immunsuppressiven Therapie Tacrolimus erhielten, traten deutlich weniger (Ellis et al. 2004) oder keine Gingivawucherungen auf (Jahn und Ender 2002, Greenberg et al. 2008). Da nicht immer eine Umstellung der Medikation möglich ist, erfordert es oft einen zahnmedizinischtherapeutischen Eingriff (Mavrogiannis et al. 2006a). Verschiedene Untersuchungen haben gezeigt, dass die Mundhygiene bei organtransplantierten Patienten eine entscheidende Rolle spielt (Somacarrera et al. 1997, Kantarci et al. 1999, Aimetti et al. 2005). Vor Beginn zahnmedizinisch-therapeutischer Interventionen sollten eine sorgfältige intraorale Inspektion sowie eine allgemeinmedizinische und spezielle Anamnese erfolgen (Dannewitz und Eickholz 2002b). Bedeutsam sind dabei die Einnahme von Komedikamenten, die Dauer einer bereits bestehenden Wucherung sowie die Existenz von lokal modifizierenden Faktoren. Primär sollte eine nicht-chirurgische Behandlung der Wucherung in Erwägung gezogen werden (Camargo et al. 2001). Der Entzündungsgrad der Gingiva könnte beispielsweise nach dem Prinzip der Full-mouth-disinfection reduziert werden (Dannewitz et al. 2010). Eine weitere wichtige Grundlage der nicht-chirurgischen Therapie bilden dabei das Beseitigen sowohl harter als auch weicher supra- und subgingivaler Beläge und die Anleitung zu einer optimalen Mundhygiene (Aimetti et al. 2005, Lemkamp und Schlagenhauf 2008). Aimetti et al. (2005) zeigten in ihrer Studie einen positiven Einfluss durch optimale häusliche Mundhygiene und stetes subgingivales Biofilmmanagement. Günay und Evers verfassten 1990 ein Therapiekonzept zum Umgang mit gingivalen Wucherungen, basierend auf Konzepten zur Gingivitis- und Parodontitisbehandlung. Das Auftreten von gingivalen Wucherungen war durch dieses Therapiekonzept nicht zu verhindern. Schwere, entzündliche Krankheitsbilder konnten jedoch gemindert werden. Deutlich wurde auch, dass eine unzureichende Patientencompliance negative Auswirkungen auf den Therapieerfolg ausübte (Günay und Evers 1990). Patienten, die sich in einem Nachsorgeprogramm nach Parodontaltherapie befanden, konnten eine deutlich geringere Anzahl an Wucherungen aufweisen, als Patienten ohne Nachsorge (Gressmann et al. 2007). Eine nicht-chirurgische Therapie sollte dabei mindestens über eine Dauer von 12 Monaten praktiziert werden (Aimetti et al. 2005). Der Einsatz von Antibiotika zur Reduzierung gingivaler Wucherungen zeigte in der bisherigen Forschung keinen Erfolg bzw. keinen zusätlichen Nutzen (Mesa et al. 2003). 
Falls nach Reevaluation kein optimales Behandlungsergebnis vorzufinden ist, können nachfolgend parodontalchirurgische Maßnahmen in Betracht gezogen werden (Ilgenli et al. 1999, Dannewitz und Eickholz 2002b). Die Wucherungen können hierbei resektiv mithilfe eines Lasers (Darbar et al. 1996, Mavrogiannis et al. 2006b) oder mit hochfrequentem Strom korrigiert werden (Mausberg et al. 1991). Ziel dieser sogenannten Gingivektomie ist es, überschüssiges und pathologisch verändertes Gewebe zu entfernen, sogenannte Pseudotaschen zu vermeiden, bzw. möglichst vollständig zu entfernen sowie dem Gingivasaum erneut eine physiologische Kontur zu verleihen (Plagmann 1998).

Um Patienten mit medikamentös-induzierten Gingivawucherungen optimal zu therapieren, ist es jedoch unabdingbar, die immunsuppressive Therapie und deren Vorgänge im Körper des Patienten zu verstehen. Aus diesem Grund werden im folgenden Kapitel die drei für diese Studie relevanten Immunsuppressiva näher beschrieben.

\subsection{Organtransplantation: Immunsuppressiva und ihre Wirkungsweise}

Im Laufe der Jahre entwickelte sich die Organtransplantation zu einer etablierten Methode geschädigte oder nicht funktionsfähige Organe zu ersetzen. Heute gilt eine Transplantation als Routineeingriff, da hinsichtlich der Labordiagnostik und der Entdeckung neuer immunsuppressiver Medikamente deutliche Fortschritte in der Transplantationsmedizin zu verzeichnen sind. Momentan werden etwa 150.000 Transplantationen weltweit durchgeführt (Thomas 2005). Die wichtigsten und häufigsten Transplantationen sind dabei Nierentransplantationen mit einem Anteil von $58 \%$, Transplantationen des Herzens mit $28 \%$, Transplantationen der Leber mit $5 \%$ und Lungentransplantationen mit $4 \%$ (Thomas 2005). Jedoch birgt eine Organtransplantation viele Komplikationen. Die wohl schwerwiegendste Komplikation ist die akute oder chronische Abstoßungsreaktion. Um dies zu vermeiden, erhalten Organtransplantierte eine immunsuppressive Langzeittherapie, die präventiv gegen eine Abstoßungsreaktion wirken soll (Thomas 2005). Immunsuppressiva setzen die Reaktion des Immunsystems herab und greifen dabei in unterschiedlicher Art und Weise an unterschiedlichen Orten der Immunabwehr ein. Von Bedeutung für eine langfristige und erfolgreiche Genesung des transplantierten Patienten ist vor allem, dass die Abwehrkraft gegenüber anderen Erregern so weit wie möglich erhalten bleibt. Aufgrund der vielen schwerwiegenden Nebenwirkungen sind eine exakte Dosiseinstellung und eine dauerhafte Überwachung (sog. drug-monitoring) unabdingbar (Thomas 2005).

Die immunsuppressive Therapie fand ihren Ursprung mit der Entdeckung von Azathioprin. Dies wurde erstmals 1960 als immunsuppressiv wirksames Medikament in der Organtransplantation eingesetzt. Azathioprin wirkt blockierend auf die DNA- und RNA- 
Synthese und ist dadurch in der Lage, die Vermehrung von B- und T-Lymphozyten zu hemmen.

1976 entdeckten Borel et al. die immunsuppressive Wirkung von Cyclosporin A, welches einen großen Fortschritt in der Transplantationsmedizin auslöste, da durch den Einsatz dieses Immunsuppressivums eine deutliche Verbesserung der Transplantat- und Patientenüberlebensrate erreicht wurde (Cakir 1999). Tacrolimus, ein ähnlich wirkendes Medikament, erlangte 1994 seine Zulassung. Sowohl Cyclosporin A als auch Tacrolimus werden als Basisimmunsuppressiva eingesetzt. Basisimmunsuppressiva der neuen Generation sind neben Tacrolimus auch Sirolimus und sein Derivat Everolimus.

Nachfolgend werden die für die vorliegende Untersuchung relevanten Immunsuppressiva Cyclosporin A, Tacrolimus und Sirolimus genauer beschrieben. Dabei sollen jeweils ihre Entdeckung, Indikationsbereiche, Wirkweise und Pharmakokinetik erläutert werden.

\subsubsection{Cyclosporin A}

Cyclosporin A wird aus dem norwegischen Schlauchpilz Hydocladium inflatum gams isoliert. Dabei handelt sich es um ein neutrales zyklisches Peptid, welches sich aus elf Aminosäuren zusammensetzt (Borel et al. 1976) und erstmals von Calne et al. im Jahre 1978 als Immunsuppressivum bei Transplantationen eingesetzt wurde. Cyclosporin A wird entweder als alleiniges Immunsuppressivum (Calne et al. 1978) oder in Kombination mit Steroiden verwendet (Starzl et al. 1982).

Cyclosporin A ist ein sehr potentes, immunsuppressiv wirkendes Medikament, welches in einem breiten Indikationsspektrum Anwendung findet. Es wird unter anderem bei der Prophylaxe von graft-versus-host-Reaktionen (Abstoßungsreaktionen) (Seymour und Jacobs 1992), der Therapie von dermatologischen Erkrankungen (Kowal et al. 2003), bei Autoimmunerkrankungen wie rheumatoider Arthritis (Bejarano et al. 2009), Colitis ulcerosa (Seymour und Jacobs 1992) und Morbus Behçet (Süss et al. 1993) eingesetzt.

Das Immunsuppressivum zählt zu den Calcineurininhibitoren. Es ist in der Lage, sowohl die humorale als auch die spezifische zelluläre Immunantwort zu unterdrücken (Borel 1981, Hess et al. 1988). Frühe Untersuchungen belegten bereits, dass Cyclosporin A die Aktivierung von T-Zellen inhibiert. Diese Wirkung beruht darauf, dass die Transkription von Interleukin-2 (IL-2) und Interleukin-4 (IL-4) in aktivierten T-Zellen inhibiert wird (Krönke et al. 1984, Herold et al. 1986, Granelli-Piperno 1988). Die Transformation von ruhenden TLymphozyten zu T-Killerzellen wird verhindert, da ruhende T-Lymphozyten in der G0oder G1-Phase des Zellzyklus blockiert werden. Nachdem Cyclosporin A die T-Zelle passiert, bindet es mit einer hohen Affinität an Cyclophilin, ein Immunophilin. Hier ist vor 
allem das zytosolische Cyclophilin A (17 kDa) betroffen, welches den größten Anteil des Cyclophilins in T-Zellen ausmacht (Handschumacher et al. 1984). Der CyclophilinCyclosporin-A-Komplex bindet an Calcineurin (Liu et al. 1991), eine Serin-ThreoninPhosphatase (Fruman et al. 1992), und inhibiert dadurch deren Phosphataseaktivität. Calcineurin wiederum dephosphoryliert den Transkriptionsfaktor NFAT, damit dieser im Zellkern bestimmte Gene ablesen kann (Flanagan et al. 1991, Loh et al. 1996). NFAT ist für die Transkription zahlreicher Zytokine, wie z.B. IL-2 (Loh et al. 1999), verantwortlich. Das heißt, durch die Inhibition von Calcineurin wird die Freisetzung von Zytokinen blockiert. Die Kommunikation innerhalb der Immunabwehrzellen durch Zytokine ist nun verhindert. Dementsprechend kann eine Aktivierung/ Proliferation der T-Lymphozyten und eine Verstärkung der Immunantwort nicht stattfinden (Matsuda und Koyasu 2000). Cyclosporin A ist somit in der Lage, die zellvermittelte Immunantwort zu unterdrücken. Ebenso wird diskutiert, ob Cyclosporin A neben der Inhibition von Calcineurin auch eine Blockade der c-Jun NH2-terminalen Kinase (JNK) und p38-mitogenaktivierten Proteinkinase in T-Lymphozyten auslöst (Su et al. 1994, Matsuda et al. 1998).

Hinsichtlich der Pharmakokinetik verfügt das Medikament über eine gute Bioverfügbarkeit, dagegen aber lediglich über eine sehr geringe therapeutische Breite. Daher sollte der Vollblut-Talspiegel genau überwacht werden. Eine Gabe des Medikaments kann sowohl oral als auch intravenös erfolgen. Die Erhaltungsdosis bei oraler Einnahme sollte zwischen 2-6 mg Cyclosporin A pro kg/KG pro Tag liegen. Hieraus resultiert ein Serumspiegel von 100-400 ng/ml. Die Resorption des Medikamentes erfolgt zu 30-50 \% im Dünndarm. Eliminiert und metabolisiert wird es in der Leber durch das Enzym Cytochrom P450 und anschließend über die Galle ausgeschieden (Thomas 2005).

\subsubsection{Tacrolimus}

Kino et al. entdeckten 1987 diesen neuen immunsuppressiven Wirkstoff in Bodenproben aus Japan. Tacrolimus (früher: „FK-506“) ist ein makrolidzyklisches Antibiotikum. Dieser Wirkstoff kann aus dem Bakterium Streptomyces tsukabaensis extrahiert werden und zählt zu den neutralen Makroliden (Allison 2000). 1989 erfolgte durch Starzl et al. die erste klinisch erfolgreiche Verwendung von Tacrolimus bei Empfängern eines Lebertransplantates, die trotz einer Immunsuppression unter Cyclosporin A eine Abstoßungsreaktion aufwiesen. 1994 wurde dieses (neue) Immunsuppressivum erstmals in der Transplantationsmedizin offiziell zugelassen.

Angewendet wird das Medikament in der Langzeittherapie von Organtransplantationen, vor allem der Leber (European FK506 Multicentre Liver Study Group 1994). Zudem be- 
währte sich die therapeutische Anwendung bei Abstoßungsreaktionen, die nicht erfolgreich mit einem anderen Immunsuppressivum behandelt werden konnten. Dermatologische Krankheiten wie Psoriasis (Michel et al. 1996) und atopische Ekzeme gehören ebenfalls zum Indikationsbereich von Tacrolimus (Assmann et al. 2000).

Tacrolimus ist in seiner immunsuppressiven Wirkung etwa um das 10-100-Fache potenter als Cyclosporin A (Sawada et al. 1987, Lauerma und Maibach 1994). Hierbei weist es keine höheren Komplikationsraten auf (Reichenspurner et al. 1997). Es gehört wie Cyclosporin A zu der Gruppe der Calcineurininhibitoren, verfügt jedoch über keine strukturelle Verwandtschaft $\mathrm{zu}$ Cyclosporin A. Tacrolimus bindet das Immunophilin FKBindungsprotein (FKPB) und übermittelt dadurch seine potente und immunsuppressive Wirkung (Schreier et al. 1993). Der Komplex aus Immunsuppressivum und Immunophilin wirkt über eine Hemmung der Serin-Threonin-Phosphatase Calcineurin (Kapturczak et al. 2004). Weiterhin ist Tacrolimus in der Lage die JNK-p38-Transkriptionsfaktorkaskade zu blockieren. Dies resultiert in einer Hemmung der Bildung von spezifischen zytotoxischen T-Zellen (Krüger et al. 1997). Die Wirkung von Tacrolimus basiert daher auf einer Inhibierung früher Ereignisse der T-Zell-Aktivierung, die für die Proliferation von Zytokinen maßgeblich verantwortlich ist (Dumont et al. 1990). Die Progression aktivierter T-Zellen wird im Übergang von der G0-Phase in die G1-Phase des Zellzyklus unterbrochen (Morris 1991).

Bezüglich der Pharmakokinetik zeigt Tacrolimus eine variable Bioverfügbarkeit. Die Absorption durch den Gastrointestinaltrakt beträgt im Durchschnitt 20-25 \%. Es wird hauptsächlich durch das Enzym Cytochrom P450 in der Leber metabolisiert (Thomas 2005). Metaboliten des Medikamentes werden über die Galle ausgeschieden (Thomas 2005).

\subsubsection{Sirolimus}

Sirolimus (Rapamycin) wurde erstmals im Jahre 1975 bei einem antibiotischen Screening der Ayerst Research Laboratories entdeckt (Vézina et al. 1975). Dabei erfolgte zuvor die Isolierung einer Stammkultur von Streptomyces hygroscopicus aus einer Bodenprobe. Diese wurde in der Vai Ator Region der im Südostpazifik liegenden Osterinsel (Rapa Nui) entnommen (Vézina et al. 1975). Sirolimus ist ein weißer, kristalliner Feststoff, welcher nahezu unlöslich in Wasser ist, aber eine gute Löslichkeit in Ethanol oder anderen organischen Lösungsmitteln aufweist (Sehgal et al. 1975). Das Immunsuppressivum verfügt über eine hohe Effektivität gegenüber Candida albicans, einem Pilz der Candidagruppe (Baker et. al 1978), jedoch nur über eine sehr geringe antibiotische Wirkung (Abraham und Wiederrecht 1996). Der erste Nachweis über die immunsuppressive Aktivität wurde bei Stu- 
dien über die Hemmung der Produktion von humanen IgE Antikörpern erlangt. Diese zeigten einen präventiven Effekt auf humane Autoimmunerkrankungen in einem Tierversuchsmodell (Encephalitis und adjuvante Arthritis) (Martel et al. 1977). 2001 fand Sirolimus seine Zulassung in der deutschen Transplantationsmedizin als selektiv immunsuppressives Medikament bei erwachsenen, nierentransplantierten Patienten mit einem geringen bis mittelgradigen Abstoßungsrisiko (Thomas 2005). Initial erfolgt eine kombinierte Gabe von Sirolimus, Cyclosporin A und Kortikosteroiden, wobei Cyclosporin A meist nach etwa zwei bis drei Monaten postoperativ abgesetzt wird.

Sirolimus ist Tacrolimus in seiner Wirkweise teilweise ähnlich, da es ebenfalls intrazellulär an das Protein FK-Bindungsprotein (FKBP) bindet. Im Gegensatz zu Tacrolimus wirkt Sirolimus aber hemmend auf die Signaltransduktion von IL-2 und blockiert somit die Aktivierung von B- und T-Lymphozyten (Thomas 2005). Anders als der Tacrolimus-FKBPKomplex, welcher sich hemmend auf Calcineurin auswirkt, bindet der Sirolimus-FKBPKomplex an den mammalian target of Rapamycin (mTOR) (Sabers et al. 1995), eine den Zellzyklus regulierende Kinase. Die Hemmung der $m$ TOR-Kinase führt zu Blockaden einiger spezifischer Signaltransduktionspfade (Thomas 2005). Sirolimus ist in der Lage sowohl die Protein- als auch die DNA-Synthese zu hemmen und arretiert die T-Zelle folglich in der späten G1-Phase. Eine weitere Vermehrung in der S-Phase wird daher unmöglich (Terada et al. 1994, Sehgal 1998). Das Ergebnis ist die Inhibierung der Lymphozytenaktivierung.

Eine Gabe des Medikamentes kann sowohl oral als auch intravenös erfolgen. Da Sirolimus zu $95 \%$ in Erythrozyten gespeichert wird (Napoli und Taylor 2001), erfolgt die Bestimmung des Sirolimus-Talspiegels aus Vollblut (Thomas 2005). Der Serumspiegel liegt meist zwischen 12-20 ng/ml. Metabolisiert wird Sirolimus in der Leber durch das Enzym Cytochrom P450 IIIA4, wie auch im Dünndarm durch die Multisubstanz-x-Pumpe P Glykoprotein (Thomas 2005). 91,1 \% werden mit dem Stuhl und lediglich 2,2\% über den Urin ausgeschieden (Thomas 2005).

\section{3 Überblick zur aktuellen Studienlage}

Aktuelle Studien beschäftigen sich vermehrt mit Auswirkungen und Veränderungen durch Immunsuppressiva auf molekularer Ebene (Cota et al. 2010, Staudinger et al. 2015). Hinzu kommen einige klinische Studien (Costa et al. 2013, Castronovo et al. 2014, Gürkan et al. 2014), die sich vorwiegend mit dem Ziel einer Verbesserung der parodontalen Parameter befassen. Die Studien setzen sich zum Ziel, wichtige Ursachen in der Entstehung von Gingivawucherungen unter immunsuppressiver Medikation zu ergründen und nutzen hier- 
für neue Forschungsansätze, vor allem auf molekularer Ebene. Tabelle 2 gibt einen Überblick über einige aktuelle In-vitro-Studien, Tierstudien und klinische Studien der Jahre 2010 - 2015 sowie deren Fragestellungen und Ergebnisse.

Tabelle 2: Überblick - aktuelle Studienlage (2010 - 2015)

\begin{tabular}{|c|c|c|c|}
\hline \multirow{3}{*}{$\begin{array}{l}\text { In-vitro- } \\
\text { Studien }\end{array}$} & Autor/Jahr & Studienhintergrund & Ergebnis \\
\hline & $\begin{array}{l}\text { Cota et al. } \\
(2010)\end{array}$ & $\begin{array}{l}\text { Zusammenhang zwischen IL-6(- } \\
174 \mathrm{C} / \mathrm{G}) \text { Genpolymorphismus } \\
\text { und dem Auftreten gingivaler } \\
\text { Wucherungen unter CSA-, TCR- } \\
\text { oder SIR-Medikation. }\end{array}$ & $\begin{array}{l}\text { Die Autoren stellten keinen } \mathrm{Zu} \text { - } \\
\text { sammenhang fest. }\end{array}$ \\
\hline & $\begin{array}{l}\text { Staudinger et al. } \\
(2015)\end{array}$ & $\begin{array}{l}\text { Untersuchung der Rolle des dis- } \\
\text { codin domain receptor } 1 \text { (DDRl) } \\
\text { hinsichtlich einer Dysregulation } \\
\text { des Kollagenumbaus, ausgelöst } \\
\text { durch den Einfluss von CSA. }\end{array}$ & $\begin{array}{l}\text { CSA scheint einen Einfluss auf } \\
\text { die } D D R 1 \text { auszuüben und } \\
\text { dadurch eine Inhibierung des } \\
\text { Kollagenumbaus auszulösen. }\end{array}$ \\
\hline \multirow[b]{2}{*}{ Tierstudien } & $\begin{array}{l}\text { Pamuk et al. } \\
(2013)\end{array}$ & $\begin{array}{l}\text { Wirkung von TCR auf die Phos- } \\
\text { phatase Phosphatase and Tensin } \\
\text { homolog }(P T E N) \text { über einen } \\
\text { Zeitraum von } 8 \text { und } 24 \text { Wochen } \\
\text { bei Ratten. }\end{array}$ & $\begin{array}{l}\text { Sowohl nach } 8 \text { als auch nach } 24 \\
\text { Wochen war das } P T E N \text {-Level } \\
\text { gegenüber der Kotrollgruppe } \\
\text { signifikant niedriger. }\end{array}$ \\
\hline & $\begin{array}{l}\text { Pamuk et al. } \\
(2015)\end{array}$ & $\begin{array}{l}\text { Einfluss von SIR in Kombinati- } \\
\text { onsgabe mit CSA und TCR über } \\
\text { einen Zeitraum von } 8 \text { Wochen bei } \\
\text { Ratten. }\end{array}$ & $\begin{array}{l}\text { SIR scheint nicht mit dem Auftre- } \\
\text { ten gingivaler Wucherungen } \\
\text { zusammenzuhängen und vermin- } \\
\text { dert in der Kombinationsgabe mit } \\
\text { CSA und TCR den Schweregrad } \\
\text { der Gingivawucherung. }\end{array}$ \\
\hline \multirow{4}{*}{$\begin{array}{l}\text { Klinische } \\
\text { Studien }\end{array}$} & $\begin{array}{l}\text { Castronovo et al. } \\
(2014)\end{array}$ & $\begin{array}{l}\text { Beurteilung des Effekts einer } \\
\text { nicht-chirurgischen Therapie bei } \\
\text { Patienten mit Gingivawucherun- } \\
\text { gen unter Medikation mit CSA } \\
\text { und TCR anhand parodontaler } \\
\text { Parameter. }\end{array}$ & $\begin{array}{l}\text { Beide Gruppen zeigten eine signi- } \\
\text { fikante Verbesserung der Parame- } \\
\text { ter: Bleeding on Probing (BOP), } \\
\text { Sondierungstiefe (ST) und Hy- } \\
\text { pertrophieindex (HI). }\end{array}$ \\
\hline & $\begin{array}{l}\text { Costa et al. } \\
(2013)\end{array}$ & $\begin{array}{l}\text { Beurteilung der Häufigkeit, des } \\
\text { Schweregrades und potentieller } \\
\text { Risikovariablen von Gingivawu- } \\
\text { cherungen bei Patienten unter } \\
\text { CSA-, TCR- und SIR-Medikation } \\
\text { über einen Beobachtungszeitraum } \\
\text { von } 44 \text { Monaten. }\end{array}$ & $\begin{array}{l}\text { Alle Gruppen zeigten eine Ab- } \\
\text { nahme in der Häufigkeit des } \\
\text { Auftretens, eine Reduzierung des } \\
\text { Schweregrades und eine Verbes- } \\
\text { serung des Papillenblutungsindex } \\
(\mathrm{PBI}) \text {. }\end{array}$ \\
\hline & $\begin{array}{l}\text { Dannewitz et al. } \\
\text { (2011) }\end{array}$ & $\begin{array}{l}\text { Korrelation zwischen der NFAT } \\
\text { Genexpression und dem Auftre- } \\
\text { ten gingivaler Wucherungen, } \\
\text { induziert durch CSA Einnahme. }\end{array}$ & $\begin{array}{l}\text { Patienten mit Gingivawucherun- } \\
\text { gen zeigten eine um den Faktor } \\
\text { zwei geringere NFAT Aktivität } \\
\text { als die Kontrollgruppe. }\end{array}$ \\
\hline & $\begin{array}{l}\text { Gürkan et al. } \\
(2014)\end{array}$ & $\begin{array}{l}\text { Vergleich der Parameter PBI, ST, } \\
\text { Plaqueausmaß und HI bei Patien- } \\
\text { ten unter CSA-Medikation mit } \\
\text { Patienten unter TCR-Medikation/ } \\
\text { ohne Medikation. }\end{array}$ & $\begin{array}{l}\text { Bei der CSA-Gruppe waren alle } \\
\text { untersuchten Parameter im Ver- } \\
\text { gleich zu beiden Kontrollgruppen } \\
\text { signifikant erhöht. }\end{array}$ \\
\hline
\end{tabular}




\section{$3 \quad$ Versuchsplanung}

$\mathrm{Da}$ es in der bisherigen Forschung an Studien fehlt, die unterschiedliche Immunsuppressiva in verschiedenen Konzentrationen und Einwirkzeiten untersuchten und diese zudem in einen direkten Vergleich miteinander stellten, wurde diese Untersuchung zunächst als Pilotstudie geplant und angelegt. Das Ziel der vorliegenden In-vitro-Untersuchung ist es, den Einfluss der Immunsuppressiva Cyclosporin A, Tacrolimus und Sirolimus auf immortalisierte Gingivafibroblasten von Mäusen in Abhänigkeit der Einwirkzeit und unterschiedlicher Konzentrationen zu ermitteln.

Es soll anhand von zwei unterschiedlichen Methoden die Auswirkung auf die Parameter Gesamtzellzahl, Lebendzellzahl, Zelldurchmesser und Menge an Prokollagen Typ I untersucht werden. Für die Untersuchung und Messung der Parameter Gesamtzellzahl, Lebendzellzahl und Zelldurchmesser wird das Zellzählgerät CASY® (Cell Counter, Modell TT, Roche Diagnostics GmbH, Roche Applied Science, Penzberg, Deutschland) ausgewählt. Die Bestimmung der Menge an Prokollagen Typ I erfolgt anhand der Methode eines Enzyme-Linked-Immunoabsorbent-Assay (ELISA: Mouse Procollagen Type I C-Terminal Propeptide, BlueGene Biotech Co., Shanghai, China). Jeder Hauptversuch wird zwölfmal wiederholt und jede Probe in Doppelbestimmung angesetzt. Jeder Untersuchungsparameter wird für sich ausgewertet.

Zum einen sollen die Ergebnisse der unterschiedlichen Konzentrationen innerhalb eines Immunsuppressivums miteinander verglichen werden, zum anderen erfolgt ein Vergleich unterhalb der drei verwendeten Immunsuppressiva. Hieraus ergeben sich die Hauptfragen der Studie:

- Wirkt sich die Behandlung der Zellen mit dem jeweiligen Immunsuppressivum in einer Zunahme der untersuchten Parameter aus?

- Ist dieser Effekt dosis-und/oder zeitabhängig und steigt mit zunehmender Dosis und Einwirkzeit?

- Weisen die Zellen im Vergleich der Immunsuppressiva unterschiedliche Ergebnisse auf?

Dabei soll die Hypothese bestätigt werden, dass sich unter Einwirkung des jeweiligen Immunsuppressivums ein dosis- und zeitabhängiger Effekt zeigt, welcher mit steigender Dosis und Einwirkzeit zunimmt. Da vornehmlich Cyclosporin A für die Entstehung einer medikamentös-induzierten Gingivawucherung steht, zeigt sich dieser Effekt hier am stärksten. 
Vor Studienbeginn ist es notwendig, einige wesentliche Arbeitsschritte im Studienablauf und -design zu klären, dazu zählen u.a.:

- Bestimmung der Ausgangszellzahl: Welche Zellzahl erweist sich als optimal für eine geplante Versuchsdauer von 120 Stunden in einer 24-Well-Platte?

- Medikamentenkonzentration: Welche Konzentrationen der Immunsuppressiva eignen sich über eine Versuchsdauer von 120 Stunden?

- Auswertung des Parameters Prokollagen Typ I: Wo ist eine größere Menge an Prokollagen Typ I messbar - in den Überständen oder im Zellpellet?

Diese Fragestellungen sollen vor Versuchsbeginn in verschiedenen Vorversuchen abgeklärt werden. 


\subsection{Zellen}

Grundlage für die vorliegende Studie bildete eine adhärent wachsende, immortalisierte Standardfibroblastenlinie (,3T3-Zellen“), die aus der Gingiva von embryonalen Mäusen gewonnen wurde (Abb. 2).

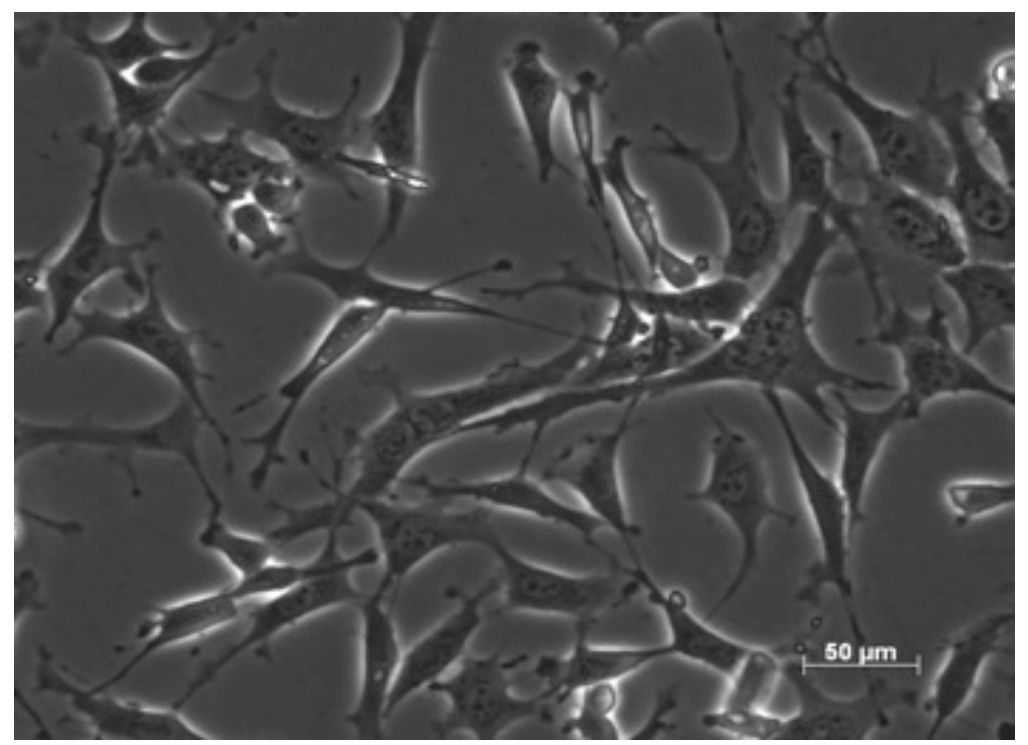

Abbildung 2: Immortalisierte Zellpopulation von 3T3-Zellen; Fotografie aus eigenem Bestand, aufgenommen mit Axiovert 200M (Zeiss, Göttingen, Deutschland)

Die Zellen stammten aus dem Bestand von Prof. Dr. W.H. Zimmermann, Leiter des Institutes für Pharmakologie der Universitätsmedizin Göttingen, und befanden sich im kryokonservierten Zustand in Passage 34. Die Bezeichnung „3T3“ basiert darauf, dass ein Passagieren der Zellen jeden dritten Tag bei einer Einsaatdichte von 3 x $10^{5}$ Zellen (pro 60 mm Schale) erfolgte. Todaro und Green gelang 1963 mit dieser Methode die Immortalisierung einer Primärkultur von embryonalen Mäusefibroblasten. Sie machten dadurch das Heranzüchten einer kontinuierlichen Fibroblastenlinie möglich (Lindl und Gstraunthaler 2013).

Die Zellen der vorliegenden Untersuchung wurden in Passage 34 vervielfältigt. In Passage 39 war eine für die Versuche ausreichende Zellzahl erreicht. Die kultivierten Zellen wurden mithilfe des Frostschutzmittels Dimethylsulfoxid (DMSO) (Merck, Darmstadt, Deutschland) in Aliquots von etwa 1,5 x $10^{6}$ Zellen pro Einfrierröhrchen aufgeteilt und bis zur weiteren Verwendung in flüssigem Stickstoff tiefgefroren.

Die 3T3-Zellen wurden auf Bakterien, Pilze und Mykoplasmen untersucht und zeigten negative Befunde. 


\subsubsection{Zellkultur zur Bereitstellung der 3T3-Zelllinie}

Die gesamten Arbeitsvorgänge fanden unter einer Sterilbank (Herasafe, Heraeus, Hannover, Deutschland) statt. Vor Arbeitsbeginn wurden alle Arbeitsflächen mit 70 \%igem Ethanol desinfiziert. Über die gesamte Dauer der Untersuchung wurden in der Zellkultur ausschließlich sterile Arbeitsinstrumente benutzt.

Als Nährmedium wurde Dulbecco's modified Eagle Medium (DMEM) (Gibco by life science, Invitrogen, Carlsberg, USA) ausgwäht. Das Nährmedium und andere Lösungen lagerten bis zur weiteren Anwendung bei $+2 /-8{ }^{\circ} \mathrm{C}$ in einem Kühlschrank. Vor Gebrauch erfolgte eine Erwärmung im Wasserbad auf $+37{ }^{\circ} \mathrm{C}$. Nach der Erwärmung auf $+37{ }^{\circ} \mathrm{C}$ wurden alle Flaschen, die verwendet werden sollten, mit 70 \%igem Ethanol abgesprüht, abgewischt und anschließend unter der Sterilbank platziert.

Im Folgenden wird das Procedere der Zellkultivierung, aufgegliedert nach den einzelnen Arbeitsschritten, beschrieben.

1. Vorbereitung:

Die in flüssigem Stickstoff aufbewahrten Einfrierröhrchen (Nunc ${ }^{\mathrm{TM}}$, Roskilde, Dänemark), welche die kyrokonservierten 3T3-Zellen enhielten, wurden nach der Entnahme aus dem Stickstofftank im Wasserbad bei $+37{ }^{\circ} \mathrm{C}$ kurz aufgetaut. Daraufhin wurde die Zellsuspension in ein $15 \mathrm{ml}$ Zentrifugenröhrchen (Greiner Bio-One, Frickenhausen, Deutschland) umgefüllt, in $10 \mathrm{ml}$ Nährmedium resuspendiert und für fünf Minuten bei $1200 \mathrm{U} / \mathrm{min}$ zentrifugiert.

Nach Verwerfen des Überstandes wurde das Zellpellet in $5 \mathrm{ml}$ Nährmedium resuspendiert und in eine T25-Zellkulturflasche (Greiner Bio-One, Frickenhausen, Deutschland) überführt. Im Anschluss wurden die Zellen in einem $\mathrm{Co}_{2}$-Brutschrank bei $+37{ }^{\circ} \mathrm{C}$ mit einem konstanten Stickstoffanteil von $5 \%$ und gesättigter Luftfeuchtigkeit kultiviert und bis zur weiteren Verwendung aufbewahrt.

2. Subkultivierung und Aussaat:

Nach mikroskopischer Kontrolle erfolgte die Umsetzung der adhärent wachsenden Zellen direkt am nächsten Tag bei einer Konfluenz von etwa 70 \%. Die Zellen wurden mit einer eingestellten Zellzahl von 3,75 x $10^{5}$ auf T75-Zellkulturflaschen (Greiner Bio-One, Frickenhausen, Deutschland) aufgeteilt.

Bei diesem Procedere wurde zuerst das verbrauchte Nährmedium mit einer Pasteurpipette aus der T25-Zellkulturflasche abgesaugt. Anschließend folgte eine Waschung der Zellen mit einer phosphatgepufferten Kochsalzlösung (phosphatbuffered saline, PBS, $\mathrm{pH}=7,4)$ (PAA, Pasching, Österreich). Hierbei wurden abgestorbene Zellen, Nährmediumreste und andere Unreinheiten entfernt. Zur Wa- 
schung wurde die Zellkulturflasche mit leichten Handbewegungen geschwenkt. Nach der Verwendung wurde die phosphatgepufferte Kochsalzlösung ebenfalls mit einer Pasteurpipette abgesaugt.

Daraufhin folgte die Trypsinierung der Zellen durch die Zugabe von 0,2 ml Trypsin (Gibco by life science, Invitrogen, Carlsbad, USA) auf eine T25-Zellkulturflasche (Greiner Bio-One, Frickenhausen, Deutschland). Durch leichte Schwenkbewegungen konnte das Trypsin auf dem gesamten Flaschenboden verteilt werden. Um eine optimale Wirkung des Trypsins zu erzielen, folgte eine vierminütige Aufbewahrung im Brutschrank bei $+37^{\circ} \mathrm{C}$. Mithilfe mikroskopischer Kontrollen konnte festgestellt werden, ob sich bereits Zellen vom Flaschenboden gelöst hatten (Axiovert 35, Zeiss, Göttingen, Deutschland). Hierfür wurde eine 100fache Vergrößerung verwendet (Okular: PL 10x/20; Objektiv: Achrostigmat 10x/0,25). Daraufhin wurde die T25Zellkulturflasche mit 4,8 ml Nährmedium aufgefüllt und durch Auf- und Abziehbewegungen mit einer Stabpipette gut durchmischt. Anschließend wurde die Suspension in ein $15 \mathrm{ml}$ Zentrifugenröhrchen pipettiert und bei $1200 \mathrm{U} / \mathrm{min}$ für fünf Minuten zentrifugiert. Nach dem Absaugen des Überstandes mit einer Pasteurpipette folgte ein Auffüllen mit $1 \mathrm{ml}$ Nährmedium. Um das Zellpellet am Boden des Zentrifugenröhrchens optimal zu lösen und in eine Suspension zu bringen, erfolgten erneut Auf- und Abziehbewegungen mit einer Stabpipette.

Darauffolgend wurde die Zellzahl mithilfe des Zellzählgerätes $C A S Y{ }^{\circledR}$ (Cell Counter, Modell TT, Roche Diagnostics GmbH, Roche Applied Science, Penzberg, Deutschland) ermittelt, die gewünschte Suspensionsmenge von 3,75 x $10^{5}$ Zellen in die oben genannten T75-Zellkulturflasche pipettiert und mit je 19 ml Nährmedium bestückt.

Anschließend wurden die neu bestückten Flaschen im Brutschrank bei $+37^{\circ} \mathrm{C}$ aufbewahrt. Ein Nährmediumswechsel erfolgte am dritten Tag der Kultivierung. Hierbei wurde das verbrauchte Nährmedium mit einer Pasteurpipette abgesaugt. Es folgte eine erneute Zugabe von je $19 \mathrm{ml}$ Nährmedium pro T75-Zellkulturflasche. Daraufhin wurden die bestückten Zellkulturflaschen im Brutschrank bei $+37{ }^{\circ} \mathrm{C}$ aufbewahrt.

Nach ca. vier Tagen erreichte der Zellrasen eine Konfluenz von etwa 70 \%, sodass die Zellzahl für das Ansetzen der folgenden Versuche ausreichte. Die Zellen wurden zu erst von dem Flaschenboden gelöst. Das Procedere glich dem oben Beschriebenen. Nachdem das Zellpellet in $1 \mathrm{ml}$ Nährmedium resuspendiert wurde, erfolgte zur direkten Weiterverwendung der Zellen eine Zählung mit dem Zellzählge- 
rät $C A S Y \circledR$. Diese Zählung wurde in drei Messvorgängen im Programm 01 (L929), welches für Fibroblasten geeignet ist, durchgeführt. Die Verdünnung betrug hierbei 1:500. Das heißt in $10 \mathrm{ml}$ CASYton ${ }^{\circledR}$ (Roche Applied Science, Mannheim, Deutschland) wurden $20 \mu \mathrm{l}$ der Zellsuspension pipettiert.

3. Vorbereitung der Well-Platten:

Anschließend wurden 24-Well-Platten für eine Versuchsreihe bestückt, sodass sich in jedem Well die in den Vorversuchen zuvor bestimmte Ausgangszellzahl von $2 \mathrm{x}$ $10^{4}$ Zellen befand.

Vor der weiteren Verwendung erfolgte ein Anwachsen der Zellen für 48 Stunden im Brutschrank bei $+37^{\circ} \mathrm{C}$. Im Anschluss wurden die Zellen mit dem jeweiligen Medikament beimpft.

In den Versuchen wurden ausschließlich 3T3-Zellen in der 39. Passage verwendet.

\subsection{Immunsuppressiva und deren Aufbereitung}

Im Rahmen der Versuchsreihe wurden drei gängige Immunsuppressiva gewählt: Cyclosporin (CSA) A, Tacrolimus (TCR; früher: FK506) und Sirolimus (SIR: Rapamycin). Tabelle 3 gibt einen Überblick über die unterschiedlichen Immunsuppressiva. Sie beinhaltet deren Handelsnamen, Firma, Bestell- und Katalognummer (Cas.Nr.) und Wirkmechanismus sowie Angaben zu dem jeweiligen Vollblut-Talspiegel (Hyland et al. 2003, Thomas 2005, Rote Liste 2015, www.merckmillipore.com).

Tabelle 3: Überblick - Immunsuppressiva (CSA: Cyclosporin A, TCR: Tacrolimus, SIR: Sirolimus)

\begin{tabular}{|l|l|l|l|l|l|}
\hline & Handelsname & Firma & $\begin{array}{l}\text { Bestellnummer/ } \\
\text { CAS-Nr. }\end{array}$ & $\begin{array}{l}\text { Wirkmecha- } \\
\text { nismus }\end{array}$ & $\begin{array}{l}\text { Vollblut- } \\
\text { Talspiegel }\end{array}$ \\
\cline { 2 - 6 } CSA & $\begin{array}{l}\text { Sandimmun } \\
\text { Cicloral }^{\circledR}\end{array}$ & $\begin{array}{l}\text { Merck Chemi- } \\
\text { cals, Millipore }\end{array}$ & $\begin{array}{l}239835-100 \mathrm{mg} \\
/ 59865-13-3\end{array}$ & $\begin{array}{l}\text { Calcineurininhi- } \\
\text { bitor }\end{array}$ & $\begin{array}{l}\text { 100-300 } \mathrm{ng} / \mathrm{ml} \\
\text { In-vitro-Studien: } \\
\text { bis zu } 2000 \\
\mathrm{ng} / \mathrm{ml}\end{array}$ \\
\hline TCR & Prograf $^{\circledR}$ & $\begin{array}{l}\text { Merck Chemi- } \\
\text { cals, Millipore }\end{array}$ & $\begin{array}{l}342500-5 \mathrm{mg} / \\
104987-11-3\end{array}$ & $\begin{array}{l}\text { Calcineurininhi- } \\
\text { bitor }\end{array}$ & $\begin{array}{l}\text { Erhaltungsdosis: } \\
10-20 \mathrm{ng} / \mathrm{ml}\end{array}$ \\
\hline SIR & Rapamune $^{\circledR}$ & $\begin{array}{l}\text { Merck Chemi- } \\
\text { cals, Millipore }\end{array}$ & $\begin{array}{l}553211-500 \mathrm{UG} \\
/ 53123-88-9\end{array}$ & mTOR Inhibitor & $\begin{array}{l}\text { Erhaltungsdosis: } \\
\text { 4-20 ng/ml }\end{array}$ \\
\hline
\end{tabular}

Für die weitere Verwendung der Immunsupressiva war eine spezielle Aufbereitung notwendig. Bei allen Immunsuppressiva wurde darauf geachtet, dass diese im Lösungsmittel Dimethylsulfoxid (DMSO) löslich waren, um eine Stocklösung der Immunsuppressiva herstellen zu können. Diese wurden im weiteren Verlauf verdünnt, um eine verwendbare Konzentration der Immunsuppressiva für die Versuchsdurchführung einzustellen. Im Folgenden wird die Aufbereitung der einzelnen Immunsuppressiva genauer beschrieben: 
a) Cyclosporin $\mathrm{A}$ :

Das Immunsuppressivum Cyclosporin A wurde in Pulverform, in einer Menge von $100 \mathrm{mg}$ bestellt. Um eine Stocklösung herzustellen, wurden die 100 mg Cyclosporin A in $1 \mathrm{ml}$ DMSO gelöst.

b) Tacrolimus:

Das Immunsuppressivum Tacrolimus wurde in Pulverform, in einer Menge von 5 $\mathrm{mg}$, angeliefert. Um eine Stocklösung herzustellen, wurden die $5 \mathrm{mg}$ Tacrolimus in $1 \mathrm{ml}$ DMSO gelöst.

c) Sirolimus:

Das Immunsuppressivum Sirolimus wurde in Form einer $5 \mathrm{mM}$ Lösung bestellt und in dieser Konzentration als Stocklösung verwendet.

Um eine pipettierbare Menge zu erhalten, erfolgte eine Verdünnung aller Stocklösungen auf eine $0,1 \mathrm{mM}$ Lösung. Diese wurde aliquotiert und bis zur weiteren Verwendung bei $20^{\circ} \mathrm{C}$ eingefroren.

\subsection{Sonstige Materialien}

Im Rahmen der Zellkultur war der Einsatz weiterer verschiedener Materialien notwendig. Die wichstigsten Materialien sind nachfolgend weiter aufgeführt (s. auch Anhang Materialliste).

a) Nährmedium:

Als Nährmedium wurde das Universalmedium Dulbecco's modified Eagle Medium (DMEM) (Gibco by life science, Invitrogen, Carlsberg, USA) verwendet. Dieses beinhaltete $1 \mathrm{~g}$ Glukose. Zur Komplettierung des Nährmediums wurden $5 \mathrm{ml} \mathrm{Am-}$ photericin B (PAN Biotech GmbH, Aidenbach, Deutschland), $5 \mathrm{ml}$ Pen/Strep (Gibco by life science, Invitrogen, Carlsberg, USA) und $50 \mathrm{ml}$ fetales Kälberserum (FKS) hinzugefügt. Das Nährmedium wurde im Dunklen bei $-4 /+8{ }^{\circ} \mathrm{C}$ aufbewahrt. Die Zusätze lagerten bei $-20{ }^{\circ} \mathrm{C}$ und wurden unmittelbar vor dem Gebrauch im Wasserbad bei $+37^{\circ} \mathrm{C}$ aufgetaut.

b) Puffer:

Als Puffer wurde eine phosphatgepufferte Kochsalzlösung (PBS, Dulbecco `s phosphate-buffered-saline, $\mathrm{pH}=7,4)$ (PAA, Pasching, Österreich) verwendet. Diese war frei von Calcium- und Magnesiumzusätzen. 
c) Trypsin:

Trypsin, eine alkalische Protease, löst adhärent wachsende Zellen von ihrer Unterlage ab. Ihr Einsatz war notwendig, um die adhärent wachsenden Zellen zur Zählung und Subkultivierung vom Boden der Zellkulturflasche abzulösen. Standardmäßig wurde dies mit einer Trypsin/EDTA Lösung (Gibco by life science, Invitrogen, Carlsbad, USA) vorgenommen. Da Trypsin sein Wirkoptimum bei $+37^{\circ} \mathrm{C}$ hat, wurden die Zellen zum Ablösen für sechs Minuten im Brutschrank inkubiert. Die proteolytische Wirkung von Trypsin wurde durch die Zugabe von FKS beendet.

d) Dimethylsulfoxid (DMSO):

DMSO (Merck, Darmstadt, Deutschland) wurde als Frostschutz- und Lösungsmittel in der vorliegenden Untersuchung verwendet.

e) Weitere Materialien:

Alle weiteren Zellkulturmaterialien waren Standardmaterialien und wurden steril geliefert (Materialliste im Anhang). Die wiederverwertbaren Gefäße wurden vor ihrer Verwendung autoklaviert.

\subsection{Messmethoden und Zielparameter}

\subsubsection{Elektrisch basierte Zellzahlbestimmung mittels CASY ${ }^{\circledR}$}

Für die Bestimmung der Zellzahl in Monolayerkulturen eignet sich die Methode der elektrisch basierten Zellzählung. In der vorliegenden Untersuchung wurde dafür das Zellzählgerät $C A S Y{ }^{\circledR}$ (Cell Counter, Modell TT, Roche Diagnostics GmbH, Roche Applied Science, Penzberg, Deutschland) ausgewählt.

Neben der Zellzahl gestattet das $C A S Y ®$-System die Messung von Zellvitalität (Lebendzellzahl) und Zellgröße. Das Prinzip beruht auf einer Tot-Lebend-Differenzierung. Die Bestimmung der Zellzahl erfolgte in der vorliegenden Untersuchung anhand eines speziell ausgewählten Programmes für Fibroblasten (L929; Norm. Cursor: 7,4 - $40 \mu \mathrm{m}$, Vedünnung 1:500). Durch die Einstellung des Zelltyps wird eine Zellzählung mit hoher Genauigkeit und Reproduzierbarkeit erreicht.

Um diese Parameter bestimmen zu können, ist es nötig, die Zellen durch Trypsinieren von der Kulturunterlage zu lösen und in eine Zellsuspension zu überführen. Die gewonnene Zellsuspension wird in eine klare, partikelfreie und geruchslose isotonische Elektrolytlösung $\left(\right.$ CASYton $\left.{ }^{\circledR}\right)$ gegeben. Die in der isotonischen Elektrolytlösung resuspendierten Zellen werden durch eine Messkapillare in definierter Menge angesaugt. An diese Messkapillare ist über zwei Platinelektroden elektrische Spannung angelegt. Eine lebende Zelle fungiert als elektrischer Isolator, da diese den elektrischen Strom durch ihre intakte Membran 
ausschließt und somit die leitfähige Elektrolytlösung verdrängt. Tote Zellen nehmen den elektrischen Strom aufgrund der elektrischen Leitfähigkeit ihres cytoplasmatischen Raumes auf. Entsprechend der Voreinstellung führt $C A S Y{ }^{\circledR}$ drei Einzelmessungen mit jeweils $400 \mu 1$ durch und gibt anschließend die zu bestimmenden Messparameter sowohl Gesamtund Lebendzellzahl als auch Zelldurchmesser an.

\subsubsection{CellTiter-Blue ${ }^{\circledR}$ Cell Viability Assay}

Der CellTiter-Blue ${ }^{\circledR}$ Cell Viability Assay (Promega Corporation, Madison, USA) wurde in der vorliegenden Studie lediglich im Rahmen der Vorversuche eingesetzt. Dieser eignet sich für Proliferations- und Zytotoxizitätsbestimmung von Zellen in Zellkulturen und ermittelt das Wachstumsverhalten über deren metabolische Aktivität. Deshalb wurde dieser Versuch parallel zur Zellzahlbestimmung mit dem Zellzählgerät $C A S Y ®$ für die Bestimmung einer optimalen Ausgangszellzahl gewählt.

Im Folgenden wird die Methodik dieses Tests genau erläutert:

Das CellTiter-Blue ${ }^{\circledR}$ Reagenz enthält den Redoxfarbstoff Resazurin. In einem 1:5 Verhältnis wird das blaue Farbreagenz in das jeweilige Well pipettiert und für eine Stunde im Brutschrank bei $+37{ }^{\circ} \mathrm{C}$ inkubiert. Nach der Zugabe des Farbreagenz sind metabolisch aktive Zellen in der Lage, das blaue Resazurin in den pinkfarbenen und fluoreszenten Farbstoff Resorufin umzusetzen. Bei abgestorbenen Zellen erfolgt hingegen keine Umsetzung des Farbstoffes. Nach einer Stunde Inkubation wurden aus jedem Well $100 \mu \mathrm{l}$ in eine 96Well-Platte umpipettiert und gemessen. Das Fluoreszenzsignal, welches der Menge an Resofurin entspricht, ist direkt proportional zur Lebendzellzahl. Die Detektion des Fluoreszenzsignales wurde in der vorliegenden Untersuchung mit einem Fluorometer (SpektraMax M2 Photometer, Molecular Devices, Biberach an der Riss, Deutschland) vorgenommen (560Ex/590Em). Die gewonnenen Daten wurden mithilfe der Software Soft Max Pro 4,8 aufgezeigt. 


\subsubsection{Messung der Menge an Prokollagen Typ I (Mouse Procollagen Type I C- Terminal Propeptide)}

Um das Potential der Medikamente hinsichtlich einer Veränderung in der Kollagenmenge zu untersuchen, wurde ein Enzyme-linked-Immunoabsorbant-Assay durchgeführt. Hierbei wurde die Menge an Prokollagen Typ I aus dem gewonnenen Überstand und den Zellpellets bestimmt. Zur Anwendung kam hierbei der kompetitive ELISA Mouse Procollagen Type I C-Terminal Propeptide (PICP) der Firma BlueGene Biotech Co (Shanghai, China). Dieser ELISA wurde aufgrund seiner sehr niedrigen Sensitivität von 0,1 ng/ml ausgewählt. Das Prinzip eines kompetitiven ELISAs beruht darauf, dass der Analyt (Antigen) in der Probenlösung mit einem markierten Antigen, welches in einer zweiten Lösung in definierter Konzentration vorhanden ist, konkurriert. Demnach wird umso weniger markiertes Antigen an den Antikörper gebunden, je höher die nicht markierte Antigenmenge der Probe ist.

\subsection{Vorversuche}

\subsubsection{Vorversuche zur Bestimmung der Ausgangszellzahl}

Um eine optimale Ausgangszellzahl für die geplante Versuchsdauer von insgesamt 120 Stunden ermitteln zu können und um in Erfahrung zu bringen, wie lange 3T3-Zellen in einer 24-Well-Platte unter normalen Bedingungen lebensfähig sind, war es nötig, eine Vorversuchsreihe durchzuführen. Zum einen wurde die Zellzahl mithilfe des zuvor bereits erläuterten Zellzählgerätes $C A S Y{ }^{\circledR}$ bestimmt, zum anderen wurde der Proliferationsassay CellTiter-Blue ${ }^{\circledR}$ Cell Viability Assay verwendet. Zunächst wurden Zellen in unterschiedlichen Zellzahlen in 24-Well-Platten gegeben. Die Ausgangszellzahlen waren hierbei $2 \mathrm{x}$ $10^{4}, 3 \times 10^{4}$ und $4 \times 10^{4}$ Zellen/1,5 ml Nährmedium/Well. Die Zellzahl wurde zu den Auswertungszeitpunkten $0,6,24,48,72$ und 120 Stunden bestimmt.

Fazit

Mithilfe des Zellzählgerätes $C A S Y{ }^{\circledR}$ wurde eine optimale Ausgangskonzentration 2 x $10^{4}$ Zellen in einer 24-Well-Platte ermittelt (Abb. 3). 


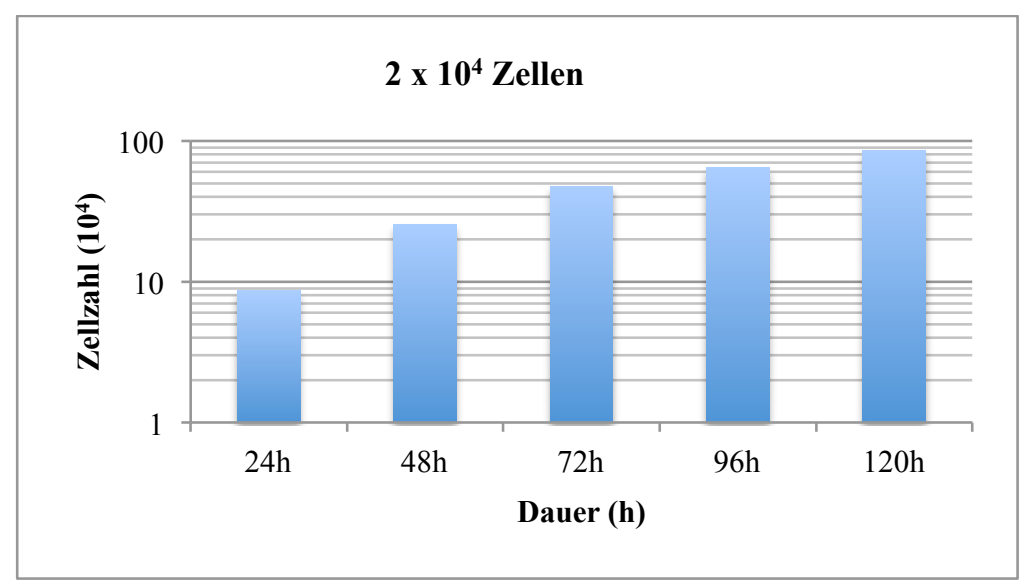

Abbildung 3: Wachstumskurve der ermittelten Lebendzellzahl mithilfe des Zellzählgerätes $C A S Y{ }^{\circledR}$ (Ausgangszellzahl von $2 \times 10^{4}$ Zellen)

Der CellTiter-Blue ${ }^{\circledR}$ Cell Viability Assay zeigte ebenfalls, dass bei einer Ausgangszellzahl von $2 \times 10^{4}$ Zellen/Well ein optimales Wachstumsverhalten bis zum fünften Tag vorlag (Abb. 4).

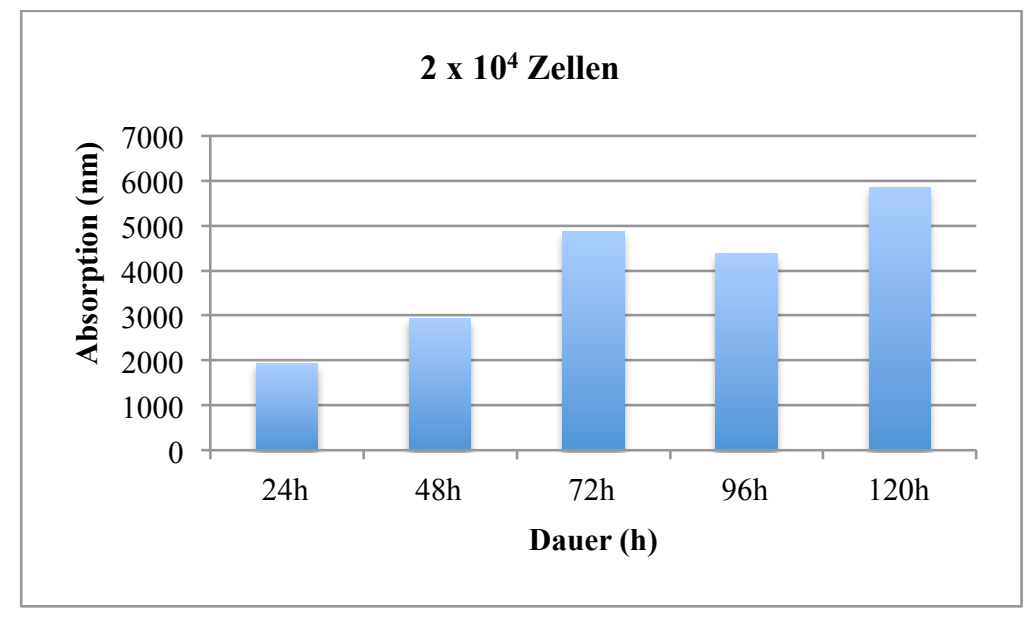

\footnotetext{
Abbildung 4: Wachstumskurve der ermittelten Ausgangszellzahl von $2 \mathrm{x}$ $10^{4}$ Zellen mithilfe des Proliferationsassays CellTiter-Blue ${ }^{\circledR}$ Cell Viability Assay
}

Deshalb wurde die Ausgangszellzahl von $2 \times 10^{4}$ Zellen/Well für die Durchführung der Hauptversuche übernommen.

\subsubsection{Vorversuche zur Bestimmung der Konzentrationen der Immunsuppressiva}

Um das Potential der Immunsuppressiva genau beleuchten zu können, sollten im Hauptversuch unterschiedliche Konzentrationen getestet werden.

Im Vorversuch wurde ausschließlich das Immunsuppressivum Cyclosporin A in unterschiedlichen Konzentrationen untersucht. Hier wurde die zuvor ermittelte Ausgangszellzahl von 2 x $10^{4}$ Zellen/ Well (24-Well-Platte) verwendet. 
Drei unterschiedliche Konzentrationen von Cyclosporin A wurden getestet, wobei jeweils eine niedrige, mittlere und hohe Dosis des Immunsuppressivums verwendet wurde. Demnach wurden folgende Konzentrationen getestet:

- $\quad$ Niedrige Dosis $=15 \mathrm{ng} / \mathrm{Well}$ :

Vergleichbare Konzentration zu den Vollblut-Talspiegeln von Tacrolimus und Sirolimus.

- $\quad$ Mittlere Dosis $=150 \mathrm{ng} /$ Well:

Reale Vollblut-Talspiegel-Konzentration von Cyclosporin A.

- $\quad$ Hohe Dosis $=750 \mathrm{ng} /$ Well:

Gemittelte Konzentration aus In-vitro-Studien verwendeten Konzentrationen und der Vollblut-Talspiegel-Konzentration von Cyclosporin A.

- Kontrolle:

Hier wurde zum einen das Nährmedium mit dem Lösungsmittel DMSO vesetzt und als Lösungsmittelkontrolle verwendet, zum anderen diente das reine Nährmedium als zweite Kontrolle in Form einer Negativkontrolle.

Erst nach 48-stündigem Anwachsen der Zellen erfolgte die Behandlung mit Cyclosporin A, da zuvor die zu messenden Parameter Gesamtzellzahl, Lebendzellzahl und Zelldurchmesser mithilfe des Zellzählgerätes $C A S Y{ }^{\circledR}$ nicht messbar waren. Dieser Zeitpunkt fungierte als Auswertungszeitpunkt 0 Stunden. Anschließend wurden die 3T3-Zellen 6, 24, 48 oder 72 Stunden mit Cyclosporin A behandelt. Die Überstände der auszuwertenden Wells wurden zu den jeweiligen Auswertungszeitpunkten abgenommen und bei $-80{ }^{\circ} \mathrm{C}$ bis zur weiteren Verwendung schockgefroren. Die folgenden Abbildungen (Abb. 5 - 7) geben eine Übersicht über die gewonnenen Ergebnisse der Untersuchung sowohlvon Gesamt- und Lebendzellzahl als auch des Zelldurchmessers.

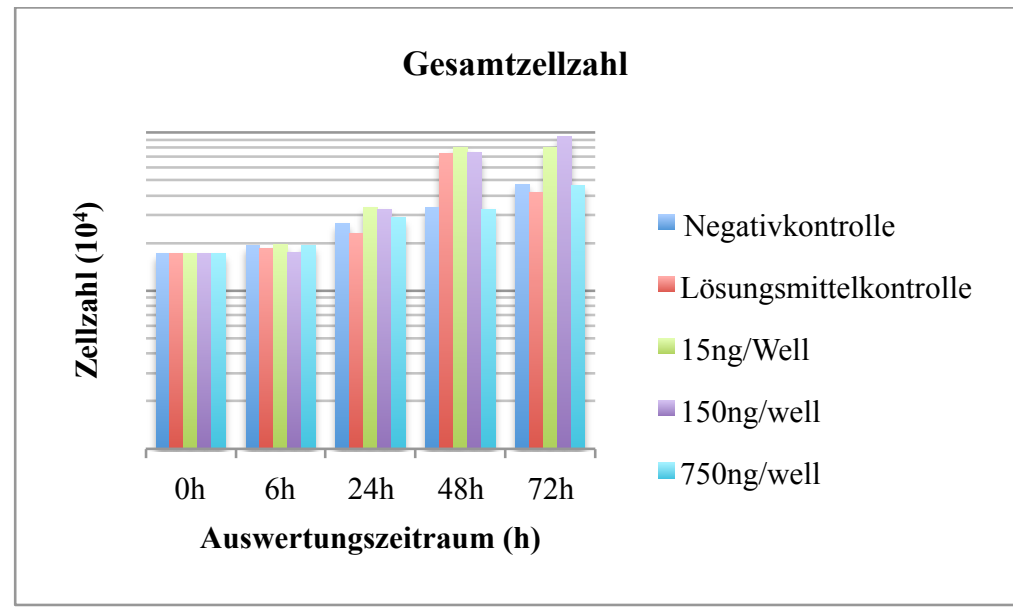

Abbildung 5: Vorversuch zur Konzentrationsfindung: Gesamtzellzahl (x10 $)$ 


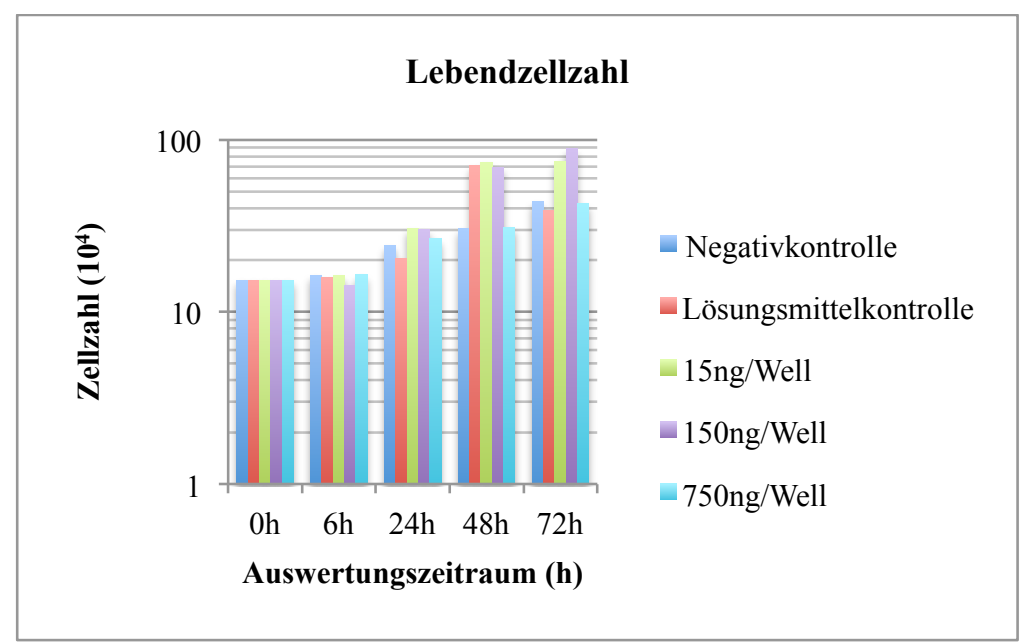

Abbildung 6: Vorversuch zur Konzentrationsfindung: Lebendzellzahl (x10 $)$

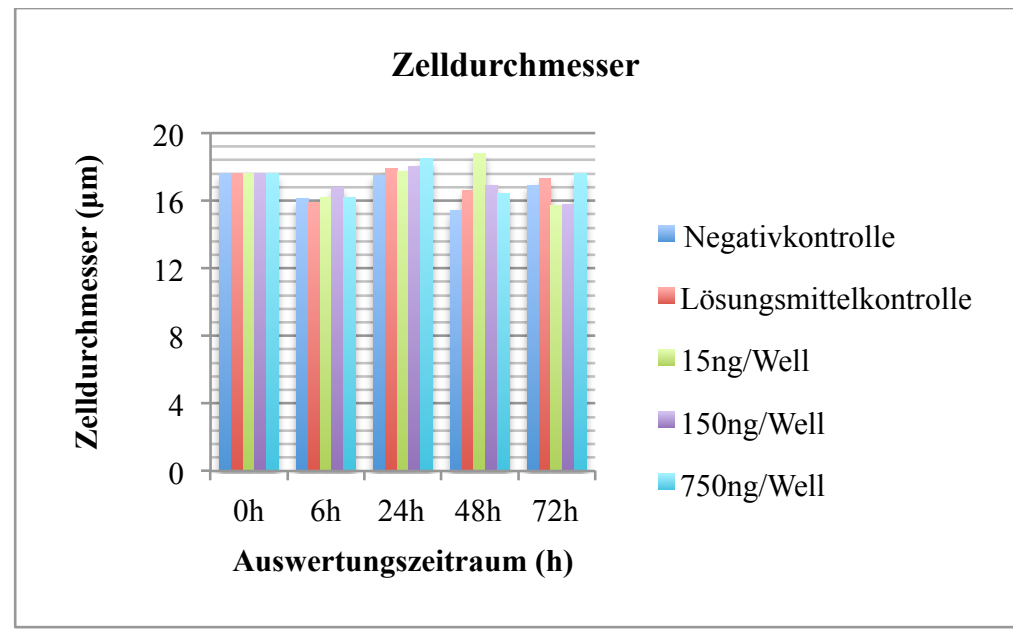

Abbildung 7: Vorversuch zur Konzentrationsfindung: Zelldurchmesser $(\mu \mathrm{m})$

Fazit

Die in diesem Vorversuch gewonnenen Ergebnisse zeigten, dass die hier verwendeten Konzentrationen von Cyclosporin A für die darauffolgenden Hauptversuche geeignet waren. Da Tacrolimus und Sirolimus bezüglich ihres Vollblut-Talspiegels sehr ähnliche Konzentrationen aufweisen und nur wenige Studien über Sirolimus in diesem Kontext existieren, lehnte man sich hier an die Konzentrationen von Tacrolimus an. Demnach wurde für beide Immunsuppressiva Konzentrationen von 10, 15 und $20 \mathrm{ng} /$ Well ausgewählt. Diese lagen alle innerhalb der jeweiligen Vollblut-Talspiegel. $10 \mathrm{ng} / \mathrm{Well}$ wurde als niedrigste Dosis verwendet, $15 \mathrm{ng} / \mathrm{Well}$ als mittlere und $20 \mathrm{ng} / \mathrm{Well}$ als höchste Dosis. Tabelle 4 gibt einen Überblick über die in den Hauptversuchen verwendeten Konzentrationen.

Tabelle 4: Angabe der Konzentrationen (ng/Well) für die Hauptversuche

\begin{tabular}{|l|c|c|c|}
\hline Immunsuppressivum & \multicolumn{4}{|l|}{ Konzentrationen } \\
\hline Cyclosporin A & $15 \mathrm{ng} /$ Well & $150 \mathrm{ng} / \mathrm{Well}$ & $750 \mathrm{ng} / \mathrm{Well}$ \\
\hline Tacrolimus & $10 \mathrm{ng} /$ Well & $15 \mathrm{ng} / \mathrm{Well}$ & $20 \mathrm{ng} / \mathrm{Well}$ \\
\hline Sirolimus & $10 \mathrm{ng} /$ Well & $15 \mathrm{ng} / \mathrm{Well}$ & $20 \mathrm{ng} / \mathrm{Well}$ \\
\hline
\end{tabular}




\subsubsection{Vorversuche zur Messung der Prokollagen Typ I Menge}

Hier musste zunächst gestestet werden, in welchem Bestandteil der Zellen die höchste Menge an Prokollagen Typ I aufzufinden war. Daher wurde in diesem Vorversuch sowohl der Überstand als auch die gewonnenen Pellets der Lösungsmittelkontrolle (DMSOKontrolle) und der Konzentration 15 ng/Well des Medikamentes Cyclosporin A zu den Zeitpunkten 0, 6 und 72 Stunden untersucht und miteinander verglichen. Da in den Pellets nur wenig Prokollagen Typ I messbar war, entschied man sich dazu, in den Hauptversuchen ausschließlich die Überstände zu anaylsieren (Grafik „,Vorversuch Pellets“ hier nicht gezeigt). Abbildung 8 zeigt die im Vorversuch gewonnenen Ergebnisse der Untersuchung des Überstandes.

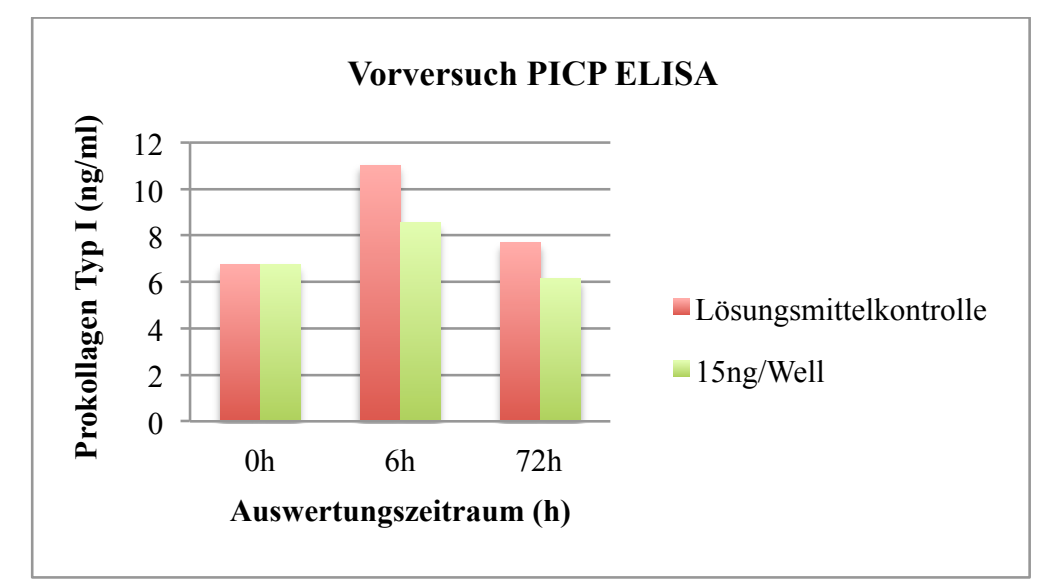

Abbildung 8: Vorversuch zur Bestimmung der Prokollagen Typ I Menge (ng/ml) aus dem Überstand mithilfe des PICP ELISAs

Fazit

Da die Überstände eine größere Menge an Prokollagen Typ I zeigten, sollten diese in den Hauptversuchen gesammelt und ausgewertet werden. Nach Betrachtung von Abbildung 8 fällt auf, dass die gemessenen Werte nach 72 Stunden, verglichen mit den Werten nach 6 Stunden, bereits niedriger waren. Demnach sollten in den Hauptversuchen die Überstände zu den Auswertungszeitpunkte 0, 6 und 48 Stunden gesammelt und ausgewertet werden. 


\subsection{Durchführung der Hauptversuche}

Abbildung 9 zeigt den Versuchsablauf der Hauptversuche. Jeder Versuch wurde $12 \mathrm{Mal}$ wiederholt und einzeln ausgewertet. Jedes Well wurde in Doppelbestimmung angesetzt. Für alle Hauptversuche wurden 3T3-Zellen in der 39. Passage verwendet. Nach dem Kultivieren der 3T3-Zellen wurden pro Hauptversuchsdurchlauf je 24-Well-Platten mit $2 \times 10^{4}$ Zellen/Well bestückt. Die Beimpfung der Zellen startete nach 48-stündigem Anwachsen. Die Zellen wurden 6, 24, 48 oder 72 Stunden mit dem jeweiligen Immunsuppressivum behandelt. Ein Mediumwechsel erfolgte nach 24 und 48 Stunden für die noch auszuwertenden Well, um eine dauerhafte Wirkung der Immunsuppressiva gewährleisten zu können. Die Durchführung der beiden Teilversuche zur Bestimmung sowohl des Zelldurchmessers, der Gesamt- und Lebendzellzahl als auch der Menge an Prokollagen Typ I werden im Folgenden genauer erläutert.

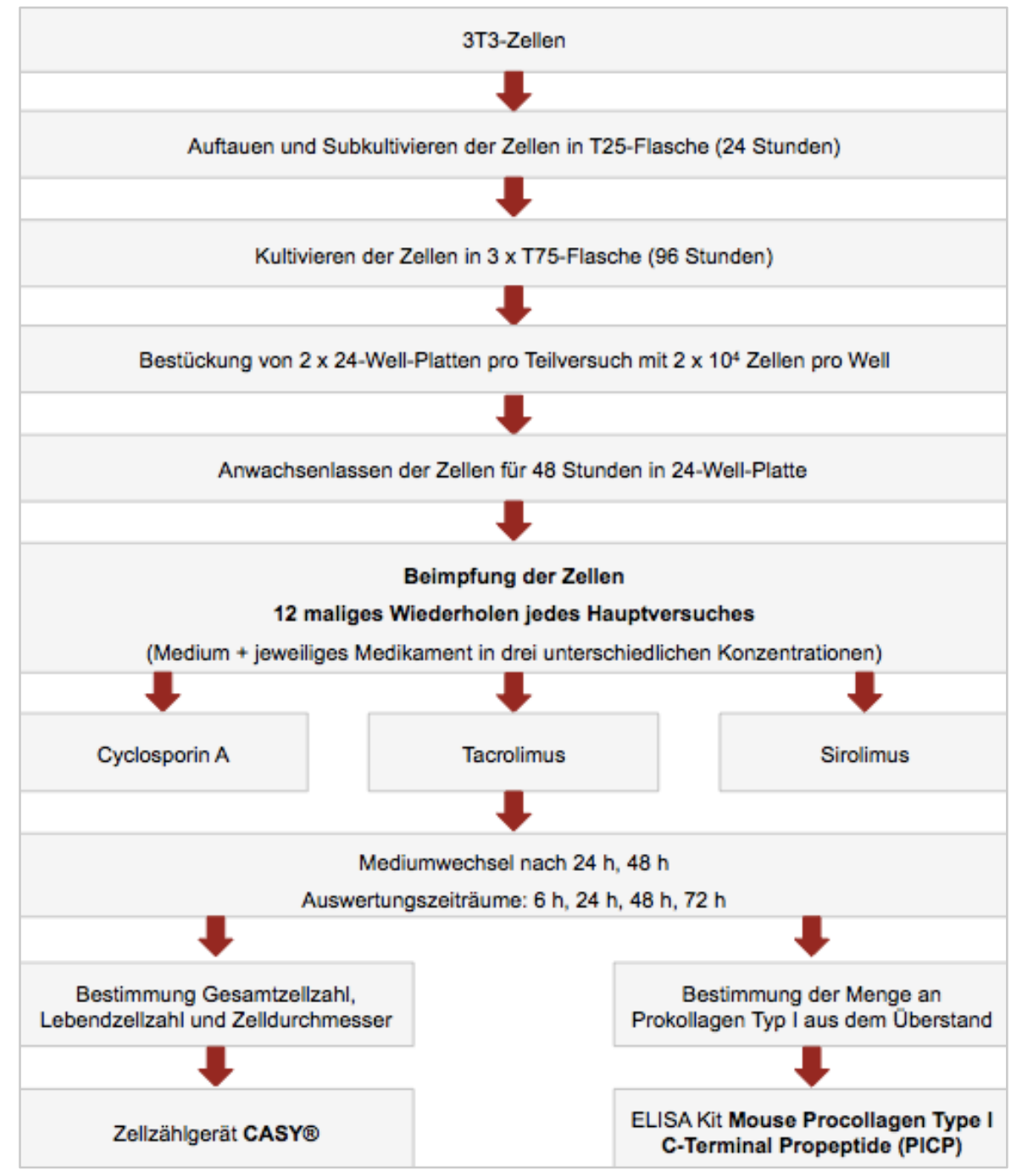

Abbildung 9: Versuchsablauf der Studie 


\subsubsection{Bestimmung der Parameter: Gesamt- und Lebendzellzahl, Zelldurchmesser}

Vor der Behandlung mit den unterschiedlichen immunsuppressiven Medikamenten wurden die Zellen nach Zellzahlbestimmung im Nährmedium resuspendiert und auf die zuvor ermittelte Ausgangskonzentration von $2 \times 10^{4}$ Zellen/1,5ml Nährmedium/Well eingestellt (Bestückung der 24-Well-Platten für je einen Versuchsdurchlauf im Anhang).

Nach 48-stündigem Anwachsen erfolgte die Behandlung der Zellen mit dem jeweiligen Immunsuppressivum in der jeweiligen Konzentration. Da die drei verwendeten Immunsuppressiva jedoch unterschiedlich lange Halbwertszeiten aufweisen (Cyclosporin A: 10 bis 27 Stunden, Tacrolimus: etwa 43 Stunden und Sirolimus: circa 60 Stunden, laut Thomas 2005), wurde sich an der kürzesten Halbwertszeit orientiert. Diese wies Cyclosporin A mit einer Halbwertszeit von 10-27 Stunden auf (Thomas 2005). Daher erfolgte 24stündlich ein Wechsel des Mediums, um eine dauerhafte Wirkung der Immunsuppressiva auf die 3T3-Zellen gewährleisten zu können. Dem Nährmedium wurden je nach Well eine bestimmte Konzentration an DMSO oder Immunsuppressivum beigefügt. Die Zellen wurden jeweils 6, 24, 48 oder 72 Stunden mit dem jeweiligen Immunsuppressivum behandelt.

Das Procedere war zu jedem Auswertungszeitpunkt gleich:

1. Mikroskopische Kontrolle der Dichte der adhärent wachsenden Zellen (Axiovert 35, 100fache Vergrößerung)

2. Sammeln und Schockgefrieren des Überstandes der auszuwertenden Wells auf Trockeneis (Aufbewahrung der Eppendorf-Cups bei $-80{ }^{\circ} \mathrm{C}$ bis zur weiteren Auswertung)

3. Waschen der Wells mit $1 \mathrm{ml}$ PBS

4. Ersetzen der PBS-Lösung mit $150 \mu 1$ Trypsin zur Ablösung der Zellen

5. Inkubation für fünf bis sieben Minuten im Brutschrank bei $+37^{\circ} \mathrm{C}$

6. Erneute visuelle Kontrolle

7. Resuspendierung in $1 \mathrm{ml}$ Nährmedium

8. Entnahme von $20 \mu 1$ der Suspensionslösung für die Messung mit dem Zellzählgerät CASY ${ }^{\circledR}$ in $10 \mathrm{ml}$ CASYTon ${ }^{\circledR}$

9. Bestimmung der Gesamtzellzahl, Lebendzellzahl und des Zelldurchmessers (Verdünnung 1:500)

Die gewonnenen Werte wurden zur Aufbereitung in das Programm Excel (Version 2011, Microsoft) eingegeben. 


\subsubsection{Bestimmung des Parameters: Prokollagen Typ I}

Die ELISAs wurden nach Abschluss des ersten Teiles der Hauptversuchsreihe durchgeführt. Kurz vor Beginn eines jeden Versuchsdurchlaufes wurden die für den ELISA benötigten Lösungen angesetzt. Als jeweilige Kontrollreferenz wurde nach dem Zufallsprinzip je eine Probe des Überstandes der Lösungsmittelkontrolle (DMSO-Kontrolle) aus jedem der 12 Hauptversuche ausgewählt. Da auch die Überstände der Lösungsmittelkontrolle in einer Doppelbestimmung genommen wurde, wurde diese hierbei gepoolt.

Der Überstand wurde im ersten Versuchsteil, wie zuvor bereits erläutert, zu jedem Auswertungszeitpunkt (0, 6 und 48 Stunden) nach Abnahme in Eppendorf-Cups bei $-80{ }^{\circ} \mathrm{C}$ bis zur weiteren Verwendung aufbewahrt.

Das Procedere der Mengenbestimmtung von Prokollagen Typ I war bei jeder Auswertung gleich:

1. Langsames Auftauen der Proben auf Raumtemperatur $\left(+20\right.$ bis $\left.25^{\circ} \mathrm{C}\right)$

2. Ansetzen der benötigten Lösungen:

Alle Bestandteile des ELISA Kits auf Raumtemperatur bringen

Ansetzen der Wash Solution: $10 \mathrm{ml}$ Wash Solution mit $990 \mathrm{ml}$ destilliertem Wasser

3. Vorbereitung der Proben:

Zentrifugieren der Eppendorf-Cups bei 3000 U/min für 15 Minuten

Abnahme des Überstandes in ein neues Eppendorf-Cup

4. Poolen der Doppelbestimmung von jeweils $200 \mu 1$ aus A- und B-Probe

5. Bestücken der gecoateten 96-Well-Platte mit jeweils $100 \mu 1$ der Standards und Proben; $100 \mu 1$ PBS fungierten als Blank Control Well

6. Zugabe von $10 \mu 1$ Balance Solution in jedes zuvor bestückte Well, anschließend gut durchmischen (nicht in Blank und Standards)

7. Zugabe von $50 \mu 1$ Conjugate in jedes Well (nicht: Blank), gut durchmischen und anschließend abgedeckt für eine Stunde bei $+37^{\circ} \mathrm{C}$ inkubieren

8. Manuelles Waschen mit Wash Solution; fünf Wiederholungen

9. Zugabe von jeweils $50 \mu 1$ Substrate $A$ und $B$ in jedes Well, anschließend abgedeckt für 10 bis 15 Minuten bei $+37^{\circ} \mathrm{C}$ inkubieren

10. Zugabe von $50 \mu 1$ Stopp Solution in jedes Well, anschließend gut durchmischen

11. Bestimmung der optischen Dichte bei $450 \mathrm{~nm}$ mithilfe des SpektraMax M2 (Molecular Devices, Biberach an der Riss, Deutschland)

Mithilfe der Standardwerte konnte am Computer eine Standardkurve generiert werden (Programm: Soft Max Pro 4,8). Anhand dieser Standardkurve war es möglich, die gemes- 
senen Werte der Überstandsproben abzulesen. Tabelle 5 gibt die vom Hersteller angegeben Standards an.

Tabelle 5: Angabe der Standards (ng/ml) zur Durchführung des ELISAs

\begin{tabular}{|l|c|}
\hline Standard & Angabe in ng/ml \\
\hline Standard A & $0 \mathrm{ng} / \mathrm{ml}$ \\
\hline Standard B & $1 \mathrm{ng} / \mathrm{ml}$ \\
\hline Standard C & $2,5 \mathrm{ng} / \mathrm{ml}$ \\
\hline Standard D & $5 \mathrm{ng} / \mathrm{ml}$ \\
\hline Standard E & $10 \mathrm{ng} / \mathrm{ml}$ \\
\hline Standard F & $25 \mathrm{ng} / \mathrm{ml}$ \\
\hline
\end{tabular}

Die gewonnenen Werte wurden zur Aufbereitung in das Programm Excel (Version 2011, Microsoft) eingegeben.

\subsection{Statistik}

Für die Auswertung wurden die Daten mithilfe des Tabellenkalkulationsprogrammes EXCEL (Version 2011, Mircosoft) gesammelt und aufbereitet. Die statistische Auswertung erfolgte mit der Statistikprogramme STATISTICA (Version 10) und SAS (Version 9.3).

Der Einfluss der drei Immunsuppressiva auf die verwendeten immortalisierten 3T3Fibroblasten wurde hinsichtlich der Parameter Gesamtzellzahl, Lebendzellzahl, Zelldurchmesser und der Menge an Prokollagen Typ I untersucht. Es wurden Unterschiede für die Faktoren Medikament, Zeit und Konzentration analysiert.

Die statistische Auswertung untergliederte sich in zwei Analysen:

- Zuerst wurde jedes Medikament einzeln ausgewertet, wobei jeder Parameter eines Medikamentes isoliert betrachtet wurde.

- Anschließend erfolgten zwei Konzentrationsvergleiche unterhalb der drei verwendeten Medikamente. Zum einen wurde die Konzentration von 15 ng/Well aller Immunsuppressiva verglichen, welches im weiteren Verlauf Konzentrationsvergleich der Konzentration $15 \mathrm{ng} /$ Well der Immunsuppressiva genannt wird. Zum anderen wurden die Vollblut-Talspiegeln Konzentration von 150 ng/Well Cyclosporin A mit 15 ng/Well Tacrolimus und Sirolimus gegenübergestellt. Dieser Vergleich wird im Folgenden Konzentrationsvergleich der mittleren Konzentration der Immunsuppressiva benannt.

Stetige Messgrößen wurden durch Mittelwert, Standardabweichung, Minimum, Maximum, Median und die jeweiligen Quantile (25\% und $75 \%$ ) der einzelnen Parameter beschrieben 
und deren Verteilung grafisch durch Box Plots dargestellt. Die Box Plots wurden nach den oben genannten Faktoren gruppiert.

Nach deskriptiver Betrachtung der Messgrößen und deren Verteilung fiel eine schiefe Verteilung der Messgrößen der Prokollagen Typ I Menge auf. Daher wurden diese Werte für die folgende Varianzanalyse logarithmiert. Die restlichen Parameter wurden aufgrund ihrer symmetrischen Verteilung nicht transformiert. Anschließend wurden die gewonnenen Daten mithilfe einer multifaktoriellen Varianzanalyse untersucht. Zuerst erfolgte eine Analyse der Faktoren Konzentration und Zeit je Medikament. Unabhängig davon wurden die Konzentrationen zwischen den Medikamenten verglichen, um mögliche Unterschiede aufdecken zu können.

Bei allen statistischen Auswertungen wurde ein Signifikanzniveau von $5 \%$ festgelegt. Das heißt, ein Testergebnis wurde bei $\mathrm{p}<0,05$ als signifikant betrachtet. Bei multiplen Vergleichen war es das Ziel, ein globales Fehlerniveau erster Art von $5 \%$ einzuhalten. Das Abschlusstestprinzip wurde bei allen Vergleichen angewendet, die genau drei Gruppen betrafen. Demnach war hier keine Alpha-Adjustierung notwendig (Marcus et al. 1976). Bei allen Vergleichen mit mehr als drei Gruppen erfolgte eine Dunnett-Adjustierung mit Alpha-Adjustierung (Dunnett 1955). 


\section{$5 \quad$ Ergebnisse}

Im folgenden Kapitel werden die in der vorliegenden Untersuchung gewonnenen Resultate der erfassten Parameter Gesamt- und Lebendzellzahl, Zelldurchmesser und Menge an Prokollagen Typ I nacheinander dargestellt. Innerhalb eines Parameters wird zunächst jedes Immunsuppressivum einzeln aufgezeigt. Anschließend werden zwei Konzentrationsvergleiche beschrieben (s. Kap. 4.2). Der erste Vergleich beinhaltet eine direkte Gegenüberstellung der Konzentration 15 ng/Well aller Immunsuppressiva, während im Rahmen des zweiten Vergleiches die mittleren Dosen aller Immunsuppressiva gegenübergestellt werden (CSA: 150 ng/Well, TCR und SIR: 15 ng/Well).

Die grafische Darstellung der Ergebnisse erfolgt mithilfe von Box Plots. Auf der Ordinate sind jeweils die einzelnen Parameter aufgezeigt, auf der Abszisse die jeweiligen Konzentrationsgruppen. Zur Beschreibung der Grafiken wird der Median herangezogen. Im Weiteren wird dargestellt, inwieweit signifikante Veränderungen und Effekte auftraten. Abschließend folgt eine fotografische Dokumentation eines Versuchsdurchlaufes.

Sowohl die tabellarische Auflistung aller gemessenen Mediane als auch die globale, statische Auswertung zu den einzelnen Parametern befinden sich im Anhang.

\subsection{Ergebnisse: Gesamtzellzahl}

\subsubsection{Cyclosporin A}

In Abbildung 10 sind die Resultate der Gesamtzellzahlmessung unter Einwirkung von Cyclosporin A grafisch dargestellt.

$\mathrm{Zu}$ den Auswertungszeitpunkten 6 und 24 Stunden wies die Konzentration von 150 ng/Well Cyclosporin A die höchste Gesamtzellzahl auf (13,7 und 27,7 x $10^{4}$ Zellen). Unter Einwirkung der Konzentration von $15 \mathrm{ng} /$ Well Cyclosporin A stieg die Gesamtzellzahl zu den Auswertungszeitpunkten 48 und 72 Stunden mit einem Median von 54,7 und 77,0 x $10^{4}$ Zellen höher an, als in den restlichen Gruppen. Nach 24-stündiger Behandlung mit 750 ng/Well Cyclosporin A konnte in dieser Gruppe eine kontinuierliche Zunahme der Gesamtzellzahl beobachtet werden. Diese lag sowohl unter den Resultaten der restlichen Konzentrationsgruppen als auch unter denen der beiden Kontrollgruppen. 


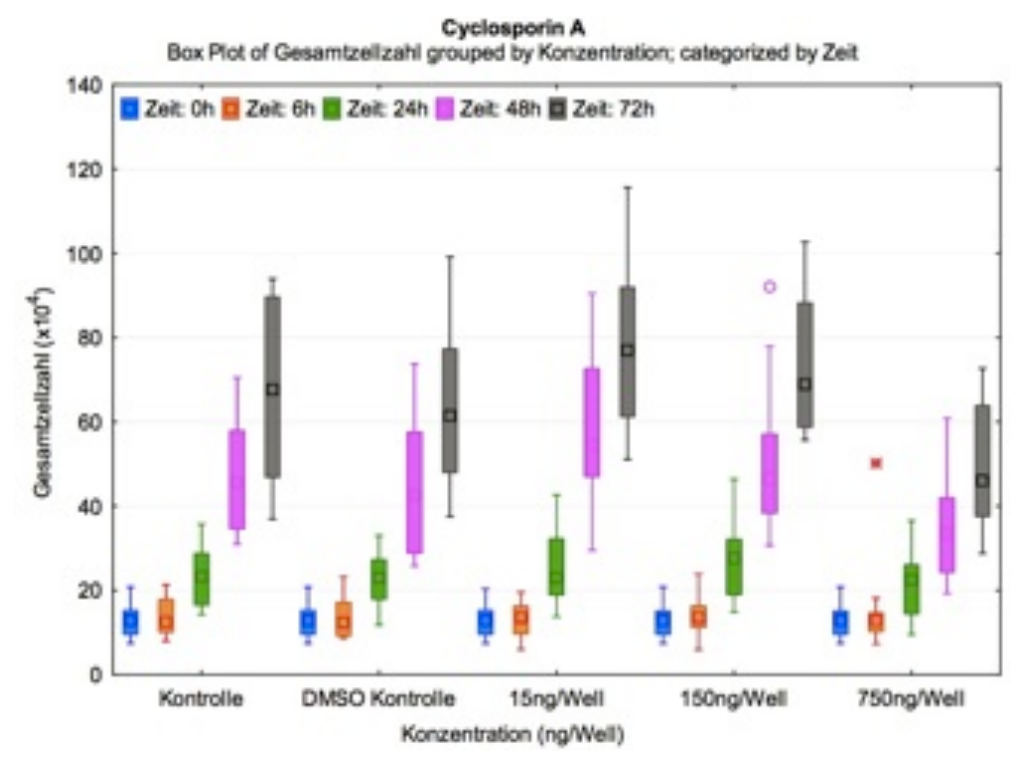

Abbildung 10: Darstellung der Gesamtzellzahl (x $10^{4}$ Zellen) über einen Auswertungszeitraum bis 72 Stunden: Behandlung mit CSA

Tabelle 6 zeigt die Ergebnisse der statistischen Auswertung, wobei Konzentration und Zeit einen signifikanten Effekt aufwiesen.

Tabelle 6: $p$-Werte der statistischen Auswertung der Gesamtzellzahl: Behandlung mit CSA

\begin{tabular}{|l|c|}
\hline Analysierte Faktoren & p-Werte \\
\hline Konzentration & 0,0046 \\
\hline Zeit & $<0,0001$ \\
\hline Konzentration $*$ Zeit & 0,4185 \\
\hline
\end{tabular}

Aufgrund des signifikanten Effektes der Konzentration folgte ein Vergleich der einzelnen Konzentrationsgruppen, bei dem jeder Auswertungszeitpunkt isoliert betrachtet wurde. Hier konnte jedoch zu keinem Messzeitpunkt ein signifikanter Unterschied festgestellt werden $(\mathrm{p}>0,05)$.

\subsubsection{Tacrolimus}

Abbildung 11 zeigt die Ergebnisse der Untersuchung der Gesamtzellzahl unter Einwirkung von Tacrolimus. Hierbei konnten folgende Auffälligkeiten beobachtet werden:

Unter Einwirkung von 20 ng/Well Tacrolimus zeigten die Zellen, verglichen mit den übrigen Gruppen zu den Auswertungszeitpunkten von 6, 24 und 72 Stunden, den jeweils geringsten Anstieg der Gesamtzellzahl. Bei einer Konzentration von 10 ng/Well Tacrolimus waren nach 48-stündiger Einwirkzeit, verglichen mit den restlichen Gruppen, mehr Zellen messbar (49,1 x $10^{4}$ Zellen). Zum Auswertungszeitpunkt von 72 Stunden wies die Gruppe der Zellen, die mit 15 ng/Well Tacrolimus behandelt wurde, die höchste Gesamtzellzahl mit einem Median von 87,9 x $10^{4}$ Zellen auf. 


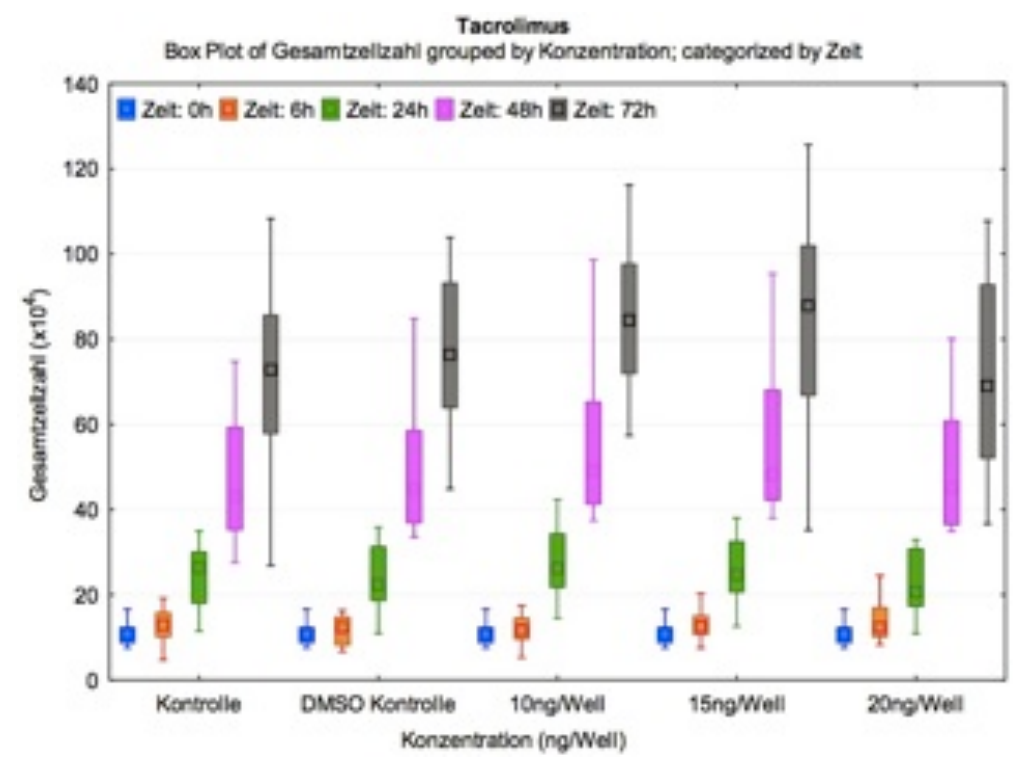

Abbildung 11: Darstellung der Gesamtzellzahl (x 10 $0^{4}$ Zellen) über einen Auswertungszeitraum bis 72 Stunden: Behandlung mit TCR

Tabelle 7 zeigt die Ergebnisse der statistischen Auswertung. Da lediglich die Zeit einen signifikanten Effekt aufwies, wurden die Konzentrationen hinsichtlich signifikanter Unterschiede nicht weiter untersucht.

Tabelle 7: $\mathrm{p}$-Werte der statistischen Auswertung der Gesamtzellzahl: Behandlung mit TCR

\begin{tabular}{|l|c|}
\hline Analysierte Faktoren & p-Werte \\
\hline Konzentration & 0,2701 \\
\hline Zeit & $<0,0001$ \\
\hline Konzentration * Zeit & 0,9652 \\
\hline
\end{tabular}

\subsubsection{Sirolimus}

Abbildung 12 gibt die Ergebnisse der Messungen der Gesamtzellzahl unter Behandlung mit Sirolimus wieder.

Zum Auswertungszeitpunkt von 6 Stunden nahm die Gesamtzellzahl unter der Einwirkung von $15 \mathrm{ng} /$ Well Sirolimus mit einem Median von 15,6 x10 4 Zellen am meisten zu. Die Behandlung mit 20 ng/Well Sirolimus wies nach einer Einwirkzeit von 24, 48 und 72 Stunden insgesamt die geringste Zunahme der Gesamtzellzahl auf. Ab einer Einwirkzeit von 48 Stunden lagen die Werte der mit Sirolimus behandelten Zellen deutlich unter den beiden Kontrollgruppen. 


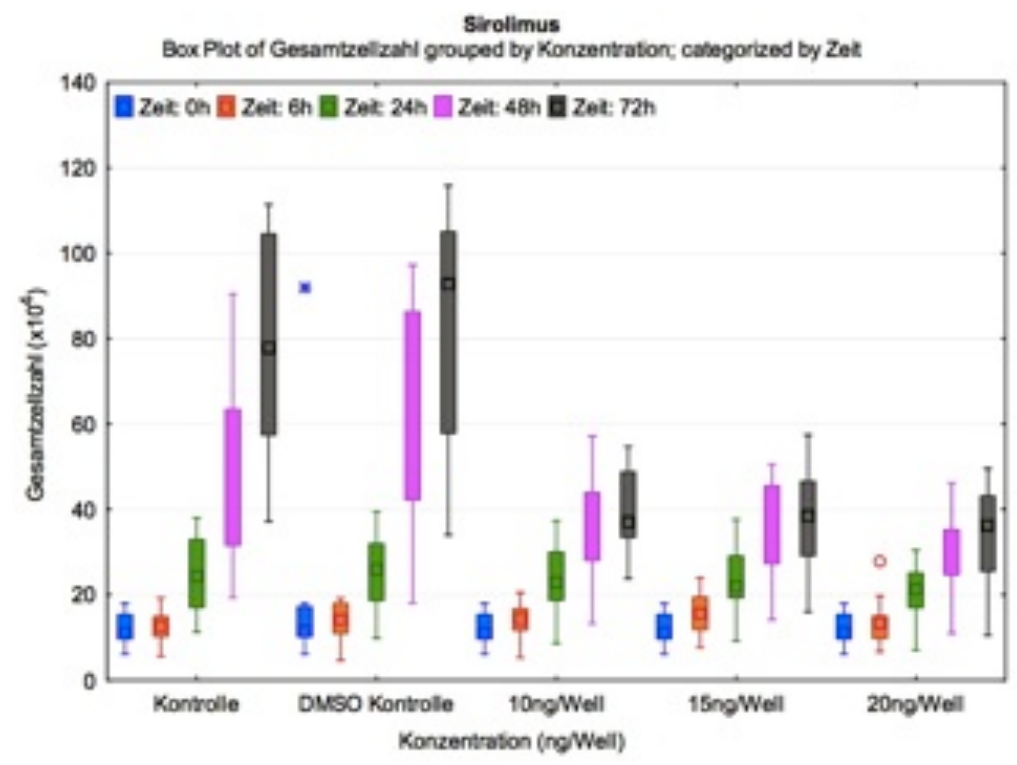

Abbildung 12: Darstellung der Gesamtzellzahl (x $10^{4}$ Zellen) über einen Auswertungszeitraum bis 72 Stunden: Behandlung mit SIR

Die Ergebnisse der statistischen Auswertung sind in Tabelle 8 aufgeführt. Alle Faktoren zeigten signifikante Einflüsse $(\mathrm{p}<0,05)$.

Tabelle 8: $p$-Werte der statistischen Auswertung der Gesamtzellzahl: Behandlung mit Sirolimus

\begin{tabular}{|l|c|}
\hline Analysierte Faktoren & p-Werte \\
\hline Konzentration & $<0,0001$ \\
\hline Zeit & $<0,0001$ \\
\hline Konzentration * Zeit & 0,0009 \\
\hline
\end{tabular}

Daher wurden die einzelnen Konzentrationsgruppen zu den jeweiligen Auswertungszeitpunkten direkt miteinander verglichen. Sowohl zum Auswertungszeitpunkt 48 Stunden als auch nach 72 Stunden Einwirkzeit konnte zwischen allen verwendeten Konzentration und der DMSO-Kontrolle ein signifikanter Unterschied festgestellt werden (Tab. 9).

Tabelle 9: $p$-Werte der statistischen Auswertung: Konzentrationsvergleich von Sirolimus nach 48 und 72 Stunden Einwirkzeit

\begin{tabular}{|c|c|c|}
\hline Vergleich & $\begin{array}{l}\text { Auswertungszeit- } \\
\text { raum } \\
48 \text { Stunden }\end{array}$ & 72 Stunden \\
\hline $10 \mathrm{ng} /$ Well * DMSO-Kontrolle & 0,0464 & 0,0002 \\
\hline $15 \mathrm{ng} /$ Well * DMSO-Kontrolle & 0,0257 & $<0,0001$ \\
\hline $20 \mathrm{ng} /$ Well * DMSO-Kontrolle & 0,0021 & $<0,0001$ \\
\hline
\end{tabular}




\subsubsection{Konzentrationsvergleich der Konzentration 15 ng/Well und Konzentrationsver- gleich der mittleren Konzentration der Immunsuppressiva}

Abbildung 13 stellt die Ergebnisse des Konzentrationsvergleiches von 15 ng/Well der Immunsuppressiva grafisch dar, wobei folgende Auffälligkeiten beobachtet werden konnten: Nach 24 Stunden Einwirkzeit zeigten die mit Sirolimus behandelten Zellen niedrigere Gesamtzellzahlen im Vergleich zu den beiden anderen Gruppen. Zum Auswertungszeitpunkt von 48 Stunden wiesen die Zellen unter Behandlung mit Cyclosporin A mit einem Median von 54,7 x $10^{4}$ Zellen im Vergleich die höchste Gesamtzellzahl auf. Nach 24 und 72 Stunden Einwirkzeit verfügte die mit Tacrolimus behandelte Zellgruppe über die höchste Gesamtzellzahl.

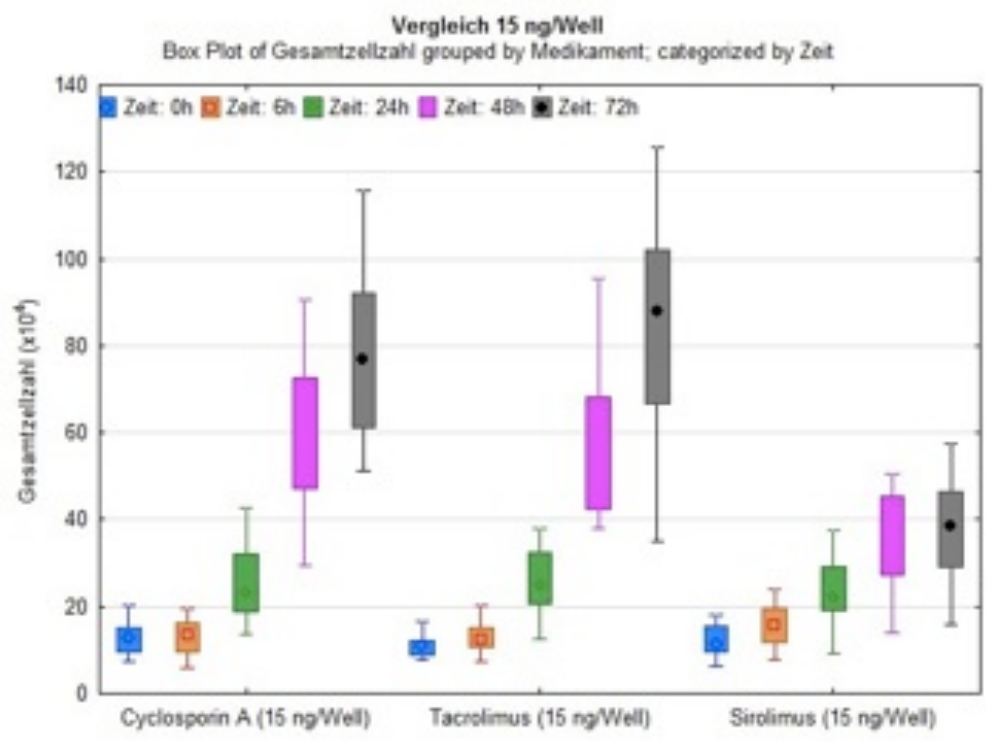

Abbildung 13: Darstellung der Gesamtzellzahl (x $10^{4}$ Zellen): Konzentrationsvergleich $15 \mathrm{ng} /$ Well der Immunsuppressiva

Abbildung 14 zeigt die Ergebnisse des Konzentrationsvergleiches der mittleren Konzentrationen der Immunsuppressiva (CSA: 150 ng/Well, TCR und SIR: 15 ng/Well).

Wie auch bei der vorherigen Vergleichsauswertung wiesen die Zellen ab einer 24stündigen Einwirkzeit unter Sirolimus, verglichen mit den Zellen unter Cyclosporin A- und Tacrolimus-Behandlung, jeweils die geringste Gesamtzellzahl auf. Zum Auswertungszeitpunkt von 24 Stunden zeigten die mit 150 ng/Well Cyclosporin A behandelten Zellen mit einem Median von 27,7 x $10^{4}$ Zellen die höchste Gesamtzellzahl. Nach 48- und 72stündiger Einwirkzeit verfügte die Tacrolimusgruppe über den höchsten Anstieg der Gesamtzellzahl. 


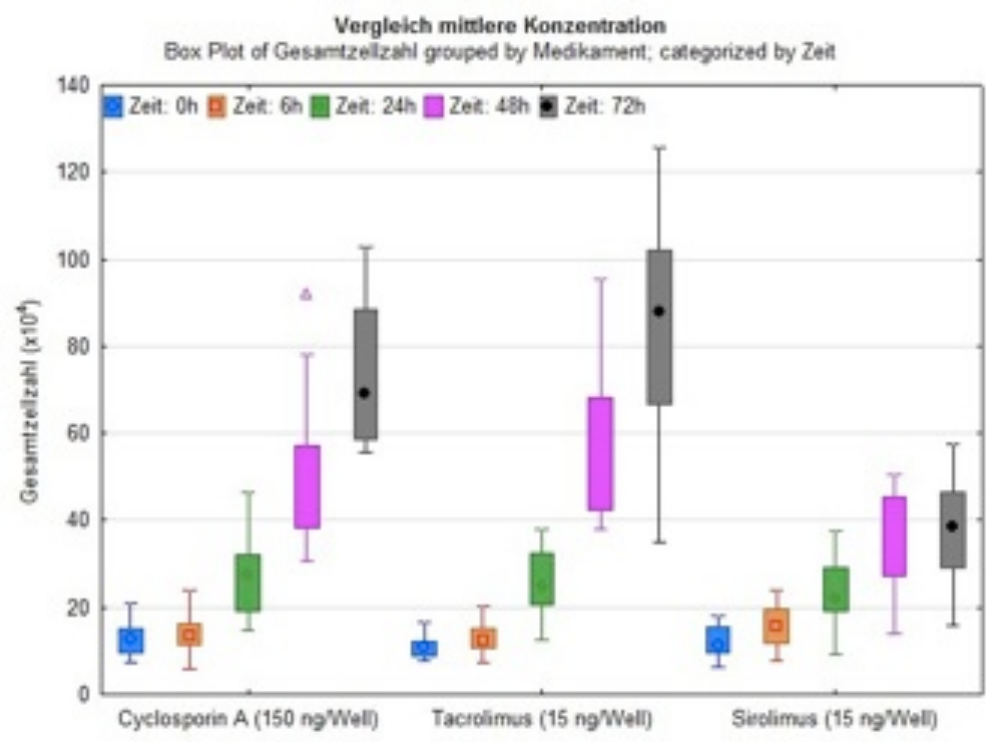

Abbildung 14: Darstellung der Gesamtzellzahl (x $10^{4}$ Zellen): Konzentrationsvergleich der mittleren Konzentration der Immunsuppressiva

Tabelle 10 gibt einen Überblick über die gewonnenen Ergebnisse der statistischen Auswertung beider Vergleichsauswertungen. Betrachtet wurden hier zunächst die einzelnen Auswertungszeitpunkte.

Tabelle 10: p-Werte der statistischen Auswertung der Gesamtzellzahlmessung beider Konzentrationsvergleiche

\begin{tabular}{|l|c|c|}
\hline $\begin{array}{l}\text { Auswertungs- } \\
\text { zeitraum }\end{array}$ & $\begin{array}{l}\text { Konzentrationsvergleich: } \\
\mathbf{1 5} \text { ng/Well }\end{array}$ & $\begin{array}{l}\text { Konzentrationsvergleich: } \\
\text { mittlere Konzentration }\end{array}$ \\
\hline 0 Stunden & 0,4395 & 0,4395 \\
\hline 6 Stunden & 0,3163 & 0,3163 \\
\hline 24 Stunden & 0,6236 & 0,6236 \\
\hline 48 Stunden & 0,0009 & 0,0009 \\
\hline 72 Stunden & $<0,0001$ & $<0,0001$ \\
\hline
\end{tabular}

Nach 6 und 24 Stunden zeigte sich nach Betrachtung der einzelnen Gruppen untereinander kein signifikanter Einfluss $(\mathrm{p}>0,05)$. Es ließ sich jedoch zu den Auswertungszeitpunkten 48 und 72 Stunden signifikanter Einfluss feststellen. Infolgedessen wurden innerhalb dieser beiden Zeiträume die Medikamente direkt miteinander verglichen. Tabelle 11 zeigt die Ergebnisse. 
Tabelle 11: p-Werte der statistischen Auswertung der Gesamtzellzahl: Konzentrationsvergleiche der Immunsuppressiva zu den Auswertungszeitpunkten 48 und 72 Stunden

\begin{tabular}{|l|c|c|}
\hline & \multicolumn{2}{|c|}{ Auswertungszeitraum } \\
Konzentrationsvergleich & 48 Stunden & 72 Stunden \\
\hline $15 \mathrm{ng} /$ Well CSA und 15 ng/Well TCR & 0,9159 & 0,6288 \\
\hline $15 \mathrm{ng} /$ Well CSA und 15 ng/Well SIR & 0,0008 & $<0,0001$ \\
\hline $15 \mathrm{ng} /$ Well SIR und 15 ng/Well TCR & 0,0011 & $<0,0001$ \\
\hline $150 \mathrm{ng} /$ Well CSA und 15 ng/Well TCR & 0,4949 & 0,4129 \\
\hline $150 \mathrm{ng} /$ Well CSA und 15 ng/Well SIR & 0,0055 & $<0,0001$ \\
\hline $15 \mathrm{ng} /$ Well TCR und 15 ng/Well SIR & 0,0009 & $<0,0001$ \\
\hline
\end{tabular}

Sowohl nach 48 als auch nach 72 Stunden Einwirkzeit zeigten sich in beiden Konzentrationsvergleichen der Gruppen Cyclosporin A und Sirolimus (15 ng/Well CSA und 15 ng/Well SIR; 150 ng/Well CSA und 15 ng/Well SIR) sowie Tacrolimus und Sirolimus (15 ng/Well TCR und 15 ng/Well SIR) signifikante Differenzen (Tab. 11). Der Vergleich Cyclosporin A mit Tacrolimus war jeweils nicht signifikant (Tab. 11).

\subsection{Ergebnisse: Lebendzellzahl}

\subsubsection{Cyclosporin A}

Abbildung 15 gibt die Ergebnisse der Messung der Lebendzellzahl unter Cyclosporin AEinwirkung wieder.

Nach 6- und 24-stündigem Einfluss unter 150 ng/Well Cyclosporin A wiesen diese Zellen je die höchste Lebendzellzahl auf. Zu den Auswertungszeitpunkten von 48 und 72 Stunden zeigte die Gruppe unter Behandlung mit 15 ng/Well Cylosporin A (Median: 49,6 und 74,2 x $10^{4}$ Zellen) einen höheren Anstieg der Lebendzellzahl, verglichen mit den anderen Gruppen. 


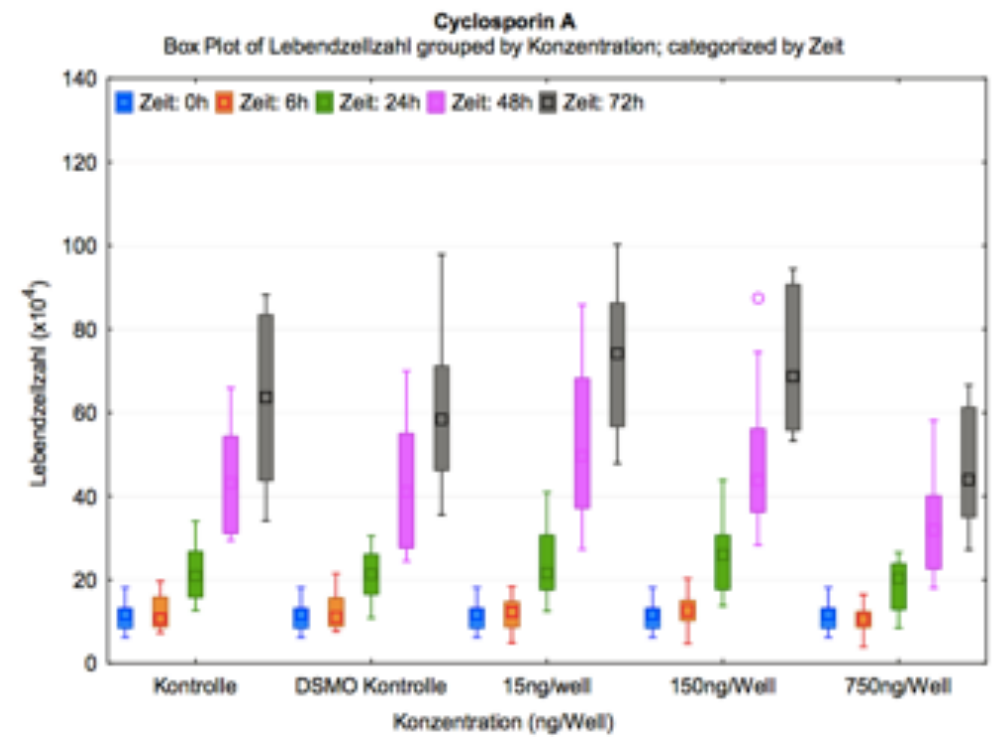

Abbildung 15: Darstellung der Lebendzellzahl (x $10^{4}$ Zellen) über einen Auswertungszeitraum bis 72 Stunden: Behandlung mit CSA

Tabelle 12 gibt die Ergebnisse der statistischen Auswertung wieder, wobei Konzentration und Zeit einen signifikanten Effekt aufwiesen.

Tabelle 12: $p$-Werte der statistischen Auswertung der Lebendzellzahl: Behandlung mit CSA

\begin{tabular}{|l|c|}
\hline Analysierte Faktoren & p-Werte \\
\hline Konzentration & 0,0001 \\
\hline Zeit & $<0,0001$ \\
\hline Konzentration * Zeit & 0,7636 \\
\hline
\end{tabular}

Aufgrund des signifikanten Effektes der Konzentration folgte ein Vergleich der einzelnen Konzentrationsgruppen untereinander. Hier wurde jeder Auswertungszeitpunkt isoliert betrachtet. Es konnte jedoch zu keinem Messzeitpunkt ein signifikanter Unterschied festgestellt werden $(\mathrm{p}>0,05)$.

\subsubsection{Tacrolimus}

Abbildung 16 stellt die Ergebnisse der Untersuchung der Lebendzellzahl unter Einwirkung von Tacrolimus dar.

Nach einer Einwirkzeit von 24 und 48 Stunden wies die Konzentrationsgruppe von 10 ng/Well mit einem Median von 24,3 und 46,6 x $10^{4}$ Zellen, verglichen mit den restlichen Gruppen, die höchste Lebendzellzahl auf. Unter Einwirkung von 15 ng/Well Tacrolimus zeigten die Zellen zu den Auswertungszeitpunkten 6 und 72 Stunden die jeweils höchste Lebendzellzahl. Eine 24- und 72-stündige Behandlung mit $20 \mathrm{ng} / \mathrm{Well}$ Tacrolimus führte während des Versuchsverlaufes, im Vergleich zu den restlichen Konzentrationen, zu einer geringeren Lebendzellzahl. 


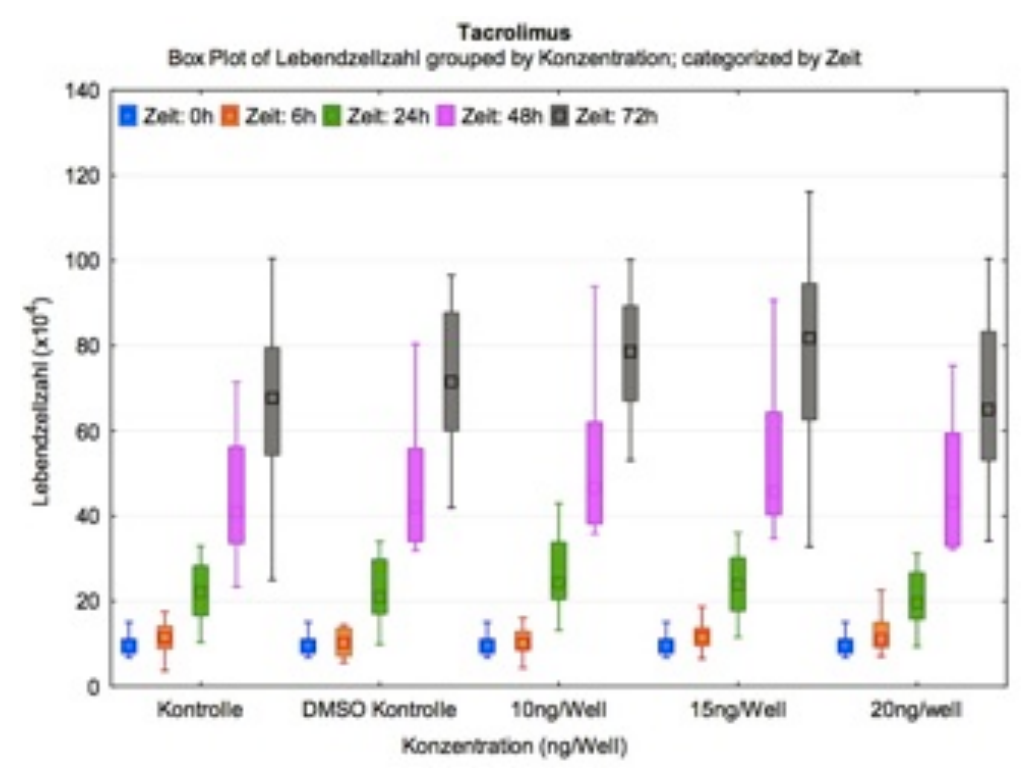

Abbildung 16: Darstellung der Lebendzellzahl (x 10 4 Zellen) über einen Auswertungszeitraum bis 72 Stunden: Behandlung mit TCR

In Tabelle 13 sind die Ergebnisse der statistischen Auswertung aufgeführt $(p<0,05)$. Da lediglich die Zeit einen signifikanten Effekt zeigte, wurden die Daten hinsichtlich eines signifikanten Unterschiedes nicht weiter untersucht.

Tabelle 13: $\mathrm{p}$-Werte der statistischen Auswertung der Lebendzellzahl: Behandlung mit TCR

\begin{tabular}{|l|c|}
\hline Analysierte Faktoren & p-Werte \\
\hline Konzentration & 0,2543 \\
\hline Zeit & $<0,0001$ \\
\hline Konzentration $*$ Zeit & 0,9399 \\
\hline
\end{tabular}

\subsubsection{Sirolimus}

Abbildung 17 gibt die Ergebnisse der Messung der Lebendzellzahl unter SirolimusEinwirkung wieder. Nach 6-stündiger Einwirkung unter $15 \mathrm{ng} / \mathrm{Well}$ Sirolimus zeigten diese Zellen mit einem Median von 14,5 x $10^{4}$ Zellen die höchste Lebendzellzahl. Die Zellen, welche mit $10 \mathrm{ng} /$ Well Sirolimus behandelt wurden, wiesen nach 24- und 48-stündiger Einwirkzeit jeweils die größte Lebendzellzahl auf. Diese war jedoch niedriger als die Ergebnisse beider Kontrollgruppen. Ab dem Auswertungszeitpunkt 24 Stunden zeigte sich unter Einwirkung von $20 \mathrm{ng} /$ Well Sirolimus, im Vergleich zu den übrigen Gruppen, der niedrigste Anstieg der Lebendzellzahl. 


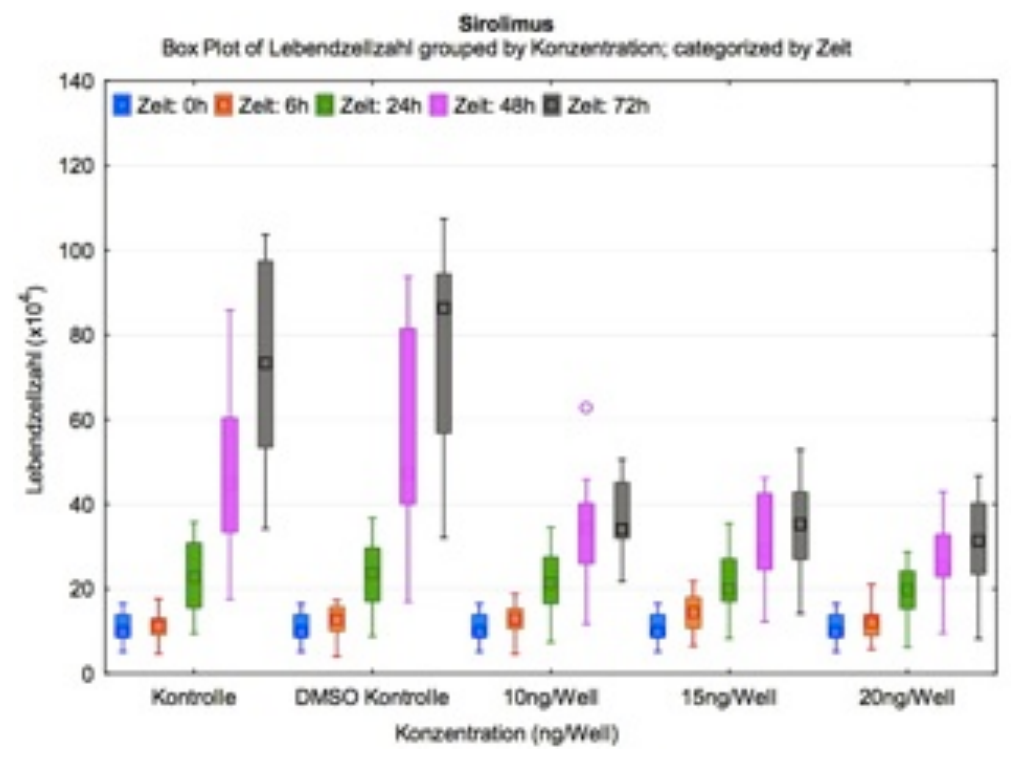

Abbildung 17: Darstellung der Lebendzellzahl (x 10 $10^{4}$ Zellen) über einen Auswertungszeitraum bis 72 Stunden: Behandlung mit SIR

Die Ergebnisse der statistischen Auswertung sind in Tabelle 14 aufgeführt. Alle Faktoren zeigten einen signifikanten Einfluss $(\mathrm{p}>0,05)$.

Tabelle 14: $\mathrm{p}$-Werte der statistischen Auswertung der Lebendzellzahl: Behandlung mit SIR

\begin{tabular}{|l|c|}
\hline Analysierte Faktoren & p-Werte \\
\hline Konzentration & $<0,0001$ \\
\hline Zeit & $<0,0001$ \\
\hline Konzentration $*$ Zeit & 0,0001 \\
\hline
\end{tabular}

Aufgrund dessen erfolgte ein Vergleich zwischen den einzelnen Konzentrationsgruppen zu den jeweiligen Auswertungszeitpunkten. Sowohl zum Auswertungszeitpunkt 48 Stunden als auch nach 72 Stunden Einwirkzeit konnte zwischen allen verwendeten Konzentrationen und der DMSO-Kontrolle ein signifikanter Unterschied festgestellt werden (Tab. 15).

Tabelle 15: p-Werte der statistischen Auswertung der Lebendzellzahl: Konzentrationsvergleich von Sirolimus nach 48 und 72 Stunden Einwirkzeit

\begin{tabular}{|l|c|c|}
\hline & \multicolumn{2}{|c|}{ Auswertungszeitraum } \\
Konzentrationsvergleich & 48 Stunden & 72 Stunden \\
\hline $10 \mathrm{ng} /$ Well und DMSO-Kontrolle & 0,0448 & 0,0002 \\
\hline $15 \mathrm{ng} /$ Well und DMSO-Kontrolle & 0,0217 & $<0,0001$ \\
\hline $20 \mathrm{ng} /$ Well und DMSO-Kontrolle & 0,0020 & $<0,0001$ \\
\hline
\end{tabular}




\subsubsection{Konzentrationsvergleich der Konzentration 15 ng/Well und Konzentrationsver- gleich der mittleren Konzentration der Immunsuppressiva}

In Abbildung 18 sind die Ergebnisse des Konzentrationsvergleiches der Konzentration von $15 \mathrm{ng} /$ Well der Immunsuppressiva untereinander dargestellt. Hierbei fielen folgende Aspekte auf:

Die Sirolimus-Gruppe wies nach 6 Stunden Einwirkzeit im Vergleich die höchste Lebendzellzahl (14,5 x 10 ${ }^{4}$ Zellen), jedoch ab 24-stündiger Behandlung mit Sirolimus die geringste Lebendzellzahl auf. Die mit $15 \mathrm{ng} /$ Well Cyclosporin A behandelten Zellen zeigten nach einer Einwirkzeit von 48 Stunden die höchste Lebendzellzahl (49, 6 x 10 $0^{4}$ Zellen). Nach 24- und 72-stündiger Behandlung mit 15 ng/Well Tacrolimus konnte hier die höchste Lebendzellzahl mit einem Median von 23,9 und 81,8 x 10 ${ }^{4}$ Zellen festgestellt werden.

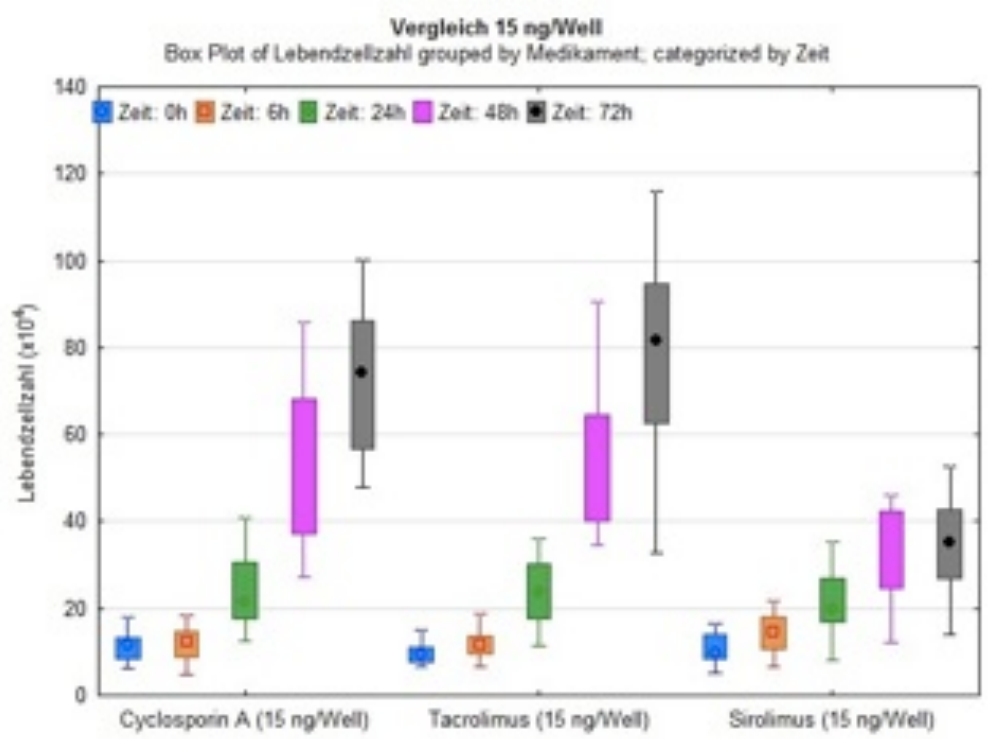

Abbildung 18: Darstellung der Lebendzellzahl (x $10^{4}$ Zellen): Konzentrationsvergleich $15 \mathrm{ng} /$ Well der Immunsuppressiva

In Abbildung 19 sind die Resultate des Konzentrationsvergleiches der mittleren Konzentration der Immunsuppressiva (CSA: $150 \mathrm{ng} / \mathrm{Well}$, TCR und SIR: $15 \mathrm{ng} / \mathrm{Well}$ ) grafisch wiedergegeben. Dabei zeigten sich folgende Auffälligkeiten:

Die Lebendzellzahl in der mit Cyclosporin A behandelten Gruppe wies zum Auswertungszeitpunkt von 24 Stunden mit einem Median von 25,9 x $10^{4}$ Zellen die höchste Lebendzellzahl auf, verglichen mit den Tacrolimus- und Sirolimus-behandelten Zellen. Nach der Behandlung mit 15 ng/Well Tacrolimus verfügte diese Zellgruppe zu den Auswertungszeitpunkten 48 und 72 Stunden jeweils über die höchste Lebendzellzahl. Die Behandlung mit Sirolimus zeigte nach 24-stündiger Einwirkzeit fortlaufend, verglichen mit den restlichen Gruppen, einen niedrigeren Anstieg der Lebendzellzahl. 


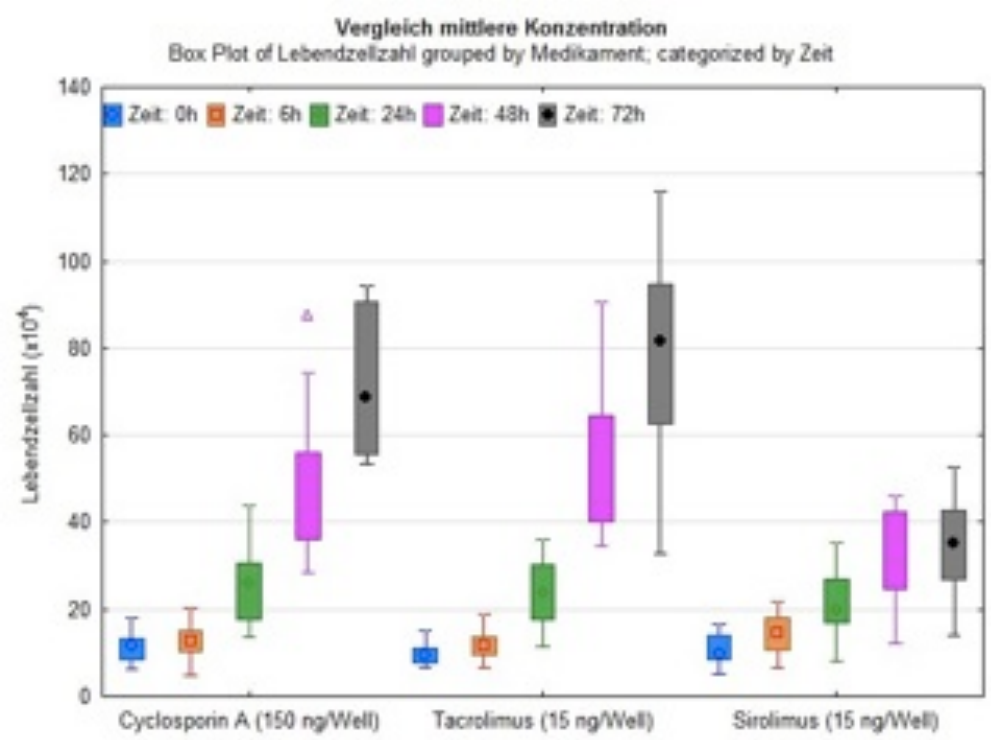

Abbildung 19: Darstellung der Lebendzellzahl (x $10^{4}$ Zellen): Konzentrationsvergleich der mittleren Konzentration der Immunsuppressiva

Tabelle 16 gibt einen Überblick über die gewonnenen Ergebnisse der statistischen Auswertung. Betrachtet wurden hier zunächst die einzelnen Auswertungszeitpunkte.

Tabelle 16: $p$-Werte der statistischen Auswertung der Lebendzellzahlmessung beider Konzentrationsvergleiche der Immunsuppressiva

\begin{tabular}{|l|c|c|}
\hline $\begin{array}{l}\text { Auswertungs- } \\
\text { zeitraum }\end{array}$ & $\begin{array}{l}\text { Konzentrationsvergleich: } \\
\mathbf{1 5} \text { ng/Well }\end{array}$ & $\begin{array}{l}\text { Konzentrationsvergleich: } \\
\text { mittlere Konzentration }\end{array}$ \\
\hline 0 Stunden & 0,6183 & 0,6183 \\
\hline 6 Stunden & 0,3055 & 0,4587 \\
\hline 24 Stunden & 0,5397 & 0,4251 \\
\hline 48 Stunden & 0,0010 & 0,0014 \\
\hline 72 Stunden & $<0,0001$ & $<0,0001$ \\
\hline
\end{tabular}

Nach 6 und 24 Stunden zeigten sich im Vergleich der einzelnen Gruppen keine signifikanten Unterschiede $(\mathrm{p}>0,05)$. Nach einer Einwirkzeit von 48 und 72 Stunden wiesen jedoch beide Konzentrationsvergleiche der Immunsuppressiva untereinander signifikante Effekte auf. Daher wurden innerhalb dieser beiden Zeiträume die Medikamente direkt miteinander verglichen (Tab. 17). 
Tabelle 17: $p$-Werte der statistischen Auswertung der Lebendzellzahl: Konzentrationsvergleiche zu den Auswertungszeitpunkten 48 und 72 Stunden

\begin{tabular}{|c|c|c|}
\hline \multirow[b]{2}{*}{ Konzentrationsvergleich } & \multicolumn{2}{|c|}{ Auswertungszeitraum } \\
\hline & 48 Stunden & 72 Stunden \\
\hline $15 \mathrm{ng} / \mathrm{Well} \mathrm{CSA}$ und $15 \mathrm{ng} / \mathrm{Well} \mathrm{TCR}$ & 0,8703 & 0,6409 \\
\hline $15 \mathrm{ng} / \mathrm{Well}$ CSA und $15 \mathrm{ng} / \mathrm{Well}$ SIR & 0,0014 & $<0,0001$ \\
\hline $15 \mathrm{ng} / \mathrm{Well}$ SIR und $15 \mathrm{ng} / \mathrm{Well} \mathrm{TCR}$ & 0,0009 & $<0,0001$ \\
\hline $150 \mathrm{ng} / \mathrm{Well}$ CSA und $15 \mathrm{ng} / \mathrm{Well} \mathrm{TCR}$ & 0,5135 & 0,6484 \\
\hline $150 \mathrm{ng} / \mathrm{Well}$ CSA und $15 \mathrm{ng} / \mathrm{Well} \mathrm{SIR}$ & 0,0038 & $<0,0001$ \\
\hline $15 \mathrm{ng} / \mathrm{Well} \mathrm{TCR}$ und $15 \mathrm{ng} / \mathrm{Well} \mathrm{SIR}$ & 0,0006 & $<0,0001$ \\
\hline
\end{tabular}

Sowohl nach 48 als auch nach 72 Stunden Einwirkzeit zeigten sich signifikante Differenzen der Lebendzellzahl in beiden Konzentrationsvergleichen der Gruppen Cyclosporin A mit Sirolimus (15 ng/Well CSA und $15 \mathrm{ng} /$ Well SIR, $150 \mathrm{ng} / \mathrm{Well} \mathrm{CSA}$ und $15 \mathrm{ng} / \mathrm{Well}$ SIR) und Tacrolimus mit Sirolimus (15 ng/Well TCR und $15 \mathrm{ng} / \mathrm{Well} \mathrm{SIR)} \mathrm{(Tab.} \mathrm{17).} \mathrm{Der}$ Vergleich Cyclosporin A mit Tacrolimus war jeweils nicht signifikant (Tab. 17).

\subsection{Ergebnisse: Zelldurchmesser}

\subsubsection{Cyclosporin A}

In Abbildung 20 sind die Resultate der Messung des Zelldurchmessers unter Einwirkung von Cyclosporin A grafisch wiedergegeben. Es zeigten sich folgende Auffälligkeiten:

Nach Versuchsstart kam es zum zweiten Auswertungszeitpunkt von 6 Stunden in allen untersuchten Gruppen zu einem geringfügigen Abfall des Zelldurchmessers. Nach 24stündiger Einwirkzeit unter Cyclosporin A zeigte sich eine generelle Zunahme des Zelldurchmessers. Hierbei wiesen sowohl die mit $150 \mathrm{ng} /$ Well Cyclosporin A als auch die mit $750 \mathrm{ng} /$ Well Cyclosporin A behandelten Zellen vergleichbare Medianwerte auf $(16,9 \mu \mathrm{m}$; 17,7 $\mu \mathrm{m})$. Im weiteren Verlauf nahm der Zelldurchmesser jedoch in allen Gruppen bis zum Versuchsende kontinuierlich ab. Nach 48 und 72 Stunden zeigte sich unter Einwirkung von 750 ng/Well Cyclosporin A der jeweils größte Zelldurchmesser. 


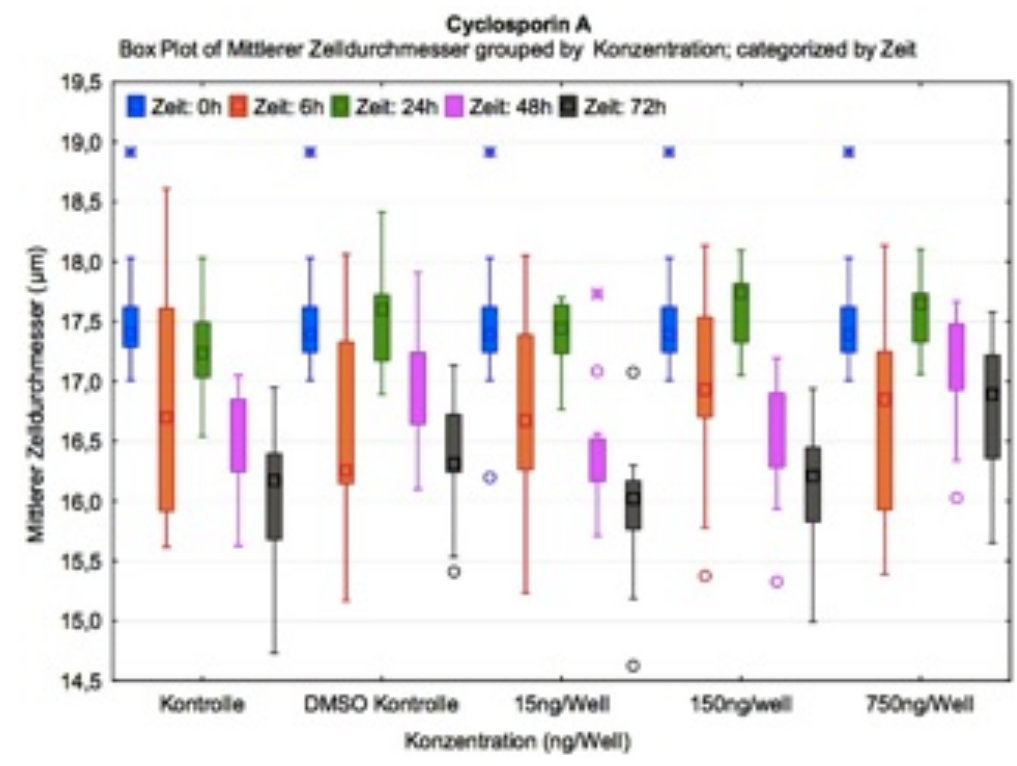

Abbildung 20: Darstellung des Zelldurchmessers $(\mu \mathrm{m})$ über einen Auswertungszeitraum von 72 Stunden: Behandlung mit CSA

Tabelle 18 stellt die Ergebnisse der statistischen Auswertung dar, wobei Konzentration und Zeit einen signifikanten Effekt aufwiesen $(p<0,05)$.

Tabelle 18: $p$-Werte der statistischen Auswertung des Zelldurchmessers: Behandlung mit CSA

\begin{tabular}{|l|c|}
\hline Analysierte Faktoren & p-Werte \\
\hline Konzentration & 0,0099 \\
\hline Zeit & $<0,0001$ \\
\hline Konzentration * Zeit & 0,1824 \\
\hline
\end{tabular}

Aufgrund des signifikanten Wertes der Konzentration folgte ein Vergleich der einzelnen Konzentrationsgruppen, bei dem jeder Auswertungszeitpunkt isoliert betrachtet wurde. Zum Auswertungszeitpunkt von 48 Stunden konnte ein signifikanter Unterschied zwischen der Konzentration von $150 \mathrm{ng} /$ Well Cyclosporin A und der DMSO-Kontrolle festgestellt werden $(p=0,0347)$. Die restlichen Vergleiche ergaben keine signifikanten Unterschiede $(\mathrm{p}>0,05)$.

\subsubsection{Tacrolimus}

Abbildung 21 zeigt die Ergebnisse der Messung des Zelldurchmessers unter TacrolimusEinwirkung.

Der Durchmesser nahm zum zweiten Auswertungszeitpunkt von 6 Stunden, verglichen mit dem Durchmesser bei Versuchsstart, in allen Gruppen zunächst geringfügig ab. Im weiteren Verlauf zeigten alle Gruppen nach einer Einwirkzeit von 24 Stunden eine Zunahme des Zelldurchmessers. Zu den Auswertungszeiträumen 48 und 72 Stunden war in allen Konzentrationsgruppen eine Abhanme des Zelldurchmessers festzustellen. Der Zelldurchmes- 
ser war nach 24- und 48-stündiger Einwirkung unter 20 ng/Well Tacrolimus, verglichen mit allen anderen Gruppen, mit einem Median von 17,9 sowie 16,6 $\mu \mathrm{m}$ am größten. Nach 72-stündiger Einwirkzeit zeigte sich in allen Gruppen ein vergleichbarer Zelldurchmesser.

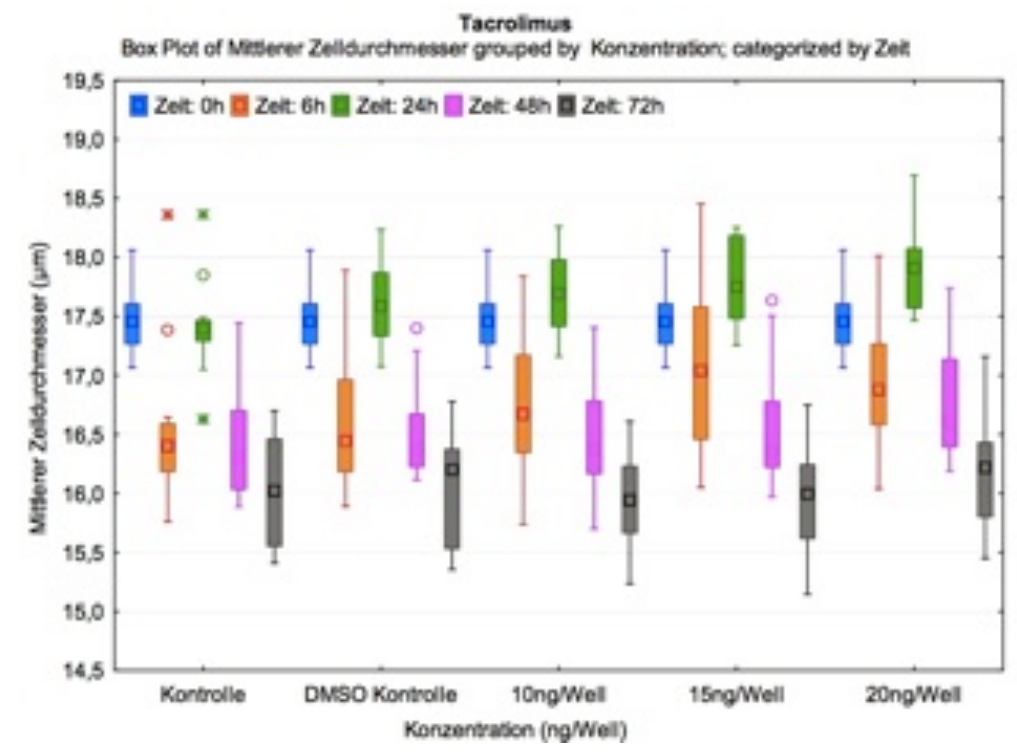

Abbildung 21: Darstellung des Zelldurchmessers ( $\mu \mathrm{m})$ über einen Auswertungszeitraum von 72 Stunden: Behandlung mit TCR

Tabelle 19 zeigt die statistischen Ergebnisse der Messung des Zelldurchmessers unter Tacrolimus mit statistisch signifikanten Effekten für Konzentration und Zeit.

Tabelle 19: $p$-Werte der statistischen Auswertung des Zelldurchmessers: Behandlung mit TCR

\begin{tabular}{|l|c|}
\hline Analysierte Faktoren & p-Werte \\
\hline Konzentration & 0,0287 \\
\hline Zeit & $<0,0001$ \\
\hline Konzentration * Zeit & 0,7700 \\
\hline
\end{tabular}

Da die Konzentration einen signifikanten Effekt zeigte, folgte ein Vergleich der einzelnen Konzentrationsgruppen von Tacrolimus, bei dem jeder Auswertungszeitpunkt isoliert betrachtet wurde. Es konnte jedoch zu keinem Auswertungszeitpunkt ein signifikanter Unterschied festgestellt werden $(p>0,05)$.

\subsubsection{Sirolimus}

Abbildung 22 gibt die Ergebnisse der Messung des Zelldurchmessers unter Einwirkung von Sirolimus wieder. Folgende Auffälligkeiten fielen bei Betrachtung der Grafik auf:

Der Zelldurchmesser nahm in allen Gruppen vom Startzeitpunkt (0 Stunden) zu dem zweiten Auswertungszeitpunkt von 6 Stunden geringfügig ab. Jedoch zeigten die Zellen unter 10 und 20 ng/Well Sirolimus zum Auswertungszeitpunkt von 24 Stunden eine Zunahme des Zelldurchmessers. Im weiteren Versuchsverlauf nahm der Zelldurchmesser bis Ver- 
suchsende in allen Gruppen ab. $\mathrm{Zu}$ den beiden Auswertungszeitpunkten von 48 und 72 Stunden war der Zelldurchmesser unter Einwirkung von $20 \mathrm{ng} / \mathrm{Well}$ Sirolimus mit einem Median von 16,7 sowie 16,5 $\mu$ m, verglichen mit den restlichen Gruppen, am größten.

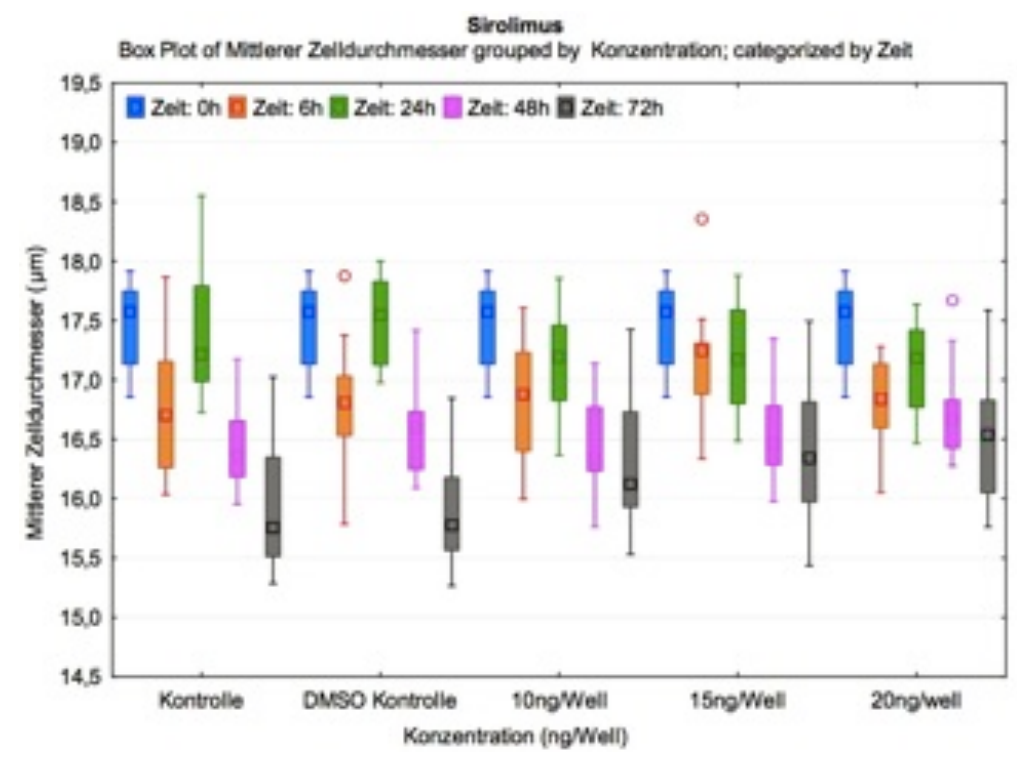

Abbildung 22: Darstellung des Zelldurchmessers ( $\mu \mathrm{m})$ über einen Auswertungszeitraum von 72 Stunden: Behandlung mit SIR

Tabelle 20 gibt die statistischen Ergebnisse der Messung des Zelldurchmessers unter Einwirkung von Sirolimus wieder. Hier konnte lediglich ein signifikanter Effekt der Zeit beobachtet werden. Demnach wurden die Daten nicht weiter statistisch analysiert.

Tabelle 20: $\mathrm{p}$-Werte der statistischen Auswertung des Zelldurchmessers: Behandlung mit SIR

\begin{tabular}{|l|c|}
\hline Analysierte Faktoren & p-Werte \\
\hline Konzentration & 0,8882 \\
\hline Zeit & $<0,0001$ \\
\hline Konzentration * Zeit & 0,7636 \\
\hline
\end{tabular}

\subsubsection{Konzentrationsvergleich der Konzentration 15 ng/Well und Konzentrationsver- gleich der mittleren Konzentration der Immunsuppressiva}

Abbildung 23 zeigt die Ergebnisse des Konzentrationsvergleiches der Konzentration 15 ng/Well aller Immunsuppressiva untereinander.

Alle mit einem der drei Immunsuppressiva behandelten Zellen zeigten vom Zeitpunkt des Versuchsstartes bis zum Auswertungszeitpunkt von 6 Stunden eine geringfügige Abnahme des Zelldurchmessers. Unter Tacrolimus-Behandlung wiesen die Zellen nach einer Einwirkzeit von 24 und 48 Stunden mit einem Median von 17,6 sowie 16,6 $\mu$ m jeweils den größten Zelldurchmesser auf. Unter Einwirkung von $15 \mathrm{ng} /$ Well Sirolimus konnte über den gesamten Versuchsverlauf einer stetige Abnahme des Zelldurchmessers beobachtet werden. 
Trotzdem zeigte diese Zellgruppe zu den Auswertungszeitpunkten von 6 und 72 Stunden im Vergleich zu den restlichen Gruppen den jeweils größten Zelldurchmesser.

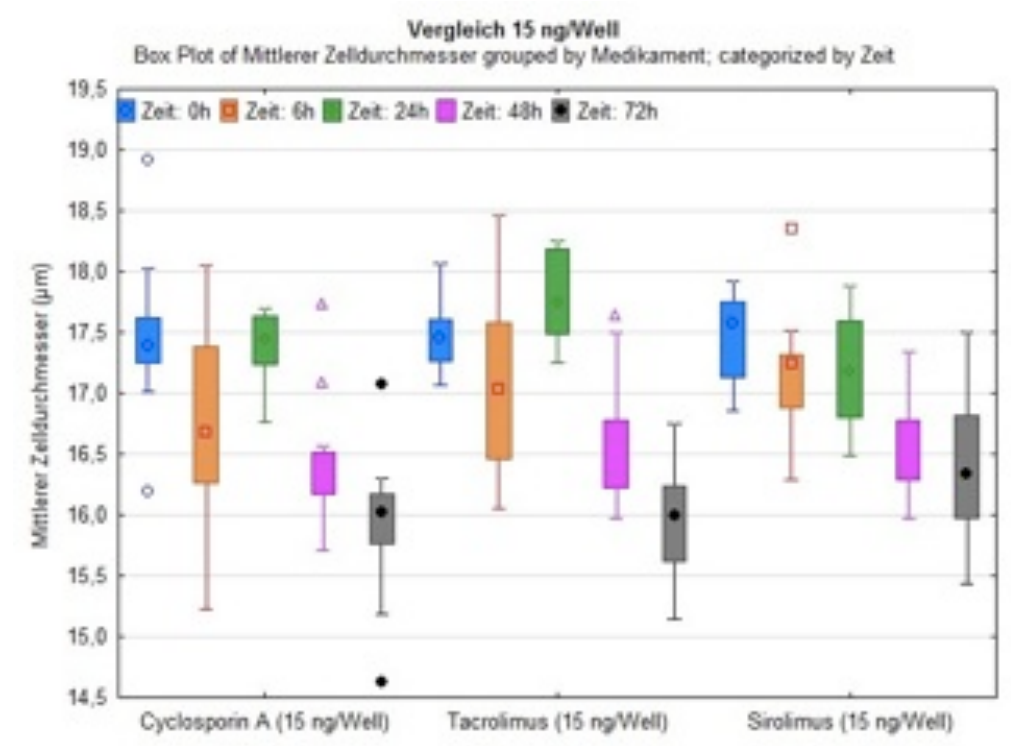

Abbildung 23: Darstellung des Zelldurchmessers $(\mu \mathrm{m})$ : Konzentrationsvergleich $15 \mathrm{ng} /$ Well der Immunsuppressiva

In Abbildung 24 sind die Resultate des Konzentrationsvergleiches der mittleren Konzentration der Immunsuppressiva (CSA: $150 \mathrm{ng} / \mathrm{Well}$, TCR und SIR: $15 \mathrm{ng} / \mathrm{Well}$ ) grafisch dargestellt.

$\mathrm{Zu}$ den Auswertungszeitpunkten von 24 und 48 Stunden wiesen die Zellen unter der Behandlung mit Cyclosporin A, mit einem Median von 17,7 sowie $16,7 \mu \mathrm{m}$, den größten Zelldurchmesser auf. Unter Behandlung mit Sirolimus nahm der Zelldurchmesser über den gesamten Versuchsverlauf stetig ab, wobei diese Zellen trotzdem zu den Auswertungszeitpunkten von 6 und 72 Stunden, mit einem Median an 17,3 sowie 16,3 $\mu \mathrm{m}$, über den größten Zelldurchmesser verfügten. 


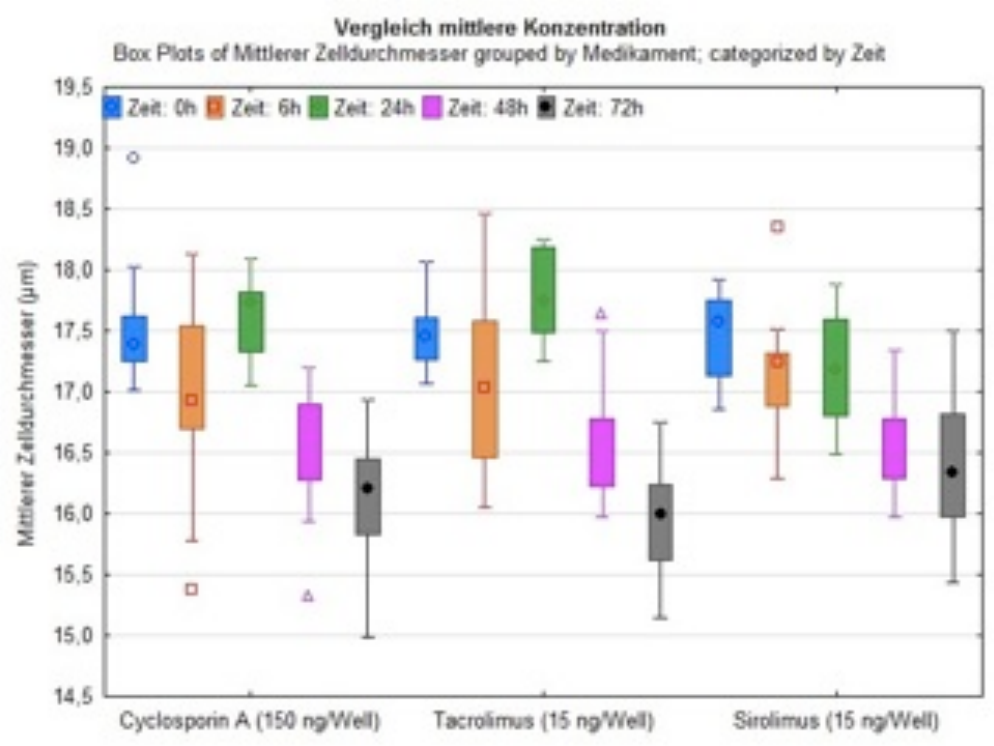

Abbildung 24: Darstellung des Zelldurchmessers $(\mu \mathrm{m})$ : Konzentrationsvergleich der mittleren Konzentration der Immunsuppressiva

Sowohl der Konzentrationsvergleich der Konzentration von 15 ng/Well der Immunsuppressiva untereinander $(\mathrm{p}=0,4921)$ als auch die Wechselwirkung zwischen Medikament und Zeit $(\mathrm{p}=0,5714)$ zeigten keine signifikanten Effekte. Lediglich der Faktor Zeit war signifikant $(\mathrm{p}<0,0001)$.

Sowohl der Konzentrationsvergleich der drei Immunsuppressiva in der mittleren Konzentration $(\mathrm{p}=0,5009)$ als auch die Wechselwirkung zwischen Medikament und Zeit wiesen ebenfalls keine signifikanten Effekte $(\mathrm{p}=0,5402)$ auf. Erneut war lediglich die Zeit signifikant ( $p<0,0001)$. Daher wurden die Daten beider Vergleichsuntersuchungen nicht weiter analysiert. 


\subsection{Ergebnisse: Prokollagen Typ I}

\subsubsection{Cyclosporin A}

Die folgende Grafik (Abb. 25) stellt die gewonnenen Resultate der Messung der Menge an Prokollagen Typ I unter Cyclosporin A dar. Die Menge an Prokollagen Typ I stieg in allen Gruppen über die gesamte Versuchsdauer kontinuierlich an. Jedoch konnte bei den mit 150 ng/Well Cyclosporin A behandelten Zellen zu den Auswertungszeitpunkten von 6 und 48 Stunden, verglichen mit den übrigen Gruppen, eine höhere Mengenzunahme an Prokollagen Typ I (4,1 ng/ml bzw. $5 \mathrm{ng} / \mathrm{ml})$ festgestellt werden.

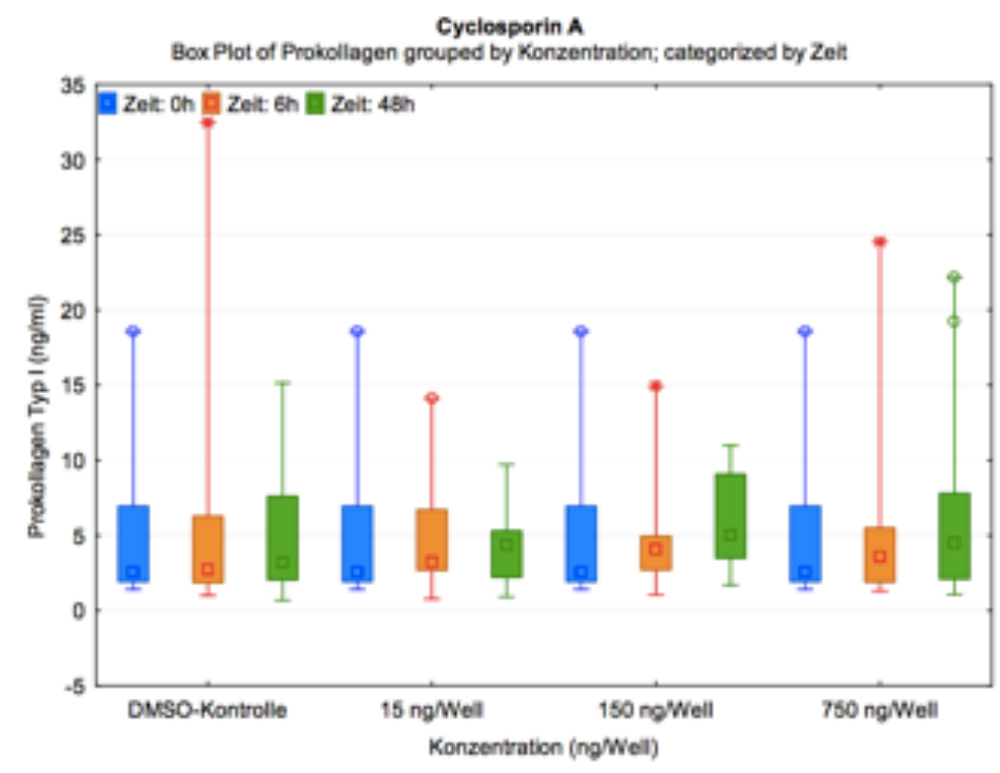

Abbildung 25: Darstellung der Menge an Prokollagen Typ I (ng/ml): Behandlung mit CSA

\subsubsection{Tacrolimus}

Die gewonnen Ergebnisse der Auswertung der Prokollagen Typ I Menge unter Tacrolimus-Einwirkung werden in Abbildung 26 aufgezeigt. In den mit 15 und 20 ng/Well Tacrolimus behandelten Gruppen zeigte sich ein kontinuierlicher Anstieg der Menge an Prokollagen Typ I. Lediglich unter Einwirkung von 10 ng/Well Tacrolimus konnte nach einem initialen Anstieg eine Abnahme zum finalen Auswertungspunkt von 48 Stunden festgestellt werden. Trotzdem zeigte diese Gruppe nach 6 Stunden Einwirkzeit, verglichen mit den anderen Gruppen, eine höhere Mengenzunahme an Prokollagen Typ I (Median: 3,9 ng/ml). Nach einer Einwirkzeit von 48 Stunden zeigte die Gruppe, welche mit 20 ng/Well Tacrolimus behandelt wurde, die größte Menge an Prokollagen Typ I (Median: $4,6 \mathrm{ng} / \mathrm{ml})$. 


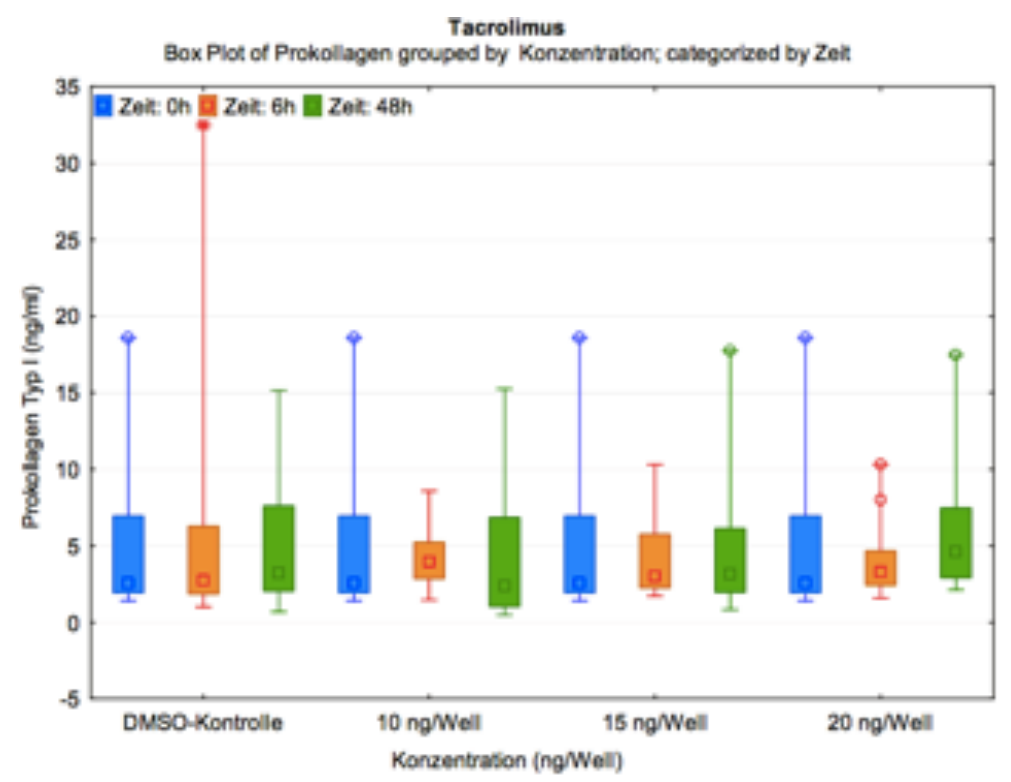

Abbildung 26: Darstellung der Menge an Prokollagen Typ I (ng/ml): Behandlung mit TCR

\subsubsection{Sirolimus}

Abbildung 27 zeigt die Ergebnisse der Auswertung der Menge an Prokollagen Typ I unter Einwirkung von Sirolimus. Die Menge an Prokollagen Typ I stieg kontinuierlich in den Gruppen unter Einwirkung von 10 und 20 ng/Well Sirolimus an. Lediglich die mit 15 ng/Well Sirolimus behandelten Zellen zeigten im Verlauf eine Abnahme. Zum Auswertungszeitpunkt von 6 Stunden verfügte die Gruppe unter Behandlung mit 10 ng/Well Sirolimus, verglichen mit den restlichen Gruppen, über eine höhere Menge an Prokollagen Typ I (3,6 ng/ml). Nach einer 48-stündigen Einwirkzeit unter 20 ng/Well Sirolimus zeigte diese Zellgruppe im Vergleich die größte Menge an Prokollagen Typ I (4,9 ng/ml).

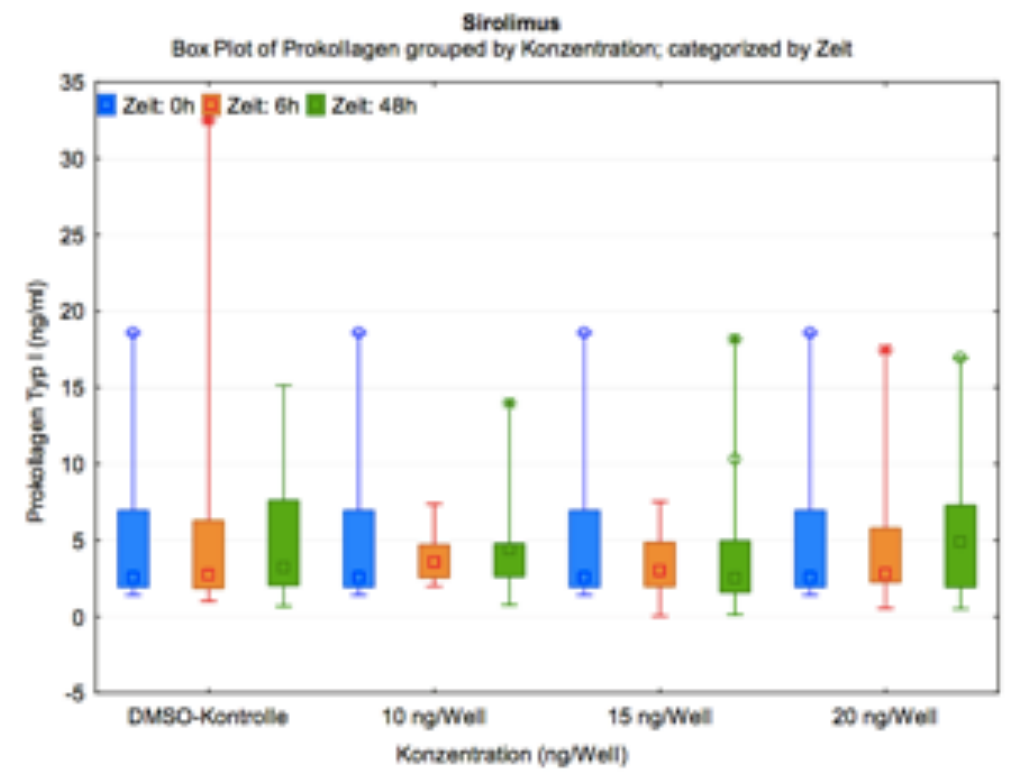

Abbildung 27: Darstellung der Menge an Prokollagen Typ I (ng/ml): Behandlung mit SIR 


\subsubsection{Konzentrationsvergleich der Konzentration 15 ng/Well und Konzentrations- vergleich der mittleren Konzentration der Immunsuppressiva}

Abbildung 28 stellt die gewonnenen Ergebnisse des Konzentrationsvergleiches der Konzentration $15 \mathrm{ng} /$ Well aller Immunsuppressiva grafisch dar.

Die mit Cyclosporin A- und Tacrolimus-behandelten Zellen zeigten über den gesamten Versuchsverlauf eine kontinuierliche Zunahme der Menge an Prokollagen Typ I. Lediglich die Zellen unter Einwirkung von Sirolimus wiesen nach einer anfänglichen Zunahme eine Abnahme zum finalen Auswertungszeitpunkt von 48 Stunden auf. Die mit Cyclosporin A behandelten Zellen verfügten, im Vergleich zu den anderen Zellgruppen, zu den Auswertungszeitpunkten 6 und 48 Stunden über die größte Zunahme der Prokollagenmenge (3,2 $\mathrm{ng} / \mathrm{ml}$ und $4,3 \mathrm{ng} / \mathrm{ml})$.

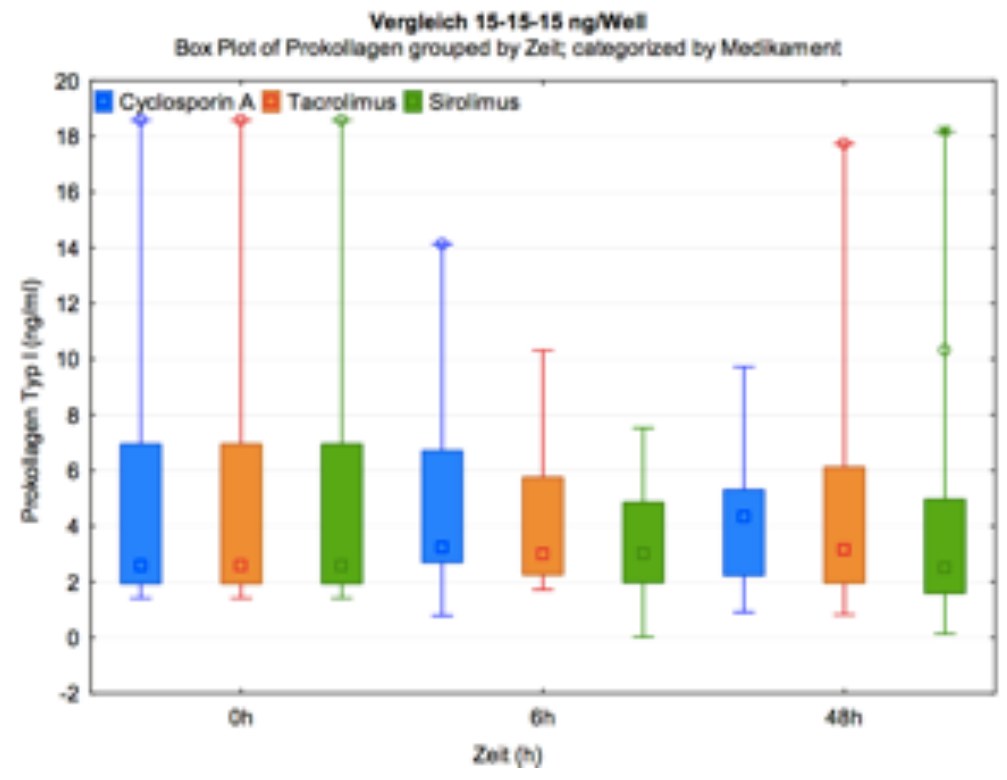

Abbildung 28: Darstellung der Menge an Prokollagen Typ I (ng/ml): Konzentrationsvergleich $15 \mathrm{ng} /$ Well der Immunsuppressiva

Abbildung 29 zeigt die Resultate des Konzentrationsvergleiches der mittleren Konzentration aller Immunsuppressiva (CSA: $150 \mathrm{ng} / \mathrm{Well}$, TCR und SIR: $15 \mathrm{ng} / \mathrm{Well}$ ).

Unter Einwirkung von 150 ng/Well Cyclosporin A und 15 ng/Well Tacrolimus stieg die Menge an Prokollagen Typ I über die gesamte Versuchsdauer an. Hierbei zeigten die mit Cyclosporin A behandelten Zellen die größte Zunahme der Prokollagenmenge. Die Menge des Prokollagens der Zellen unter Behandlung mit 15 ng/Well Sirolimus nahm nach initialer Zunahme zum finalen Auswertungszeitpunkt von 48 Stunden wieder ab (3,0 ng/ml bzw. $2,5 \mathrm{ng} / \mathrm{ml})$. 


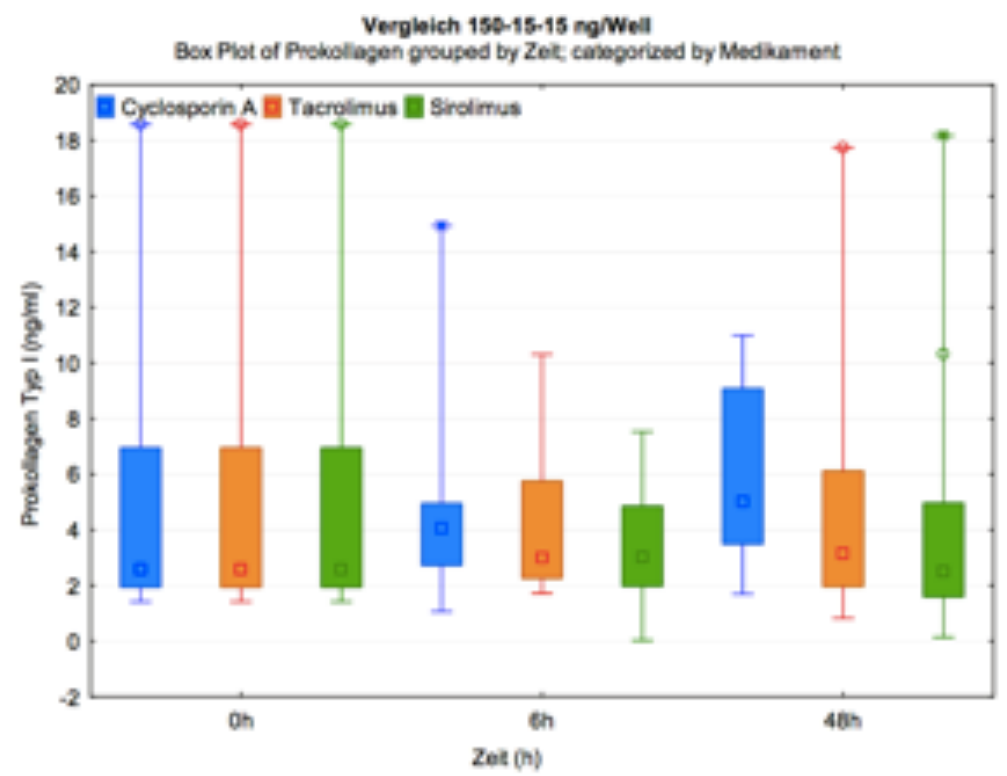

Abbildung 29: Darstellung der Prokollagen Typ I Menge (ng/ml): Konzentrationsvergleich der mittleren Konzentration der Immunsuppressiva

\subsubsection{Statistische Auswertung der Menge an Prokollagen Typ I}

Bei der statistischen Analyse der einzelnen Immunsuppressiva zeigten sich keine signifikanten Einflüsse (Tab. 21).

Tabelle 21: $p$-Werte der statistischen Auswertung der Menge an Prokollagen Typ I

\begin{tabular}{|l|c|}
\hline Effekt & Pr $>$ F \\
\hline Konzentration & 0,4899 \\
\hline Zeit & 0,6242 \\
\hline Konzentration*Zeit & 0,8166 \\
\hline Medikament & 0,7510 \\
\hline Konzentration*Medikament & 0,9982 \\
\hline Zeit*Medikament & 0,9904 \\
\hline Konz*Zeit*Medikament & 1,0000 \\
\hline
\end{tabular}

\subsection{Fotografische Dokumentation der behandelten Zellen}

Die 3T3-Zellen wurden regelmäßig unter einem Auflichtmikroskop (Axiovert 200M, Zeiss, Göttingen, Deutschland) kontrolliert und erfasst. Die Abbildungen 30-44 zeigen in einer mikroskopischen Verlaufsdokumentation den Vergleich zwischen der DMSO-Kontrolle, der niedrigsten und der höchsten Konzentration des jeweiligen Immunsuppressivums. 


\subsubsection{Zellfotografie: Cyclosporin A}

Die folgende fotografische Darstellung zeigt sowohl die Zellen unter 15 und $750 \mathrm{ng} / \mathrm{Well}$

Cyclosporin A als auch die DMSO-Kontrolle zu allen Auswertungszeitpunkten. Zudem wird der Versuchsstart gezeigt.

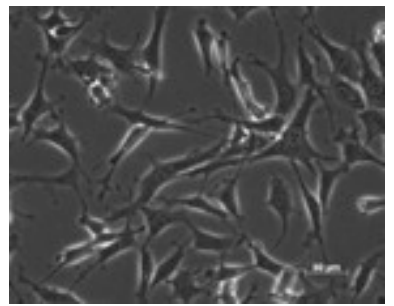

Abbildung 30: Versuchsstart
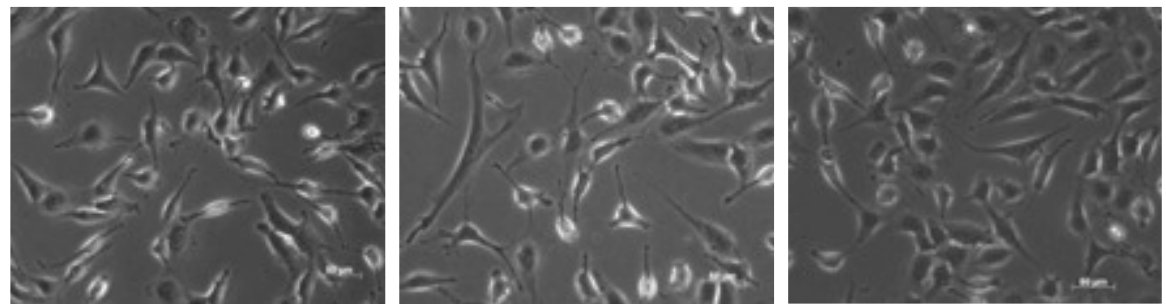

Abbildung 31:

a) $6 \mathrm{~h}$; Kontrolle

b) $6 \mathrm{~h} ; 15 \mathrm{ng} / \mathrm{Well}$

c) $6 \mathrm{~h} ; 750 \mathrm{ng} / \mathrm{Well}$

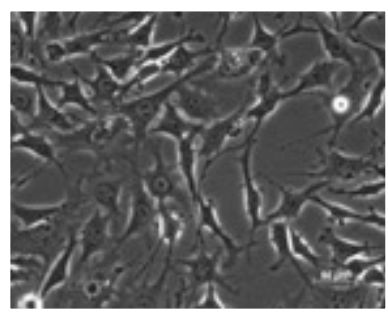

Abbildung 32:

a) $24 \mathrm{~h}$; Kontrolle

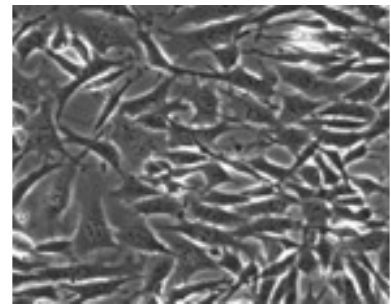

Abbildung 33:

a) $48 \mathrm{~h}$; Kontrolle

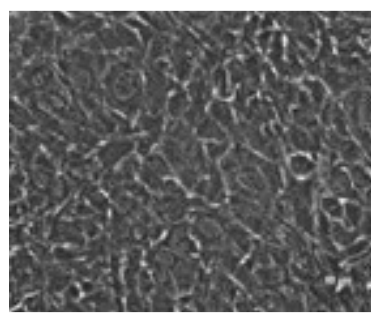

Abbildung 34:

a) $72 \mathrm{~h}$; Kontrolle

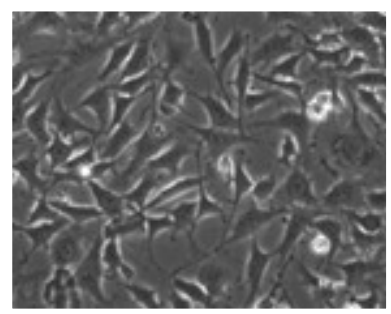

b) $24 \mathrm{~h} ; 15 \mathrm{ng} / \mathrm{Well}$

c) $24 \mathrm{~h} ; 750 \mathrm{ng} /$ Well
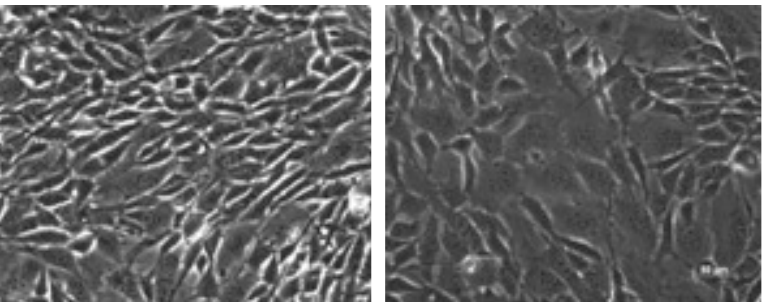

b) $48 \mathrm{~h} ; 15 \mathrm{ng} / \mathrm{Well}$

c) $48 \mathrm{~h} ; 750 \mathrm{ng} / \mathrm{Well}$
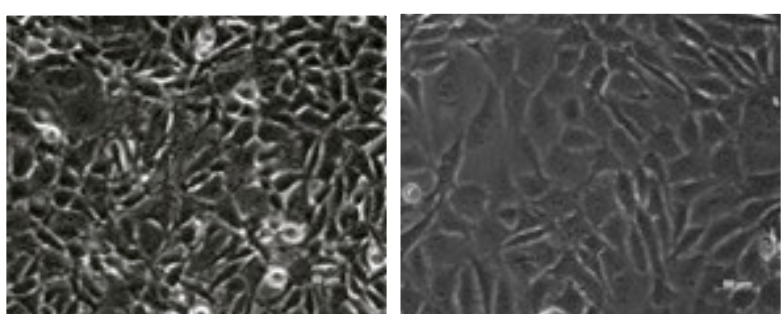

b) $72 \mathrm{~h} ; 15 \mathrm{ng} / \mathrm{Well}$

c) $72 \mathrm{~h} ; 750 \mathrm{ng} /$ Well 


\subsubsection{Zellfotografie: Tacrolimus}

Nachfolgend werden sowohl die Zellen unter Einwirkung von 10 und 20 ng/Well Tacrolimus als auch die DMSO-Kontrolle zu allen Auswertungszeitpunkten dargestellt. Des Weiteren wird der Versuchsstart gezeigt.

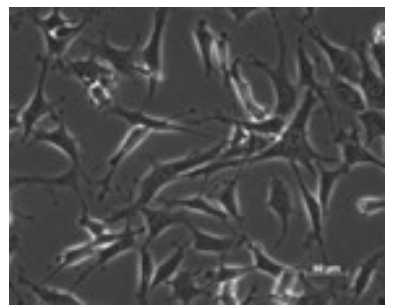

Abbbildung 35: Versuchsstart
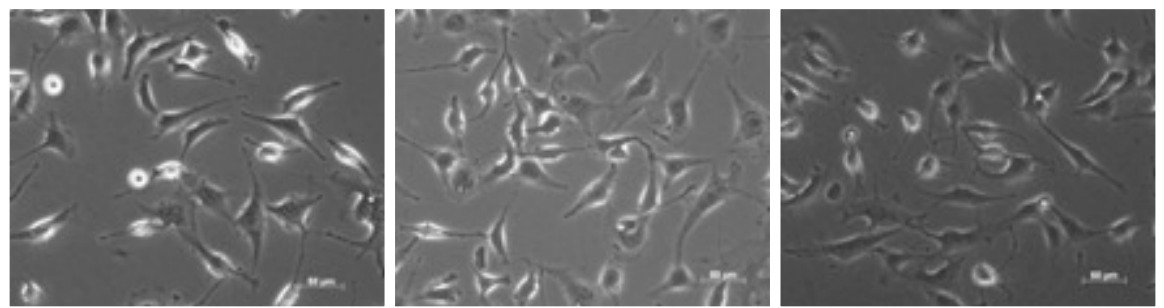

\section{Abbildung 36:}

a) $6 \mathrm{~h}$; Kontrolle

b) $6 \mathrm{~h} ; 10 \mathrm{ng} / \mathrm{Well}$

c) $6 \mathrm{~h} ; 20 \mathrm{ng} / \mathrm{Welll}$
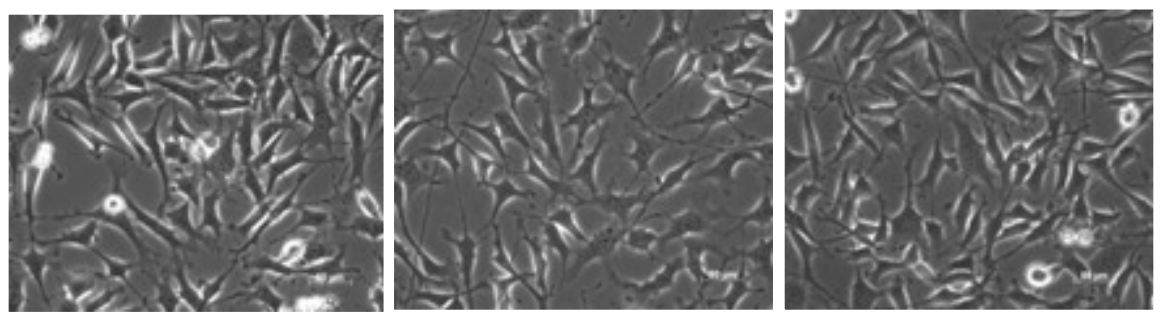

Abbildung 37:

a) $24 \mathrm{~h}$; Kontrolle

b) $24 \mathrm{~h} ; 10 \mathrm{ng} / \mathrm{Well}$

c) $24 \mathrm{~h} ; 20 \mathrm{ng} /$ Well
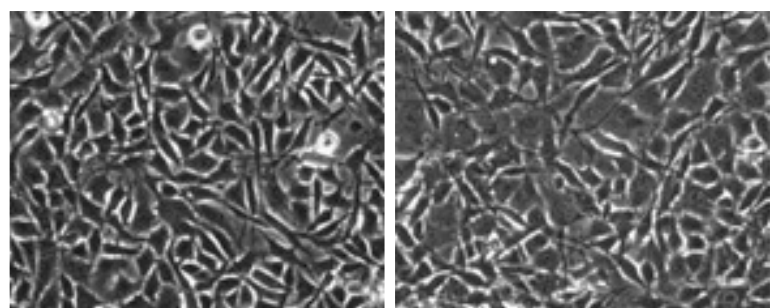

Abbildung 38:

a) $48 \mathrm{~h}$; Kontrolle

b) $48 \mathrm{~h} ; 10 \mathrm{ng} / \mathrm{Well}$

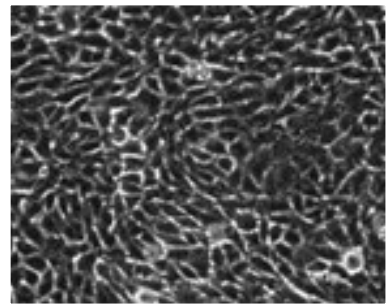

Abbildung 39:

a) $72 \mathrm{~h}$; Kontrolle

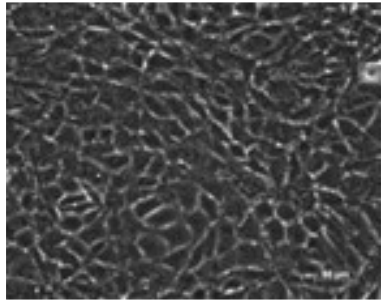

b) $72 \mathrm{~h} ; 10 \mathrm{ng} / \mathrm{Well}$ c) $48 \mathrm{~h} ; 20 \mathrm{ng} / \mathrm{Well}$
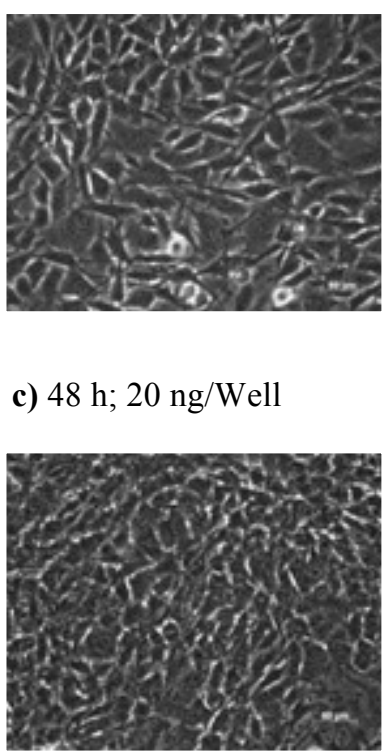

c) $72 \mathrm{~h} ; 20 \mathrm{ng} / \mathrm{Well}$ 


\subsubsection{Zellfotografie: Sirolimus}

Sowohl die Zellen unter Behandlung mit 10 und $20 \mathrm{ng} /$ Well Sirolimus als auch die DMSO-Kontrolle werden im Folgenden fotografisch dargestellt. Hierbei werden der Versuchsstart und alle Auswertungszeitpunkte gezeigt.

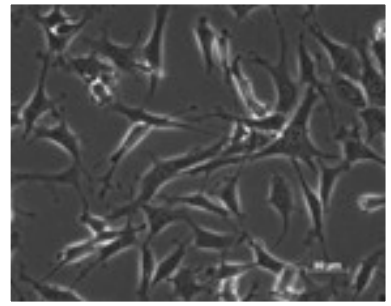

Abbildung 40: Versuchsstart
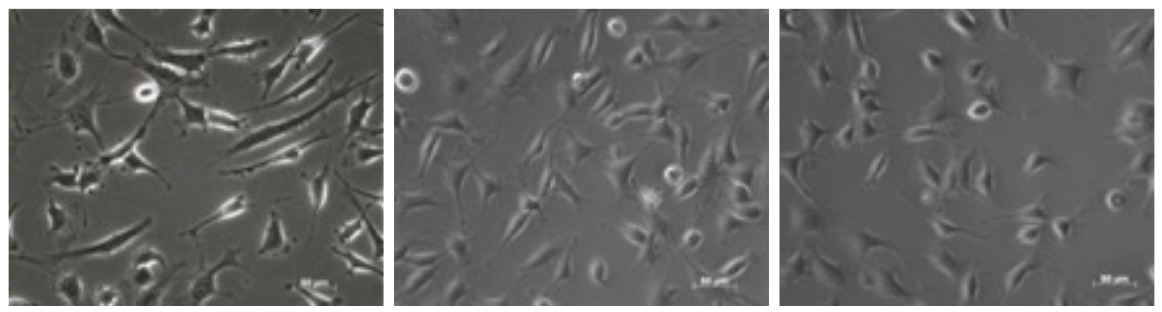

Abbildung 41:

a) $6 \mathrm{~h}$; Kontrolle

b) $6 \mathrm{~h} ; 10 \mathrm{ng} / \mathrm{Well}$

c) $6 \mathrm{~h} ; 20 \mathrm{ng} / \mathrm{Well}$
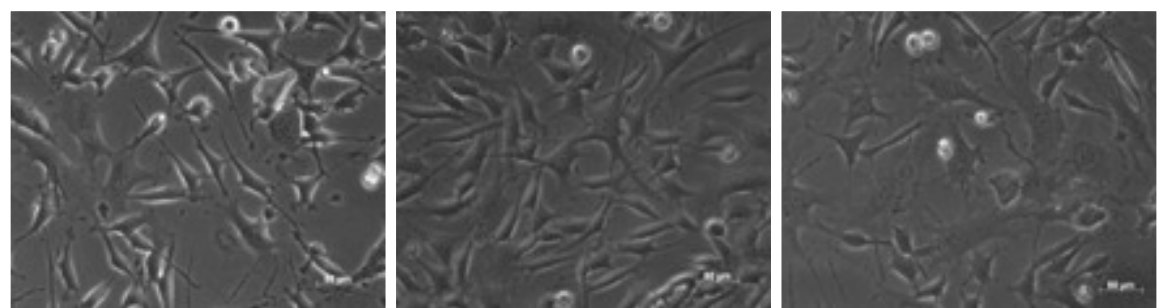

Abbildung 42:

a) $24 \mathrm{~h}$; Kontrolle

b) $24 \mathrm{~h} ; 10 \mathrm{ng} / \mathrm{Well}$

c) $24 \mathrm{~h} ; 20 \mathrm{ng} / \mathrm{Well}$
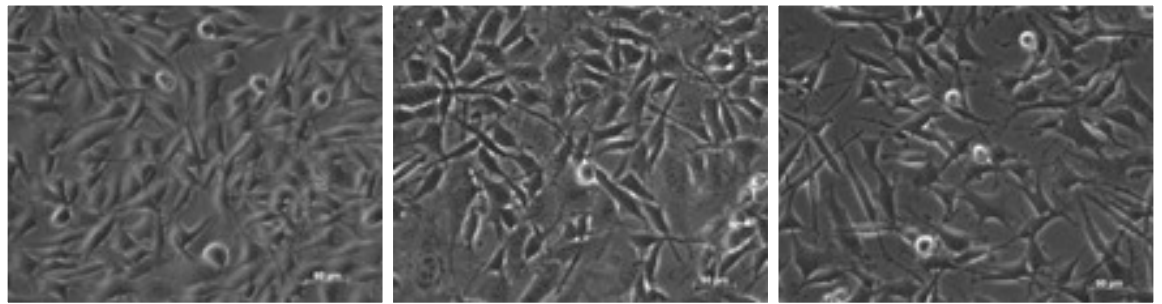

Abbildung 43:

a) $48 \mathrm{~h}$; Kontrolle

b) $48 \mathrm{~h} ; 10 \mathrm{ng} / \mathrm{Well}$

c) $48 \mathrm{~h} ; 20 \mathrm{ng} / \mathrm{Well}$
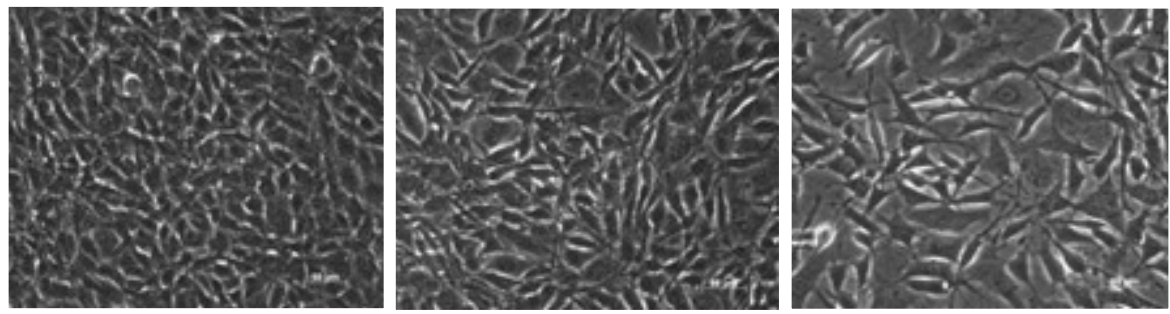

Abbildung 44:
a) $72 \mathrm{~h}$; Kontrolle
b) $72 \mathrm{~h} ; 10 \mathrm{ng} / \mathrm{Well}$
c) $72 \mathrm{~h} ; 20 \mathrm{ng} / \mathrm{Well}$ 


\subsection{Zusammenfassung der wichtigsten Ergebnisse}

\section{Gesamtzellzahl}

- Die mit unterschiedlichen Konzentrationen von Cyclosporin A behandelten Zellen zeigten jeweils im Vergleich untereinander und im Vergleich mit beiden Kontrollgruppen keine signifikanten Unterschiede der Gesamtzellzahl.

- Gleiches galt auch für die Zellen, welche mit Tacrolimus behandelt wurden.

- Die Zellen unter Sirolimus-Einwirkung wiesen niedrigere Gesamtzellzahlen als die Kontrollgruppen auf. Nach einer Einwirkzeit von 48 und 72 Stunden konnte ein signifikanter Unterschied aller Konzentrationsgruppen, verglichen mit der DMSOKontrolle, beobachtet werden.

- Beide Vergleichsuntersuchungen (15 ng/Well und mittlere Konzentration aller Immusuppressiva) zeigten zu den Auswertungszeitpunkten 48 und 72 Stunden signifikante Unterschiede der Gesamtzellzahlen zwischen der Cyclosporin A- und Sirolimusgruppe und der Tacrolimus- und Sirolimusgruppe. Cyclsporin A und Tacrolimus wiesen im Vergleich keine signfikanten Unterschiede auf.

\section{Lebendzellzahl}

- Die Ergebnisse der Lebendzellzahl glichen denen der Gesamtzellzahl.

\section{Mittlerer Zelldurchmesser}

- Zwischen der Konzentration von 150 ng/Well Cyclosporin A und der DMSOKontrolle konnte zum Auswertungszeitpunkt von 48 Stunden ein signifikanter Unterschied festgestellt werden.

- Sowohl unter Tacrolimus- als auch Sirolimus-Einwirkung traten keine signifikanten Unterschiede des Zelldurchmessers auf. Die beiden Vergleiche der Immunsuppressiva ergaben keine signifikanten Differenzen.

\section{Prokollagen Typ I}

- Bei der Analyse der Menge an Prokollagen Typ I wiesen die einzelnen Immunsuppressiva keine signifikanten Effekte auf. 


\section{Diskussion}

Nach wie vor ist die Transplantationsmedizin auf immunsupprimierende Medikamente angewiesen. Infolgedessen werden immer wieder Gingivawucherungen als orale Nebenwirkung unter Medikation mit Immunsuppressiva beschrieben (Greenberg et al. 2008). Immunkompromittierte Patienten stellen daher für den behandelnden Zahnarzt, unter Berücksichtigung der dadurch bedingten Risiken und Nebenwirkungen, eine ernstzunehmende Risikogruppe dar.

Studien über die Pathogenese und Ätiologie von Gingivawucherungen, ausgelöst durch die Einnahme von Immunsuppressiva (v.a. durch Cyclosporin A), zeigen insgesamt widersprüchliche Ergebnisse, wobei die hierbei involvierten zellulären Mechanismen noch nicht klar untersucht und verstanden sind (Hyland et al. 2003, Dannewitz et al. 2009).

Demnach erschien es sinnvoll, der Frage nachzugehen, ob die Immunsuppressiva Cylosporin A, Tacrolimus und Sirolimus über unterschiedliche Potentiale verfügen, eine einwirkungszeit- und konzentrationsabhängige Änderung der Parameter Gesamtzellzahl, Lebendzellzahl, mittlerer Zelldurchmesser und Menge an Prokollagen Typ I herbeizuführen bzw. zu erwirken. Diese Fragestellung bildete die Grundlage der vorliegenden Studie.

\subsection{Diskussion des Untersuchungsmaterials}

\subsubsection{Zellmaterial}

Im Rahmen der vorliegenden Studie wurden Tierzellen in Form embryonaler gingivaler Mäusefibroblasten verwendet. Genauer fand eine Standardfibroblastenlinien von 3T3Zellen aufgrund ihrer Reproduzierbarkeit und Zugänglichkeit Verwendung.

Fibroblasten bilden den vorherrschenden Zelltyp im weichen Gewebe des Parodontiums und spielen somit eine wesentliche Rolle bei pathologischen Veränderungen des Zahnhalteapparates (Schroeder 1986). Sie fungieren als Produzenten des Stützgewebes, indem sie Kollagen und andere wichtige Komponenten der extrazellulären Matrix synthetisieren. Im Gegensatz zu der komplexen Multilayerstruktur, in der Fibroblasten in der Mundhöhle eingebunden sind, lagen diese in der vorliegenden In-vitro-Studie in einer Monolayerstruktur vor. Hier darf die Problematik von In-vitro-Untersuchungen nicht außer Acht gelassen werden, da Zellen in einer Monolayerstruktur möglicherweise anders auf die verwendeten Immunsuppressiva reagieren als im Gefüge einer komplexen Multilayerstruktur. Um trotzdem möglichst mundhöhlen-ähnliche Umstände und optimale Lebendbedingungen zu schaffen, wurden die Zellen zwischen den einzelnen Messungen bei $+37^{\circ} \mathrm{C}$ und $5 \%$ konstantem Stickstoffanteil inkubiert (Dannewitz et al. 2009). 
Demnach könnte empfohlen werden, dass weiterführende Untersuchungen im Hinblick auf In-vivo-orientierte Umstände mit Multilayerschichten arbeiten, um eine bessere Anpassung an die realen Verhältnisse der Gingiva zu erzielen (Dongari-Bagtzoglou und Kashleva 2006). Dannewitz et al. (2009) verwendeten in ihrer Studie bereits Kokulturen aus Fibroblasten und Keratinozyten, um realitätsnähere In-vivo-Umstände zu kreieren.

Daneben wäre es für Folgeuntersuchungen empfehlenswert, humane gingivale Fibroblastenlinien $\mathrm{zu}$ verwenden. Andere Studien arbeiteten bereits mit primären humanen Gingivafibroblasten als Untersuchungsobjekt (Gagliano et al. 2004, Gagliano et al. 2005 a und b, Gagliano et al. 2008, Dannewitz et al. 2006, Dannewitz et al. 2009, Salman et al. 2013).

Gagliano et al. (2004) verwendeten primäre humane Gingivafibroblasten von jungen gesunden Menschen. Hier könnte das Studiendesign der vorliegenden Arbeit dahingehend weiterentwickelt werden, indem primäre Gingivafibroblasten von Patienten mit Zahnfleischwucherungen unter immunsuppressiver Medikation mit primären Gingivafibroblasten gesunder Spender verglichen werden. Dannewitz et al. zeigten bereits 2006 einen Unterschied zwischen primären Gingivafibroblasten, gewonnen aus der Schleimhaut von Patienten unter Immunsuppression und gesunden humanen Gingivafibroblasten. Beide Zellgruppen wurden mit Cyclosporin A behandelt.

Daher bieten sich im Hinblick auf das Untersuchungsobjekt viele Ansatzpunkte zur Weiterentwicklung der vorliegenden Arbeit.

\subsubsection{Verwendete Immunsuppressiva}

Die Immunsuppressiva sollten dem klinischen Gebrauch möglichst gut entsprechen. Daher wurden die drei gängigen Immunsuppressiva Cyclosporin A, Tacrolimus und Sirolimus in der vorliegenden Studie verwendet.

Neben einigen anderen Nebenwirkungen werden für Cyclosporin A, als Immunsuppressivum der ersten Generation, immer wieder gingivale Wucherungen beschrieben (Greenberg et al. 2008, Ghafari et al. 2010). Bereits 1983 wiesen Rateitschak-Plüss et al. auf erste gingivale Veränderungen durch die Gabe des Immunsuppressivums Cyclosporin A hin. In zahlreichen In-vitro-Studien wurde der mögliche Zusammenhang einer Cyclosporin-AEinnahme und dem Auftreten von Gingivawucherungen untersucht (Schincaglia et al. 1992, Gagliano et al. 2004, Mariani et al. 1993, Dannewitz et al. 2009, Salman et al. 2013).

Die neueren Immunsuppressiva weisen nach Walker et al. (2007) weniger unerwünschte gingivale Nebenwirkungen auf. 
Pistorius et al. (2003) und Gagliano et al. (2005 a und b, 2008) untersuchten in ihren Invitro-Studien eine mögliche Wirkung von Tacrolimus auf humane Gingivafibroblasten als ursächlicher Faktor für die Induktion gingivaler Wucherungen. Gagliano et al. (2005b) zeigten keinen Einfluss von Tacrolimus auf das von ihnen untersuchte Glykoprotein $S P A R C$, wiesen jedoch eine reduzierte Proliferation der Fibroblasten unter TacrolimusEinwirkung (Gagliano et al. 2005a) nach. Pistorius et al. (2003) wiederum stellten eine Änderung in der metabolischen Aktivität der Zellen fest.

Leider finden sich keine In-vitro-Studien, die eine durch Sirolimus induzierte Gingivawucherung untersuchen. Allerdings beschrieben Cota et al. (2008) in ihrer In-vivo-Studie unter Sirolimus-Medikation auftretende gingivale Wucherungen.

Jedoch gibt es einige weitere und wichtige Faktoren, welche in dieser Studie leider unberücksichtigt blieben. Sowohl in der Induktions- als auch in der Erhaltungsphase immunsupprimierter Patienten bevorzugen behandelnde Ärzte eine Kombinationsgabe aus verschiedenen immunsuppressiven Medikamenten, um bei einem gleichzeitig reduzierten $\mathrm{Ne}-$ benwirkungsrisiko eine stärkere Immunsuppression zu erzielen (Renz-Polster und Krautzig 2012). Die meisten Protokolle basieren auf der Kombination von einem Calcineurininhibitor (z.B. Cyclosporin A und Tacrolimus) und Steroiden (Schrem et al. 2009). Demnach bestünde die Möglichkeit einer Induktion von Gingivawucherungen durch die Interaktion der unterschiedlichen immunsuppressiven Medikamente.

Ein anderer wichtiger Aspekt ist der multimorbide Patient als solcher, welcher zusätzlich neben Immunsuppressiva additive andere Medikamente einnimmt (beispielsweise Kalziumkanalblocker). Schon früh zeigten diverse Studien den Zusammenhang zwischen der Ätiologie von gingivalen Wucherungen und Kalziumkanalblockern (Bowman et al. 1988, Lederman et al. 1984, Pernu et al. 1989, Seymour und Smith 1991). Die Kombinationsgabe von Cyclosporin A und Nifedipin (Thomason et al. 1992) sowie Amlodipin induziert eine verstärkte Ausprägung gingivaler Wucherungen (López-Pintor et al. 2009). Salman et al. (2013) behandelten in ihrer Studie beispielsweise juvenile und adulte Primärzellen mit Cyclosporin A, stellten jedoch keinen Unterschied zwischen beiden Gruppen fest. Dabei sollte jedoch das Patientenalter als wichtiger Risikofaktor berücksichtigt werden, insbesondere unter Medikation mit Cyclosporin A (Schulz et al. 1990, Hefti et al. 1994), da dieses Immunsuppressivum bei einer breitgefächerten Altersgruppe indiziert ist (Seymour et al. 2000). 


\subsection{Diskussion der Untersuchungsmethoden}

\subsubsection{Auswertungszeiträume}

In der vorliegenden Versuchsreihe wurden die 3T3-Zellen nach 48-stündigem Anwachsen 6, 24, 48 oder 72 Stunden mit dem jeweiligen Immunsuppressivum behandelt. Die gewählten Auswertungszeiträume orientierten sich teilweise an der In-vitro-Studie von Dannewitz et al. (2009) und Esposito et al. (2000).

Um einen möglichst realistischen Zustand zu simulieren und eine dauerhafte und konstante Wirkung der Immusuppressiva auf die Zellen gewährleisten zu können, wurde die Halbwertszeit der Immunsuppressiva miteinbezogen.

Unter klinischen Bedingungen dauerte es nach initialer Gabe von Cyclosporin A etwa einen Monat bis erste gingivale Wucherungen auftraten (Tyldesley und Rotter 1984). Um diesen Zustand zu imitieren, wäre ein Studiendesign mit einer Langzeitinkubation des jeweiligen Immunsuppressivums denkbar. Hierzu finden sich jedoch nur wenige Zellkulturstudien mit realistischen Einwirkzeiten. Willershausen-Zönnchen et al. (1991) inkubierten daher humane, gingivale Fibroblasten über einen Zeitraum von sechs Wochen mit $1 \mu \mathrm{g} / \mathrm{ml}$ Cyclosporin A und verglichen dies mit einer Inkubationszeit von 72 Stunden. Sie beschrieben einen direkten, signifikanten Effekt auf die Proliferation der Fibroblasten unter einer Langzeitinkubation von sechs Wochen, verglichen mit der Kontrollgruppe. Die Inkubation über 72 Stunden zeigte keinen signifikanten Effekt.

Die meisten in der Vergangenheit durchgeführten Zellkulturstudien arbeiteten jedoch mit einem maximalen Einwirkzeitraum von 72 Stunden (Schincaglia et al. 1992, Esposito et al. 2000, Gagliano et al. 2005b, Dannewitz et al. 2009).

In der vorliegenden Studie wurden die verwendeten 3T3-Zellen ebenfalls maximal 72 Stunden mit dem jeweiligen Immunsuppressivum inkubiert. Da lediglich Sirolimus einen signifikanten Effekt auf die Gesamt- und Lebendzellzahl nach 48 und 72 Stunden Einwirkzeit ausübte, sollte in einem neuen Studiendesign über eine Langzeitinkubation der Zellen nachgedacht werden, um In-vivo Zustände noch besser imitieren zu können.

\subsubsection{Verwendete Konzentrationen}

In der vorliegenden Arbeit wurde von jedem der drei Immunsuppressiva eine niedrige, mittlere und eine hohe Dosis ausgewählt.

Cyclosporin A wurde in den Konzentrationen 15, 150 und 750 ng/Well verwendet. Die Dosen orientierten sich unter anderem an den in Tabelle 22 beschriebenen Studien, an dem Vollbluttalspiegel von Cyclosporin A und an einem gemittelten Wert aus Vollbluttalspiegel und In-vitro-Studien-Dosen. Tabelle 22 gibt einen Überblick über verschiedene Studien, 
welche Cyclosporin A und dessen mögliche Induktion einer Gingivawucherung untersuchten.

Tabelle 22: Übersicht - Studien zu Cyclosporin A (unter Angabe der verwendeten Dosen)

\begin{tabular}{|l|l|l|l|}
\hline Autor & Studie & Dosis & Ergebnis \\
\hline Bolzani et al. (2000) & In-vitro-Studie & $100-1000 \mathrm{ng} / \mathrm{ml}$ & $\begin{array}{l}\text { Signif. Inhibierung von } \\
\text { Matrixkomponenten }\end{array}$ \\
\hline Dannewitz et al. (2009) & In-vitro-Studie & $750 \mathrm{ng} / \mathrm{ml}$ & $\begin{array}{l}\text { Signif. erhöhte Kollagen- } \\
\text { Typ-I mRNA Expression }\end{array}$ \\
\hline Esposito et al. (2000) & In-vitro-Studie & $\begin{array}{l}50,200,400 \mathrm{und} 800 \\
\mathrm{ng} / \mathrm{ml}\end{array}$ & $\begin{array}{l}\text { Kein antiproliferativer Effekt } \\
\text { auf humane Fibroblasten }\end{array}$ \\
\hline Gagliano et al. (2005b) & In-vitro-Studie & $800 \mathrm{ng} / \mathrm{Well}$ & $\begin{array}{l}\text { Minimale, nicht signif. Zu- } \\
\text { nahme von SPARC }\end{array}$ \\
\hline Hefti et al. (1994) & $\begin{array}{l}\text { In-vivo- } \\
\text { Doppelblindstudie }\end{array}$ & $\begin{array}{l}\text { Initial: } 400-600 \\
\mathrm{ng} / \mathrm{ml} \\
\mathrm{ng} / \mathrm{ml}\end{array}$ & $\begin{array}{l}\text { Ein konstanter Vollblut- } \\
\text { Talspiegel }>400 \mathrm{ng} / \mathrm{ml} \text { zeigte } \\
\text { ein erhöhtes Risiko gingiva- } \\
\text { ler Wucherungen }\end{array}$ \\
\hline Hyland et al. (2003) & In-vitro-Studie & $100-2000 \mathrm{ng} / \mathrm{ml}$ & $\begin{array}{l}\text { Signif. Inhibierung von } \\
\text { MMP-I und TIMP-I }\end{array}$ \\
\hline Wentz et al. (2012) & In-vivo-Studie & $156,12-162,75 \mathrm{ng} / \mathrm{ml}$ & $\begin{array}{l}\text { Niedriges Auftreten von } \\
\text { Gingivawucherungen }\end{array}$ \\
\hline $\begin{array}{l}\text { Willershausen- } \\
\text { Zönnchen et al. (1991) }\end{array}$ & In-vivo-Tierstudie & $1000 \mathrm{ng} / \mathrm{ml}$ & $\begin{array}{l}\text { Nach sechs Wochen Lang- } \\
\text { zeitinkubation- signif. erhöh- } \\
\text { te Proliferation }\end{array}$ \\
\hline
\end{tabular}

$\mathrm{Zu}$ beachten ist hierbei allerdings, dass der Zusammenhang zwischen Serumkonzentration und der Prävalenz gingivaler Wucherungen sehr kontrovers diskutiert wird. Lin und Yang (2010) zeigten in ihrer Studie, dass die Serumkonzentration nicht mit dem Auftreten und Schweregrad Cyclosporin-A-induzierter Gingivawucherungen korreliert. Bestätigt wurden sie durch verschiedene andere Studien (Daley et al. 1986, Seibel et al. 1989, Allman et al. 1994). Fu et al. (1995) hingegen beobachteten in ihrem Tierversuch einen dosisabhängigen Zusammenhang.

Alle Konzentrationen von Tacrolimus und Sirolimus orientierten sich in der vorliegenden Arbeit an den jeweiligen Vollblut-Talspiegeln, wobei Dosen von 10, 15 und 20 ng/Well verwendet wurden. Tabelle 23 zeigt Dosen von Tacrolimus, welche in zwei unterschiedlichen In-vitro-Studien Verwendung fanden.

Tabelle 23: Übersicht - Studien zu Tacrolimus (unter Angabe der verwendeten Dosen)

\begin{tabular}{|l|l|l|l|}
\hline Autor & Studie & Dosis & Ergebnis \\
\hline $\begin{array}{l}\text { Gagliano et al. } \\
(2005 \mathrm{~b})\end{array}$ & In-vitro-Studie & $1 \mu \mathrm{M}$ & $\begin{array}{l}\text { Tacrolimus übte keinen Einfluss } \\
\text { auf das } S P A R C \text { aus. }\end{array}$ \\
\hline $\begin{array}{l}\text { Gagliano et al. } \\
(2008)\end{array}$ & In-vitro-Studie & $\begin{array}{l}8,80 \text { und } 800 \\
\mathrm{ng} / \mathrm{ml}\end{array}$ & $\begin{array}{l}\text { Ab } 800 \mathrm{ng} / \mathrm{ml} \text { erfolgt eine Zu- } \\
\text { nahme von MMP-Proteinlevels. }\end{array}$ \\
\hline
\end{tabular}

Zellkulturstudien im Rahmen einer durch Sirolimus induzierten gingivalen Wucherung sind nicht existent. Daher wurde sich an die Konzentrationen von Tacrolimus angelehnt, da beide über einen sehr ähnlichen Vollblut-Talspiegel verfügen. 


\subsubsection{Verwendete Methoden}

\subsubsection{Zellzählgerät CASY®}

Um eine Bestimmung der Zellzahl in Monolayerkulturen vorzunehmen, gibt es unterschiedliche Methoden. In der vorliegenden Studie wurde eine elektrisch basierte Zellzählung nach einem Widerstandsmessprinzip mithilfe des Zellzählgerätes $C A S Y{ }^{\circledR}$ (Cell Counter, Modell TT, Roche Diagnostics GmbH, Roche Applied Science, Penzberg, Deutschland) verwendet. Das Zellzählgerät $C A S Y{ }^{\circledR}$ diente der Bestimmung dreier Auswertungskriterien der vorliegenden Studie. Gesamtzellzahl, Lebendzellzahl und mittlerer Zelldurchmesser wurden mithilfe dieses Zellzählgerätes ausgewertet. Typisch für dieses Gerät sind das Erfassen von Zellen einer Größe von 0,7 - $160 \mu \mathrm{m}$, höchste Reproduzierbarkeit und Schnelligkeit (Roche Diagnostics Corporation, 2010).

Andere Zellzähl-Methoden, wie beispielsweise das Cellometer, wären ebenfalls dafür geeignet, die in der vorliegenden Arbeit gewählten Parameter Gesamtzellzahl, Lebendzellzahl und mittlerer Zelldurchmesser auszuwerten. Dies zeigten themenfremde Studien, welche das Cellometer als Methode zur Bestimmung der eben genannten Parameter verwendeten (Zyba 2010, Schalaikin 2013). Das Cellometer ist jedoch auf die Verwendung des Färbemittels Trypanblau angewiesen. Hier ist zu berücksichtigen, dass Trypanblau ein zytotoxisches Agens ist (Halle 1998). Diese Toxizität reicht aus, um bereits geschwächte, aber noch vitale Zellen abzutöten. Deshalb wurde in der vorliegenden Studie bewusst auf jene Methode verzichtet, um eine möglichst genaue Bestimmung der Lebendzellzahl zu erlangen. Aufgrund dessen wurde das Zellzählgerät $C A S Y ®$ ausgewählt, welches auf einer noninvasiven, elektronischen Bestimmung ohne Notwendigkeit von toxischen Färbemitteln basiert.

\subsubsection{Mouse Procollagen Type I C-Terminal Propeptide ELISA}

Die Bestimmung der Menge an Prokollagen Typ I erfolgte mit einem kompetitiven ELISA (Mouse Procollagen Type I C-Terminal Propeptide) der Firma BlueGene Biotech Co. (Shanghai, China). Zuvor wurden unterschiedliche Tests zur Kollagenmessung ausprobiert (u.a. Sircol Assay, Biocolor Ltd, Carrickfergus, Nordirland). Aufgrund der teilweise kurzen Auswertungszeiträume von 0, 6 und 24 Stunden war kein messbares Ergebnis der Kollagen Typ I Menge zu erzielen. Daher fiel die Entscheidung auf die Messung von Prokollagen Typ I anhand eines kommerziellen, kompetitiven ELISAs.

Ausschließlich themenfremde Studien verwendeten den Mouse-PICP-ELISA (Todorova et al. 2010, Chen et al. 2014, He et al. 2014). Ergänzend ist zu erwähnen, dass die in diesen 
Studien verwendeten Mouse-PICP-ELISAs zudem von unterschiedlichen Firmen stammten.

Die Menge von Kollagen lässt sich auch durch andere Methoden bestimmen. Dannewitz et al. (2009) untersuchten auf molekularer Ebene die Expression von Kollagen Typ I mRNA. Schincaglia et al. (1992) analysierten anhand der gleichen Methode die Menge an Prokollagen Typ I mRNA. Proteinexpression und -sekretion können mithilfe von Western Blot und Immunfluoreszenz bestimmt werden (Dannewitz et al. 2009). Dannewitz et al. (2009) verwendeten additiv zur hier vorliegenden Arbeit neben den Überständen auch Zellextrakte. Demnach gibt es diverse Methoden zur Mengenanalyse von Prokollagen und Kollagen Typ I.

\subsection{Diskussion der Ergebnisse}

\subsubsection{Gesamt- und Lebendzellzahl}

Cyclosporin A

In der vorliegenden Arbeit konnte kein signifikantes dosis- und zeitabhängiges Potential des Immunsuppressivums Cyclosporin A hinsichtlich einer Veränderung der Gesamt- und Lebendzellzahl beobachtet werden.

Wysocki et al. (1983) hingegen beschrieben in ihrer Zellkulturstudie eine Zunahme der Fibroblasten bei Patienten unter Cylosporin A-Medikation. Bestätigt wurden sie durch Bonnaure-Mallet et al. (1995). Die Autoren berichteten über eine erhöhte Anzahl der Fibroblasten in der Cyclosporin A-Gruppe gegenüber der Kontrollgruppe. Diese war jedoch nicht signifikant. Weitere Studien zeigten eine signifikant erhöhte Epitheldicke und eine erhöhte Dichte an Fibroblasten (Nassar et al. 2008, Pamuk et al. 2013) wie auch eine direkte Wirkung von Cyclosporin A auf Fibroblasten, indem eine gesteigerte Proliferation nachgewiesen werden konnte (Willershausen-Zönnchen et al. 1991).

Rostock et al. (1986) und McGaw und Porter (1988) konnten diese Beobachtungen nicht bestätigen und erzielten gleiche Ergebnisse wie die vorliegende Arbeit. James et al. (1995) wiederum zeigten, dass ab einer Konzentration von $10 \mathrm{~g} / \mathrm{ml}$ Cyclosporin A die Zellproliferation signifikant gehemmt wurde.

Demzufolge resultieren niedrigere Dosen in einer reduzierten Prävalenz und einem geringeren Schwergrad der oralen Nebenwirkung in Form einer Gingivawucherung, so Wentz et al. (2012). 


\section{Tacrolimus}

Ein Ergebnis der vorliegenden Studie ist, dass Tacrolimus über kein signifikantes dosisund zeitabhängiges Potential hinsichtlich einer Veränderung der Gesamt- und Lebendzellzahl im Vergleich der Konzentrationen untereinander und der einzelnen Konzentrationen zu beiden Kontrollgruppen (Negativkontrolle und Lösungsmittelkontrolle) verfügte.

Nach Analyse und Vergleich der Mediane konnte zwischen den einzelnen Gruppen zu den einzelnen Auswertungszeitpunkten kein auffälliges Muster beobachtet werden.

Gagliano et al. (2005a) zeigten nach 48 und 72 Stunden eine Abnahme der Proliferation humaner Gingivafibroblasten unter Tacrolimus-Einwirkung. Pamuk et al. (2013) behandelten im Rahmen ihrer Tierstudie Ratten 24 Wochen lang mit Tacrolimus. Die Autoren berichteten nach der Analyse der gewonnenen histologischen Proben sowohl über eine signifikante Zunahme der Epithel- und Bindegewebsdichte als auch der Höhe des Bindegewebes. Bestätigt wurden sie durch Nassar et al. (2008), die nach 180 und 240 Tagen unter Tacrolimus-Medikation ebenfalls eine signifikante Zunahme des Epithel- und Bindegewebes der behandelten Ratten beschrieben.

\section{Sirolimus}

Die vorliegende Studie zeigte ein signifikantes dosis- und zeitabhängiges Potential von Sirolimus. Dies äußerte sich in einer Veränderung der Gesamt- und Lebendzellzahl. Ein signifikanter Unterschied konnte zu den Auswertungszeitpunkten von 48 und 72 Stunden beobachtet werden. Verglichen mit der DMSO-Kontrolle (Lösungsmittelkontrolle) waren sowohl bei allen Konzentrationen (10, 15 und 20 ng/Well) hinsichtlich der Gesamt- als auch der Lebendzellzahl die Ergebnisse unter Sirolimus-Einwirkung signifikant geringer. Somit zeigte sich hier ein vermutlich antiproliferativer Effekt. Interessanterweise weist Sirolimus eine Stimulation des Zyokins transforming growth factor $\beta$ (TGF- $\beta$ ) auf (Dodge et al. 2000). TGF- $\beta$ führt die Apoptose in Fibroblasten herbei und stimuliert das Fibroblastenwachstum sowie die daraufhin folgende Produktion extrazellulärer Matrixproteine (Border und Noble 1994). Sirolimus ist in der Lage, die Proliferation von Fibroblasten dosisabhängig zu inhibieren. Bei einer Dosis von etwa $20 \mathrm{ng} / \mathrm{ml}$ Sirolimus erfolgte eine vollkommene Aufhebung der Proliferation (Dodge et al. 2000). Der wachstumsinhibierende Effekt von Sirolimus scheint untrennbar mit den Mechanismen verbunden zu sein, welche die einleitende Synthese von spezifischen Proteinen in wachstumsstimulierenden Zellen kontrolliert (Abraham und Wiederrecht 1996). Bereits andere Studien verweisen auf den hier bestätigten antiproliferativen Effekt von Sirolimus (Terada et al. 1994, Tyler et al. 2011). Das Wissen über dieses Potential fand seinen Einsatz bereits in der Onkologie und 
zeigte eine erfolgreiche Bekämpfung von Nierentumoren (Hudes et al. 2007) und rezidivierendem Brustkrebs (Chan et al. 2005).

Konzentrationsvergleich der Konzentration 15 ng/Well und Konzentrationsvergleich der mittleren Konzentrationen der Immunsuppressiva

Beide Konzentrationsvergleiche der drei verwendeten Immunsuppressiva ergaben signifikante Unterschiede. $\mathrm{Zu}$ den Auswertungszeitpunkten von 48 und 72 Stunden konnte sowohl zwischen der Gesamt- und Lebendzellzahl der Cyclosporin A- und Sirolimus-Gruppe als auch zwischen der Tacrolimus- und Sirolimus-Gruppe ein signifikanter Unterschied festgestellt werden, indem sowohl Gesamt- als auch Lebendzellzahl unter SirolimusEinwirkung deutlich niedriger waren. Der Vergleich zwischen Cycloporin A und Tacrolimus war unauffällig. Diese Ergebnisse untermauern die These, dass Sirolimus einen hemmenden Proliferationseffekt auf die verwendeten Zellen ausübt (Terada et al. 1994, Tyler et al. 2011).

\subsubsection{Zelldurchmesser}

Cyclosporin A

In der vorliegenden Studie übte Cyclosporin A hinsichtlich der Konzentrationen und Einwirkzeit lediglich einen signifikanten Effekt zum Auswertungszeitpunkt 48 Stunden zwischen der Konzentration von 150 ng/Well und der DMSO-Kontrolle auf den Zelldurchmesser aus. Unter der Einwirkung von 150 ng/Well Cyclosporin A war der Zelldurchmesser deutlich erhöht. Hier ist zu berücksichtigen, dass die Größe des Zelldurchmessers mit der Anzahl der Zellen zu korrelieren schien. Anlass zu dieser Interpretation gibt die Tatsache, dass bei der verwendeten Konzentration von 750 ng/Well jeweils in Gesamt- und Lebendzellzahl die geringste Anzahl von Fibroblasten bei den Auswertungszeitpunkten 48 und 72 Stunden beobachtet wurde, aber auch der größte Zelldurchmesser. Studien im Kontext gingivaler Wucherungen, ausgelöst durch eine Immunsuppression unter Cyclosporin A, sind mit Blick auf Veränderungen des Zelldurchmessers derzeit nicht bekannt. Lediglich Gagliano et al. (2005b) stellten keine morphologischen Veränderungen unter Einwirkung einer Konzentration von $800 \mathrm{ng} / \mathrm{ml}$ Cyclosporin A fest.

\section{Tacrolimus}

$\mathrm{Zu}$ keinem Messzeitpunkt konnte ein signifikanter Unterschied sowohl zwischen den einzelnen Konzentrationen im Vergleich zu beiden Kontrollgruppen als auch bei einem Konzentrationsvergleich untereinander festgestellt werden. Demnach übte Tacrolimus in der vorliegenden Studie hinsichtlich der Konzentrationen und Einwirkzeit keinen signifikanten 
Effekt auf den Zelldurchmesser der behandelten Zellen aus. Auffällig war jedoch, dass die höchste Konzentration von 20 ng/Well zu den Auswertungszeitpunkten von 24, 48 und 72 Stunden, verglichen mit den restlichen Gruppen, den größten Zelldurchmesser aufwies. Diese Beobachtung könnte mit der Gesamt- und Lebendzellzahl korrelieren, da die Konzentration von $20 \mathrm{ng} / \mathrm{Well} \mathrm{zu}$ den Auswertungszeitpunkten von 24 und 72 Stunden die niedrigsten Mediane zeigte. Derzeit sind keine Studien im Kontext gingivaler Wucherungen bekannt, welche den Zusammenhang zwischen Veränderungen des Zelldurchmessers und der Einnahme von Tacrolimus untersuchten. Ungeachtet des Zelldurchmessers, beschrieben Gagliano et al. (2005b) keine Veränderung in der Morphologie der humanen Fibroblasten unter Behandlung mit $1 \mu \mathrm{M}$ Tacrolimus.

\section{Sirolimus}

Sirolimus übte in der vorliegenden Arbeit keinen signifikanten dosisabhängigen Effekt auf den Zelldurchmesser der behandelten Zellen, verglichen mit den jeweiligen Kontrollen, aus. Jedoch zeigte die höchste Konzentration von $20 \mathrm{ng} / \mathrm{Well} \mathrm{zu}$ den Auswertungszeitpunkten von 48 und 72 Stunden, verglichen mit den restlichen Gruppen, den größten Zelldurchmesser. Hier ist erneut zu berücksichtigen, dass die Größe des Zelldurchmessers mit der Anzahl der Zellen korrelieren könnte, da jeweils bei der verwendeten Konzentration 20 ng/Well sowohl bei Betrachtung der Gesamt- als auch Lebendzellzahl der geringste Wert zu den Auswertungszeitpunkten von 48 und 72 Stunden beobachtet wurde, aber auch der größte Zelldurchmesser. Studien im Kontext Sirolimus-bedingter gingivaler Wucherungen, welche eine Veränderung des Zelldurchmessers untersuchen, sind derzeit nicht bekannt.

Konzentrationsvergleich der Konzentration $15 \mathrm{ng} /$ Well und Konzentrationsvergleich der mittleren Konzentrationen aller Immunsuppressiva

Die vorliegende Studie zeigte, dass beide Vergleichsauswertungen zwischen den einzelnen Immunsuppressiva hinsichtlich des Zelldurchmessers keine signifikanten Unterschiede aufwiesen. Vergleichbare Studien sind nicht existent.

\subsubsection{Prokollagen Typ I}

In der vorliegenden Studie ergaben sich sowohl bei der Analyse der einzelnen Immunsuppressiva als auch bei der Betrachtung der Konzentration 15 ng/Well und der mittleren Konzentrationen aller Immunsuppressiva keine signifikanten Unterschiede zwischen den Medikamenten und deren verwendeter Dosen. Die Daten zeigten aufgrund der hohen Standardabweichungen keine eindeutigen Ergebnisse. Nichtsdestotrotz sollte auf das subepitheliale Gewebe ein besonderes Augenmerk gelegt werden. Histologisch weisen Gingivawu- 
cherungen hier zumeist eine Zunahme auf (Dannewitz 2012). Dies äußert sich in Form einer Akkumulation von Fibroblasten und einer Zunahme von kollagenen Fasern (Mariani et al. 1993).

\section{Cyclosporin A}

Hinsichtlich der Parameter Prokollagen Typ I und Kollagen Typ I zeigten verschiedene Invitro-Studien unterschiedliche Ergebnisse für Cyclosporin A. Schincaglia et al. (1992) beschrieben eine zunehmende Produktion von Prokollagen Typ I durch gingivale Fibroblasten unter Cyclosporin A-Medikation. Ebenso beobachteten Gagliano et al. (2004) eine vermehrte Genexpression von Kollagen Typ I, welche nach Meinung der Autoren durch einen gestörten Abbau aufgrund einer reduzierten MMP-1 Aktivität zustande kommen konnte. Andere Studien zeigten wiederum keinen signifikanten Effekt (Tipton et al. 1991, Barber et al. 1992).

\section{Tacrolimus und Sirolimus}

Es gibt nur wenige Studien, die ihren Fokus auf die Wirkung von Tacrolimus und Sirolimus auf Kollagen legen. Gagliano et al. (2008) behandelten primäre humane Gingivafibroblasten mit unterschiedlichen Dosen von Tacrolimus $(8,80$ und $800 \mathrm{ng} / \mathrm{ml})$ und stellten mittels Polymerase-Chain-Reaction (PCR) keine erhöhte Genexpression von Kollagen Typ I fest.

Pamuk et al. (2013) kamen zu dem Ergebnis, dass Sirolimus keinen Effekt in Form einer Zunahme von Kollagenfibrillen hat. Hierbei handelt es sich jedoch um eine In-vivoTierstudie. Andere In-vitro-Studien, mit einer der vorliegenden Arbeit ähnlichen Fragestellung, sind derzeit nicht bekannt. Durch die Verwendung anderer Methoden wäre es eventuell möglich, noch genauere und reproduzierbare Ergebnisse zu erzielen.

Ebenso ist es denkbar, den Fokus auf anderer molekularer Ebene zu setzen. Beispielsweise steigert das Zytokin $T G F-\beta$, ein Mediator der Zellapoptose, die Genexpression von Prokollagen in Fibroblasten (Massagúe 1990, Shihab et al. 1996). TGF- $\beta$ findet sich vor allem in der interdentalen Papille (Csiszar et al. 2007), in welcher die gingivale Wucherung vornehmlich stattfindet (Hassell und Hefti 1991). Weiterführend könnten andere Zytokine und Enzyme, welche im Auf- und Abbau der extrazellulären Matrix eine Rolle spielen, miteinbezogen werden. 


\subsubsection{Interpretation der Ergebnisse im Kontext des multifaktoriellen Modells}

Die Interpretation der Ergebnisse der vorliegenden Studie lässt darauf schließen, dass die Immunsuppressiva Cyclosporin A, Tacrolimus und Sirolimus als singulär einwirkende Faktoren über kein eindeutiges Potential verfügen, die untersuchten Parameter signifikant im Hinblick auf die Ätiologie einer Gingivawucherung zu verändern. Auch ist zum jetzigen Zeitpunkt keine Studie existent die drei Immunsuppressiva in unterschiedlichen Konzentration hinsichtlich der untersuchten Parameter dieser Studie betrachtet.

Viele Studien wiesen jedoch darauf hin, dass die Entstehung eines übermäßigen Wachstums der Gingiva multifaktoriell bedingt ist (Seymour und Smith 1991, Seymour und Jacobs 1992, Somacarrera et al. 1994, Seymour et al. 1996). Hierbei sind sowohl genetische Prädispositionen (Wysocki et al. 1983), die häusliche Mundhygiene als auch gingivale Entzündungen, die Dosis und Dauer der Einnahme des Immunsuppressivums, das Alter des Patienten und die zusätzliche Komedikation mit anderen Arzneimitteln von eminenter Bedeutung (Seymour und Jacobs 1992, Somacarrera et al. 1994).

Das von Seymour und Smith (1991) beschriebene multifaktorielle Modell bietet somit die Grundlage für weitere Möglichkeiten eines neuen Studiendesigns, indem mehrere, einwirkende Faktoren berücksichtigt werden können.

\subsection{Klinische Relevanz und Ausblick}

Vasanthan und Dallal (2007) fordern eine bestmögliche Unterstützung der Risikogruppe immunsupprimierter Patienten. Allgemeinmedizinische Kenntnisse über Grunderkrankungen, Transplantation und Medikation sowie Wechselwirkungen zwischen Arzneimitteln sind für jeden behandelten Zahnarzt essentielles Wissen. Die Ergebnisse der vorliegenden Studie wiesen keinen eindeutigen Effekt der Immunsuppressiva als singulär einwirkende Faktoren auf die verwendeten Gingivafibroblasten auf. Nach wie vor zeigt sich epidemiologisch ein Auftreten von Schleimhautveränderungen unter der Medikation mit Immunsuppressiva (Cota et al. 2010, Paixão et al. 2011). Diese Prävalenz ist sehr wahrscheinlich auf das multifaktorielle Modell von Seymour und Smith (1991) zurückzuführen. Diverse unterschiedliche Faktoren und deren Zusammenwirken scheinen demnach eine gingivale Wucherung zu induzieren und zu begünstigen.

Hraský (2010) beobachtete in ihrer Querschnittsstudie mit immunkompromittierten organtransplantierten Patienten neben einem verbesserungswürdigen zahnärztlichen Sanierungsgrad ebenfalls eine verbesserungsbedürftige Mundhygiene und ein großes Interesse seitens der Patienten an einer Optimierung ihrer dentalen Zustände. Viele Patienten zeigten nach erfolgreicher Transplantation eine mangelhafte Mundhygiene und bargen damit ein deut- 
lich erhöhtes Risiko für die Entstehung kariöser Läsionen und parodontaler Erkrankungen. Eine durch Plaque induzierte gingivale Entzündung spielt eine große Rolle in der Entwicklung von Cyclosporin A induzierter Gingivawucherung, so Dannewitz et al. (2011). Hornecker (2001) beobachtete bei einem unter Cyclosporin A immunsupprimierten Patienten einen deutlichen Rückgang der Gingivawucherungen, nachdem dieser das Medikament absetzen musste und vor der erneuten Medikationseinstellung mit Cyclosporin A eine komplette zahnärztliche Sanierung erhielt. Bei kontinuierlicher Mundhygieneinstruktion, Motivation und Reinigung zeigten sich langfristig rückbildende Tendenzen der Gingivawucherungen. Jedoch sind Patienten vor und nach Transplantationen häufig nicht optimal versorgt, so Guggenheimer et al. (2005). Deshalb fordern Velich et al. (2002) einheitliche und verbindliche Richtlinien der zahnärztlichen Behandlung immunsupprimierter Patienten.

Ansatzpunkte für ein weitergehendes Studiendesign finden sich sowohl auf molekularer Ebene als auch in klinisch orientierten Studien. Bereits viele Studien suchen den Ursprung gingivaler Wucherungen auf molekularer Ebene. Dannewitz et al. (2006) zeigten den Einfluss von Molekülen der extrazellulären Matrix auf die Entstehung gingivaler Wucherungen unter Cyclosporin A Medikation. Das Gleichgewicht zwischen Synthese und Abbau der extrazellulären Matrix scheint gestört zu sein (Hyland et al. 2003). Wie bereits zuvor diskutiert, wiesen Studien auf die Beteiligung anderer Proteine, wie beispielsweise $T G F-\beta$, unter Medikation mit Cyclosporin A (Shin et al. 1998) oder Tacrolimus (Khanna et al. 1999) hin. Subramani et al. (2007) ermittelten ein erhöhtes Vorkommen des Insulin Like Growth Factor Binding Protein-5 bei Gingivawucherungen, induziert durch Cyclosporin A. Ma et al. (2014) beschrieben eine Inhibierung der epithelialen Apoptose in Epithelgewebe von Ratten durch die Einwirkung von Cyclosporin A. Die Autoren wiesen eine Erhöhung der Bcl-2 Expression und ein niedrigeres Level an Caspase-3 Expression nach. Dies könnte ein Ansatzpunkt für die Ursache von Gingivawucherungen sein. Ein ähnlich aufgebautes Studiendesign über einen Vergleich der drei Immunsuppressiva Cyclosporin A, Tacrolimus und Sirolimus auf molekularer Ebene könnte hier mehr Aufschluss geben.

Aktuelle klinische Studien bieten ebenfalls neue Ansätze. Untersuchungen von Speichelproben immunsupprimierter Patienten unter Medikation mit Cyclosporin A, Tacrolimus oder Sirolimus zeigten eine erhöhte Menge an Tannerella forsythia, so Cota et al. (2010). Die pathogenen Bakterien des roten Komplexes koexistieren als Konsortium in tieferen parodontalen Taschen (Socransky et al. 1999). Als Folge der gingivalen Wucherungen entstehen durch ein Anschwellen der Gingiva Pseudotaschen, in denen sich zunehmend Plaque ablagert, wobei die Möglichkeit einer Reservoirbildung für Cyclosporin A besteht 
(Niimi et al. 1990). Die Entfernung harter und weicher supra- und vor allem subgingivaler Beläge ist daher unabdingbar (Aimetti et al. 2005, Lemkamp und Schlagenhauf 2008).

\subsection{Schlussfolgerung}

Die Resultate dieser Untersuchung zeigten, dass Cyclosporin A und Tacrolimus über kein eindeutiges Potential verfügten, eine Veränderung der verwendeten gingivalen Mäusefibroblasten herbeizuführen. Die untersuchten Parameter veränderten sich nicht dahingehend, das klinische Bild einer Gingivawucherung begründen zu können. Lediglich unter Sirolimus-Einwirkung zeigten sich signifikante Veränderungen der Parameter Gesamt- und Lebendzellzahl. Diese Veränderungen können jedoch nicht hinsichtlich der Ätiologie einer Gingivawucherung interpretiert werden. Ganz im Gegenteil wird hier eher der hemmende Proliferationseffekt von Sirolimus bestätigt. Nach dem multifaktoriellen Modell von Seymour und Smiths (1991) müssen mehrere unterschiedliche Faktoren auf gingivale Firboblasten einwirken, um eine Gingivawucherung zu induzieren. Zukünftig gilt es jedoch herauszufinden, welche Faktoren schwerwiegend auf die Prävalenz eines übermäßigen Wachstums der Gingiva einwirken, um immunkompromittierte Patienten vor möglichen Gingivawucherungen und den daraus resultierenden Folgen bewahren zu können. 


\section{$7 \quad$ Zusammenfassung}

Das Ziel der vorliegenden Studie war es, Wirkung und Potential dreier gängiger Immunsuppressiva als singulär einwirkende Faktoren in unterschiedlichen Konzentrationen und Einwirkzeiten auf Fibroblasten zu untersuchen. Dabei sollten mögliche Unterschiede der drei Immunsuppressiva in einem direkten Vergleich untereinander deutlich herausgestellt werden.

Grundlage der vorliegenden Studie war eine adhärent wachsende immortalisierte Standdardfibroblastenlinie von 3T3-Zellen, gewonnen aus der Gingiva von embryonalen Mäusen. Als Immunsuppressiva wurden Cyclosporin A, Tacrolimus und Sirolimus in drei verschiedenen Konzentrationen betrachtet. Tacrolimus und Sirolimus wurden jeweils in den Konzentrationen von 10, 15 und 20 ng/Well verwendet, Cyclosporin A in den Konzentrationen von 15, 150 und 750 ng/Well. Zum einen wurden die Konzentrationen innerhalb eines Immunsuppressivums verglichen. Zum anderen wurden Konzentrationen aller Immunsuppressiva im direkten Vergleich miteinander betrachtet.

Gesamt- und Lebendzellzahl, Zelldurchmesser und Menge an Prokollagen Typ I bildeten die dabei zu untersuchenden Parameter. Sowohl Gesamt- und Lebendzellzahl als auch der Zelldurchmesser wurden mithilfe eines Zellzählgerätes (CASY® Cell Counter, Modell TT, Roche Diagnostics GmbH, Roche Applied Science, Penzberg, Deutschland) untersucht. Zur Analyse der Menge an Prokollagen Typ I wurde ein Enzyme Linked Immunosorbent Assay (Mouse Procollagen Type I C-Terminal Propeptide, BlueGene Biotech Co., Shanghai, China) ausgewählt.

Die statistische Auswertung der Parameter Gesamt- und Lebendzellzahl der einzelnen Immunsuppressiva zeigte unter Einwirkung von Cyclosporin A und Tacrolimus im Vergleich der einzelnen Konzentrationen eines Immunsuppressivums sowohl untereinander als auch im Vergleich zu beiden Kontrollgruppen keine signifikanten Unterschiede $(p>0,05)$. Bei Sirolimus hingegen unterschieden sich alle Konzentrationsgruppen zu den Auswertungszeitpunkten von 48 und 72 Stunden signifikant von der Lösungsmittelkontrolle (DMSOKontrolle; $\mathrm{p}<0,05)$.

Bei dem Konzentrationsvergleich der Konzentration 15 ng/Well und dem der mittleren Konzentration der Immunsuppressiva konnte sowohl zwischen der Cyclosporin A- und Sirolimusgruppe als auch zwischen der Tacrolimus- und Sirolimusgruppe ein signifikanter Unterschied zu den Auswertungszeitpunkten von 48 und 72 Stunden beobachtet werden $(\mathrm{p}<0,05)$. Cyclosporin A und Tacrolimus wiesen in beiden Vergleichsauswertungen $z u$ keinem Auswertungszeitpunkt einen signifikanten Unterschied auf $(p>0,05)$. 
Die statistische Auswertung der Parameter Zelldurchmesser und der Menge an Prokollagen Typ I ergaben bei Cyclosporin A, Tacrolimus und Sirolimus im Vergleich der einzelnen Konzentrationen eines Immunsuppressivas untereinander als auch im Vergleich zu beiden Kontrollgruppen keinen signifikanten Effekt $(p>0,05)$. Gleiches zeigte sich auch bei beiden Vergleichssauswertungen der Immunsuppressiva, wobei jeweils die Konzentration $15 \mathrm{ng} /$ Well als auch die mittlere Dosis aller verwendeten Immunsuppressiva untereinander verglichen wurden. Lediglich zum Auswertungszeitpunkt von 48 Stunden fiel ein signifikanter Unterscheid zwischen der Konzentration von $150 \mathrm{ng} / \mathrm{Well}$ Cyclosporin A und der DMSO-Kontrolle (Lösungsmittelkontrolle) $(\mathrm{p}=0$,0347) bei Betrachtung des mittleren Zelldurchmessers auf.

Zusammenfassend ist zu sagen, dass die Resultate der vorliegenden Untersuchung die zuvor formulierte Hypothese nicht unterstützen. Ein möglicher Rückschluss ist, dass mehrere unterschiedliche Faktoren auf gingivale Fibroblasten einwirken müssen, um Veränderungen der Fibroblasten zu bewirken und das klinische Bild einer Gingivawucherung zu induzieren. Dies entspricht der These des multifaktoriellen Modells, welches Seymour und Smith (1991) postulierten. Zukünftige Forschung sollte sich zum Ziel setzen, den Einfluss der einzelnen Faktoren auf Gingivafibroblasten besser zu verstehen, um immunkompromittierte Patienten vor möglichen Gingivawucherungen mit den daraus resultierenden Folgen bewahren zu können. 


\begin{abstract}
Due to the decreasing number of organ transplants, their tolerability gains greater significance for affected patients. Therefore, these patients are permanently depended on taking immunosuppressive drugs, which have numerous side effects. One of those side effects most commonly encountered in dental treatment, is gingival enlargement.

In this study, we thus analysed the effect of three prevalent immunosuppressants (cyclosporine, tacrolimus and sirolimus) as singular factors on fibroblasts representing the dominant celltype in the gingiva. In order to evaluate the potential of these immunosuppressants, embryonic gingival mice were treated in different concentrations of cyclosporine, tacrolimus and sirolimus. In addition, exposure times were altered and two control groups were applied. In the first step of the present study design, the different concentrations within one immunosuppressant were compared to each other and to the control groups. In a second step, the three immunosuppressants were compared to each other with regard to selected concentrations.

In detail, we tested the effect of the immunosuppressants on the number of cells and the viability, the cell diameter and the amount of procollagen type I. Number of cells, viability and cell diameter were explored using the cell counter CASY® Modell TT (Roche Diagnostics GmbH, Roche Applied Science, Penzberg, Deutschland). Procollagen-typeI was determined using an ELISA (Mouse Procollage Type I C-Terminal Propeptide, BlueGene Biotech Co, Shanghai, China).
\end{abstract}

Our results show that sirolimus has a significant negative effect on the number of cells and the viability after an exposure time of 48 and 72 hours $(p<0,05)$. For cyclosporine and tacrolimus our data indicate no effect on the number of cells and their viability ( $p>$ $0,05)$.

The comparison between the three immunosuppressants with regard to selected concentrations revealed a significant difference between the sirolimus group and the two other immunosuppressants after an exposure time of 48 und 72 hours $(p<0,05)$. The number of cells and the viability of sirolimus treated cells were both significantly lower as compared to the other two immunosuppressants. Comparing cyclosporine treated cells with tacrolimus treated ones, no significant difference was found for both parameters $(\mathrm{p}>0,05)$.

The statistical analysis of the cell diameter and procollagen type I rarely showed significant effects. Neither the comparison of different concentrations within one immunosuppressant, nor contrasting the three immunosuppressants for selected concentrations indicated any statistically significant effect. Only the cells treated with $150 \mathrm{ng} / \mathrm{Well}$ cyc- 
losporine showed a significant increase in cell diameter compared with one control group (DMSO-control) after an exposure time of 48 hours $(\mathrm{p}=0,0347)$.

Overall, the results do not support the hypothesis assuming a positive effect of the tested immunosuppressants on the number of cells, the viability, the cell diameter and the amount of procollagen type I. In the present study design the immunosuppressants do not show the potential to change embryonic gingival mice fibroblasts leading to the clinical picture of gingival enlargement as singular factors. This may indicate that several different factors are needed to induce gingival enlargement as reflected in the multifactorial model of Seymour and Smith (1991). As a conclusion, future studies should contribute to a better understanding of singular influencing factors on gingival fibroblasts in order to prevent immunocompromised patients from drug-induced gingival enlargement and the resulting consequences for their dental treatment. 
Anhang

\subsection{Materiallisten}

Tabelle 24: Angabe der verwendeten Materialien bei Durchführung der Zellkultur

\begin{tabular}{|c|c|}
\hline 3T3 Zellen (immortalisierte Zelllinie) & $\begin{array}{l}\text { Prof. Dr. W.H. Zimmermann, Leiter des Instituts } \\
\text { für Pharmakologie der Universitätsmedizin Göt- } \\
\text { tingen, } \\
\text { eingefroren in Dimethylsulfoxid (DMSO), Passa- } \\
\text { ge: } 34\end{array}$ \\
\hline $\begin{array}{l}\text { DMEM + GlutamMAX-I 1g/L D- Glukose, } \\
\text { 500ml }\end{array}$ & $\begin{array}{l}\text { Gibco by life science, Invitrogen, Carlsbad, USA } \\
\text { Bestellnummer: } 31966-047\end{array}$ \\
\hline Pen./Strep., flüssig, $100 \mathrm{ml}$ & $\begin{array}{l}\text { Gibco by life science, Invitrogen, Carlsbad, USA } \\
\text { Bestellnummer: } 15140-122\end{array}$ \\
\hline Amphotericin B, $250 \mu \mathrm{l} / \mathrm{ml}$ & $\begin{array}{l}\text { PAN Biotech GmbH, Aidenbach, Deutschland } \\
\text { Cat.Nr.: P06-01100 }\end{array}$ \\
\hline $\begin{array}{l}\text { Dulbecco's PBS ohne Calcium \& Magnesium, } \\
500 \mathrm{ml}\end{array}$ & $\begin{array}{l}\text { PAA, Pasching,Österreich } \\
\text { Cat.Nr.: H15-002 }\end{array}$ \\
\hline Trypsin- EDTA, flüssig & $\begin{array}{l}\text { Gibco by life science, Invitrogen, Carlsbad, USA } \\
\text { Bestellnummer: } 25-300-054\end{array}$ \\
\hline T25 Zellkulturflaschen & $\begin{array}{l}\text { Greiner Bio-One, Frickenhausen, Deutschland } \\
\text { Prod/Cat.Nr: } 690175\end{array}$ \\
\hline T75 Zellkulturflaschen & $\begin{array}{l}\text { Greiner Bio-One, Frickenhausen, Deutschland } \\
\text { Cat.Nr.: } 658175\end{array}$ \\
\hline 24 Multiwell Plate Flat Bottom & $\begin{array}{l}\text { Becton \& Dickinson, Heidelberg, Deutschland } \\
\text { Cat.Nr.: } 353226\end{array}$ \\
\hline BD Falcon ${ }^{\mathrm{TM}}$ Röhrchen $15 \mathrm{ml}$ & $\begin{array}{l}\text { Greiner Bio-One, Frickenhausen, Deutschland } \\
\text { Cat.Nr.: } 227285\end{array}$ \\
\hline BD Falcon ${ }^{\mathrm{TM}}$ Röhrchen $50 \mathrm{ml}$ & $\begin{array}{l}\text { Greiner Bio-One, Frickenhausen, Deutschland } \\
\text { Cat.Nr.: } 188161\end{array}$ \\
\hline Nunc $^{\mathrm{TM}}$ CyroTubes ${ }^{\mathrm{TM}}$ Vials & Nunc $^{\text {TM }}$, Roskilde, Dänemark \\
\hline Dimethylsulfoxid (DMSO) & Merck, Darmstadt, Deutschland \\
\hline
\end{tabular}

Tabelle 25: Angabe der verwendeten Materialien im Bezug auf das Zellzählgerät CASY®

\begin{tabular}{|l|l|}
\hline \multirow{2}{*}{ CASYTon ${ }^{\circledR}$} & $\begin{array}{l}\text { Roche Diagnostics GmbH, Roche Applied Science, } \\
\text { Mannheim, Deutschland } \\
\text { Cat.Nr.: 43002 }\end{array}$ \\
\hline \multirow{3}{*}{ CASYTubes ${ }^{\circledR}$} & $\begin{array}{l}\text { Roche Diagnostics GmbH, Roche Applied Science, } \\
\text { Mannheim, Deutschland } \\
\text { Cat.Nr.:05651794001 }\end{array}$ \\
\hline
\end{tabular}

Tabelle 26: Angabe der verwendeten Immunsuppressiva

\begin{tabular}{|l|l|}
\hline \multirow{2}{*}{ Cyclosporin A (100mg) } & $\begin{array}{l}\text { Merck Chemicals, Millipore } \\
\text { Darmstadt, Deutschland } \\
\text { Bestellnummer/ CAS Nr.: 239835-100mg / 59865-13-3 }\end{array}$ \\
\hline \multirow{3}{*}{ Tacrolimus (5mg) } & $\begin{array}{l}\text { Merck Chemicals, Millipore } \\
\text { Darmstadt, Deutschland } \\
\text { Bestellnummer/ CAS Nr.: 342500- 5mg/ 104987-11-3 }\end{array}$ \\
\hline \multirow{3}{*}{ Sirolimus (5mM) } & $\begin{array}{l}\text { Merck Chemicals, Millipore } \\
\text { Darmstadt, Deutschland } \\
\end{array}$ \\
& Bestellnummer/ CAS Nr.: 553211-500 UG/ 53123-88-9 \\
\hline
\end{tabular}


Tabelle 27: Angabe der verwendeten Methoden

\begin{tabular}{|l|l|}
\hline CASY® Cell Counter, Modell TT & $\begin{array}{l}\text { Roche Diagnostics GmbH, Roche Ap- } \\
\text { plied Science, Penzberg, Deutschland }\end{array}$ \\
\hline Cell Titer ${ }^{\circledR}-$ Blue Cell Viability Assay & $\begin{array}{l}\text { Promega, Madison, USA } \\
\text { LOT: 0000050648 }\end{array}$ \\
\hline $\begin{array}{l}\text { Mouse Procollagen Type I C-Terminal } \\
\text { Propeptide (PICP), ELISA Kit }\end{array}$ & $\begin{array}{l}\text { BlueGene Biotech Co., Ltd, Shanghai, } \\
\text { China } \\
\text { Bestellnummer: E03P0015 }\end{array}$ \\
\hline Axiovert 35 Mikroskop & Zeiss, Göttingen, Deutschland \\
\hline Axiovert 200M Mikroskop & Zeiss, Göttingen, Deutschland \\
\hline SpektraMax M2 Photometer & $\begin{array}{l}\text { Molecular Devices, Biberach an der Riss, } \\
\text { Deutschland }\end{array}$ \\
\hline
\end{tabular}

\subsection{Ergebnisse}

\subsubsection{Ergebnisse: Gesamt- und Lebendzellzahl}

Im Folgenden werden die Mediane der Gesamt- und Lebendzellzahl in grafischer Form, aufgeteilt nach den einzelnen Immunsuppresiva, dargelegt. Anschließend folgen die beiden Vergleichsauswertungen.

\section{Cyclosporin A}

Tabelle 28 gibt die Mediane der Gesamt- (GZ) und Lebendzellzahl (LZ), aufgeteilt nach Einwirkzeit und Konzentration, wieder.

Tabelle 28: Mediane der Gesamt- und Lebendzellzahl (x 104): Behandlung mit CSA

\begin{tabular}{|c|c|c|c|c|c|c|c|c|c|c|}
\hline \multirow{4}{*}{$\begin{array}{l}\text { CSA- } \\
\text { Konzentration }\end{array}$} & \multicolumn{10}{|c|}{ Einwirkzeit } \\
\hline & \multicolumn{2}{|c|}{0 Stunden } & \multicolumn{2}{|c|}{6 Stunden } & \multicolumn{2}{|c|}{24 Stunden } & \multicolumn{2}{|c|}{48 Stunden } & \multicolumn{2}{|c|}{72 Stunden } \\
\hline & $\mathrm{GZ}$ & LZ & $\mathrm{GZ}$ & LZ & GZ & LZ & $\mathrm{GZ}$ & LZ & & LZ \\
\hline & 12,9 & 11,6 & 12,5 & 10,6 & 23,3 & 20,9 & 45,5 & 43,1 & 67,7 & 63,6 \\
\hline DMSO Kontrolle & 12,9 & 11,6 & 12,4 & 11,1 & 23,1 & 21,3 & 42,7 & 41,0 & 61,4 & 58,4 \\
\hline $15 \mathrm{ng} /$ Well & 12,9 & 11,6 & 13,6 & 12,3 & 23,0 & 21,6 & 54,7 & 49,6 & 77,0 & 74,2 \\
\hline 150ng/Well & 12,9 & 11,6 & 13,7 & 12,6 & 27,7 & 25,9 & 46,5 & 43,9 & 69,0 & 63,9 \\
\hline 750ng/Well & 12,9 & 11,6 & 12,8 & 10,6 & 22,6 & 20,3 & 33,4 & 31,8 & 46,0 & 43,9 \\
\hline
\end{tabular}

\section{Tacrolimus}

Die Mediane der Gesamt- (GZ) und Lebendzellzahl (LZ) werden, aufgeteilt nach Einwirkzeit und Konzentration, werden in Tabelle 29 wiedergegeben. 
Tabelle 29: Mediane der Gesamt- und Lebendzellzahl (x 104): Behandlung mit TCR

\begin{tabular}{|c|c|c|c|c|c|c|c|c|c|c|}
\hline \multirow{4}{*}{$\begin{array}{l}\text { TCR- } \\
\text { Konzentration }\end{array}$} & \multicolumn{10}{|c|}{ Einwirkzeit } \\
\hline & \multirow{2}{*}{\multicolumn{2}{|c|}{$\begin{array}{l}0 \text { Stunden } \\
\text { GZ LZ }\end{array}$}} & \multirow{2}{*}{\multicolumn{2}{|c|}{$\begin{array}{l}\text { 6 Stunden } \\
\text { GZ LZ }\end{array}$}} & \multirow{2}{*}{\multicolumn{2}{|c|}{$\begin{array}{l}\text { 24 Stunden } \\
\text { GZ LZ }\end{array}$}} & \multirow{2}{*}{\multicolumn{2}{|c|}{$\begin{array}{l}\text { 48 Stunden } \\
\text { GZ LZ }\end{array}$}} & \multirow{2}{*}{\multicolumn{2}{|c|}{$\begin{array}{l}\text { 72 Stunden } \\
\text { GZ LZ }\end{array}$}} \\
\hline & & & & & & & & & & \\
\hline & 10,8 & 9,5 & 12,7 & 11,4 & 26,3 & 22,0 & 43,0 & 40,9 & 72,8 & 67,8 \\
\hline DMSO Kontrolle & 10,8 & 9,5 & 12,4 & 10,2 & 22,4 & 21,0 & 44,8 & 42,0 & 76,4 & 71,5 \\
\hline 10ng/Well & 10,8 & 9,5 & 11,7 & 10,1 & 26,3 & 24,3 & 49,1 & 46,6 & 84,5 & 78,6 \\
\hline 15ng/Well & 10,8 & 9,5 & 12,5 & 11,6 & 24,7 & 23,9 & 48,2 & 45,7 & 87,9 & 81,8 \\
\hline 20ng/Well & 10,8 & 9,5 & 12,4 & 11,0 & 20,8 & 19,6 & 45,2 & 43,2 & 69,0 & 65,0 \\
\hline
\end{tabular}

\section{Sirolimus}

Tabelle 30 gibt die Mediane der Gesamt- und Lebendzellzahl, aufgeteilt nach Einwirkzeit und Konzentration, wieder.

Tabelle 30: Mediane der Gesamt- und Lebendzellzahl (x 10 $\left.{ }^{4}\right)$ : Behandlung mit SIR

\begin{tabular}{|c|c|c|c|c|c|c|c|c|c|c|}
\hline \multirow{4}{*}{$\begin{array}{l}\text { SIR- } \\
\text { Konzentration } \\
\text { Kontrolle }\end{array}$} & \multicolumn{10}{|c|}{ Einwirkzeit } \\
\hline & \multirow{2}{*}{\multicolumn{2}{|c|}{$\begin{array}{l}\text { 0 Stunden } \\
\mathrm{GZ} \quad \mathrm{LZ}\end{array}$}} & \multirow{2}{*}{\multicolumn{2}{|c|}{$\begin{array}{l}\text { 6 Stunden } \\
\text { GZ LZ }\end{array}$}} & \multirow{2}{*}{\multicolumn{2}{|c|}{$\begin{array}{l}\text { 24 Stunden } \\
\text { GZ LZ }\end{array}$}} & \multirow{2}{*}{\multicolumn{2}{|c|}{$\begin{array}{l}\text { 48 Stunden } \\
\mathrm{GZ} \quad \mathrm{LZ}\end{array}$}} & \multirow{2}{*}{\multicolumn{2}{|c|}{$\begin{array}{l}\text { 72 Stunden } \\
\mathrm{GZ} \quad \mathrm{LZ}\end{array}$}} \\
\hline & & & & & & & & & & \\
\hline & 11,1 & 9,8 & 12,6 & 11,3 & 24,3 & 22,8 & 47,1 & 44,8 & 77,8 & 73,4 \\
\hline DMSO Kontrolle & 11,1 & 9,8 & 14,1 & 12,7 & 26,0 & 23,7 & 51,3 & 47,4 & 92,8 & 86,3 \\
\hline 10ng/Well & 11,1 & 9,8 & 14,3 & 12,9 & 22,9 & 21,4 & 37,0 & 34,2 & 37,0 & 34,1 \\
\hline 15ng/Well & 11,1 & 9,8 & 15,6 & 14,5 & 21,9 & 19,8 & 30,9 & 28,9 & 38,4 & 35,3 \\
\hline 20ng/Well & 11,1 & 9,8 & 13,3 & 12,2 & 21,4 & 19,8 & 26,9 & 25,2 & 36,3 & 31,3 \\
\hline
\end{tabular}

\section{Konzentrationsvergleich der Konzentration von $15 \mathrm{ng} /$ Well der Immunsuppressiva}

Tabelle 31 gibt die Mediane, aufgeteilt nach Einwirkzeit und Konzentration der Gesamtzellzahl- (GZ) und Lebendzellzahlmessung (LZ) wieder.

Tabelle 31: Mediane der Gesamt- und Lebendzellzahl (x 104): Behandlung mit $15 \mathrm{ng} /$ Well CSA, TCR und SIR

\begin{tabular}{|c|c|c|c|c|c|c|c|c|c|c|}
\hline \multirow{4}{*}{$\begin{array}{l}\text { Medikament } \\
\text { Cyclosporin A }\end{array}$} & \multicolumn{10}{|c|}{ Einwirkzeit } \\
\hline & \multicolumn{2}{|c|}{0 Stunden } & \multicolumn{2}{|c|}{6 Stunden } & \multicolumn{2}{|c|}{24 Stunden } & \multicolumn{2}{|c|}{48 Stunden } & \multicolumn{2}{|c|}{72 Stunden } \\
\hline & GZ & $\mathrm{LZ}$ & GZ & $\mathrm{LZ}$ & GZ & $\mathrm{LZ}$ & $\mathrm{GZ}$ & $\mathrm{LZ}$ & GZ & $\mathrm{LZ}$ \\
\hline & 12,9 & 11,6 & 13,6 & 12,3 & 23,0 & 21,6 & 54,7 & 49,6 & 77,0 & 74,2 \\
\hline Tacrolimus & 10,8 & 9,5 & 12,5 & 11,6 & 24,7 & 23,9 & 48,2 & 45,7 & 87,9 & 81,8 \\
\hline Sirolimus & 11,1 & 9,8 & 15,6 & 14,5 & 21,9 & 19,8 & 30,9 & 28,9 & 38,4 & 35,3 \\
\hline
\end{tabular}


Konzentrationsvergleich der mittleren Konzentration der Immunsuppressiva

Die Mediane, aufgeteilt nach Einwirkzeit und Konzentration, der Auswertung der Gesamtzellzahl- (GZ) und Lebendzellzahlmessung (LZ) sind in Tabelle 32 aufgeführt.

Tabelle 32: Mediane der Gesamt- und Lebendzellzahl (x 10 $0^{4}$ ): Behandlung mit der mittleren Konzentration von CSA, TCR und SIR

\begin{tabular}{|c|c|c|c|c|c|c|c|c|c|c|}
\hline \multirow[b]{3}{*}{ Medikament } & \multicolumn{10}{|c|}{ Einwirkzeit } \\
\hline & \multirow{2}{*}{\multicolumn{2}{|c|}{$\begin{array}{l}0 \text { Stunden } \\
\text { GZ LZ }\end{array}$}} & \multicolumn{2}{|c|}{6 Stunden } & \multicolumn{2}{|c|}{24 Stunden } & \multicolumn{2}{|c|}{48 Stunden } & \multicolumn{2}{|c|}{72 Stunden } \\
\hline & & & GZ & LZ & GZ & $\mathrm{LZ}$ & & LZ & GZ & $\mathrm{LZ}$ \\
\hline Cyclosporin A & 12,9 & 11,6 & 13,7 & 12,6 & 27,7 & 25,9 & 46,5 & 43,9 & 69,0 & 68,7 \\
\hline Tacrolimus & 10,8 & 9,5 & 12,5 & 11,6 & 24,7 & 23,9 & 48,2 & 45,7 & 87,9 & 81,8 \\
\hline Sirolimus & 11,1 & 9,8 & 15,6 & 14,5 & 21,9 & 19,8 & 30,9 & 28,9 & 38,4 & 35,3 \\
\hline
\end{tabular}

\subsubsection{Ergebnisse: Zelldurchmesser}

Im Folgenden werden die Mediane des Zelldurchmessers in grafischer Form, aufgeteilt nach den einzelnen Immunsuppresiva, dargelegt. Anschließend folgen die beiden Vergleichsauswertungen. Die Angabe des Zelldurchmessers erfolgt in der Maßeinheit $\mu m$.

\section{Cyclosporin A}

Tabelle 33 gibt die Mediane des Zelldurchmessers, aufgeteilt nach Einwirkzeit und Konzentration, wieder.

Tabelle 33: Mediane des Zelldurchmessers $(\mu \mathrm{m})$ : Behandlung mit CSA

\begin{tabular}{|l|c|c|c|c|c|}
\hline $\begin{array}{l}\text { CSA- } \\
\text { Konzentration }\end{array}$ & E Stunden & 6 Stunden & 24 Stunden & 48 Stunden & 72 Stunden \\
\hline Kontrolle & 17,4 & 16,7 & 17,2 & 16,5 & 16,2 \\
\hline DMSO Kontrolle & 17,4 & 16,3 & 17,6 & 17,0 & 16,3 \\
\hline $15 \mathrm{ng} /$ Well & 17,4 & 16,7 & 17,4 & 16,3 & 16,0 \\
\hline $150 \mathrm{ng} /$ Well & 17,4 & 16,9 & 17,7 & 16,7 & 16,2 \\
\hline $750 \mathrm{ng} /$ Well & 17,4 & 16,9 & 17,7 & 17,2 & 16,9 \\
\hline
\end{tabular}

\section{Tacrolimus}

Die Mediane der Messung des Zelldurchmessers, aufgeteilt nach Einwirkzeit und Konzentration, sind in Tabelle 34 aufgeführt.

Tabelle 34: Mediane des Zelldurchmessers $(\mu \mathrm{m})$ : Behandlung mit TCR

\begin{tabular}{|l|c|c|c|c|c|}
\hline $\begin{array}{l}\text { TCR- } \\
\text { Konzentration }\end{array}$ & 0 Stunden & 6 Stunden & 24 Stunden & 48 Stunden & 72 Stunden \\
\hline Kontrolle & 17,5 & 16,4 & 17,4 & 16,3 & 16,0 \\
\hline DMSO Kontrolle & 17,5 & 16,5 & 17,6 & 16,4 & 16,2 \\
\hline $10 \mathrm{ng} /$ Well & 17,5 & 16,7 & 17,7 & 16,4 & 16,0 \\
\hline $15 \mathrm{ng} /$ Well & 17,5 & 17,0 & 17,8 & 16,4 & 16,0 \\
\hline $20 \mathrm{ng} /$ Well & 17,5 & 16,9 & 17,9 & 16,6 & 16,2 \\
\hline
\end{tabular}




\section{Sirolimus}

Tabelle 35 gibt die Mediane, aufgeteilt nach Einwirkzeit und Konzentration von Sirolimus, der Messung des Zelldurchmessers wieder.

Tabelle 35: Mediane des Zelldurchmessers $(\mu \mathrm{m})$ : Behandlung mit SIR

\begin{tabular}{|l|c|c|c|c|c|}
\hline & \multicolumn{5}{|c|}{ Einwirkzeit } \\
Konzentration & 0 Stunden & 6 Stunden & 24 Stunden & 48 Stunden & 72 Stunden \\
\hline Kontrolle & 17,6 & 16,7 & 17,2 & 16,4 & 15,8 \\
\hline DMSO Kontrolle & 17,6 & 16,8 & 17,6 & 16,6 & 15,8 \\
\hline $10 \mathrm{ng} /$ Well & 17,6 & 16,9 & 17,2 & 16,3 & 16,1 \\
\hline 15ng/Well & 17,6 & 17,3 & 17,2 & 16,5 & 16,3 \\
\hline 20ng/Well & 17,6 & 16,8 & 17,2 & 16,7 & 16,5 \\
\hline
\end{tabular}

\section{Konzentrationsvergleich der Konzentration $15 \mathrm{ng} /$ Well der Immunsuppressiva}

In Tabelle 36 sind die Mediane des Zelldurchmessers, aufgeteilt nach Einwirkzeit und Konzentration, angegeben.

Tabelle 36: Mediane des Zelldurchmessers $(\mu \mathrm{m})$ : Konzentrationsvergleich der $15 \mathrm{ng} /$ Well aller Immunsuppressiva

\begin{tabular}{|l|c|c|c|c|c|}
\hline & \multicolumn{5}{|c|}{ Einwirkzeit } \\
Medikament & 0 Stunden & 6 Stunden & 24 Stunden & 48 Stunden & 72 Stunden \\
\hline Cyclosporin A & 17,4 & 16,7 & 17,4 & 16,5 & 16,0 \\
\hline Tacrolimus & 17,5 & 17,0 & 17,6 & 16,6 & 16,0 \\
\hline Sirolimus & 17,6 & 17,3 & 17,2 & 16,5 & 16,3 \\
\hline
\end{tabular}

\section{Konzentrationsvergleich der mittleren Konzentration der Immunsuppressiva}

In Tabelle 37 sind die Mediane des Vergleiches der mittleren Konzentration aller Immunsuppressiva hinsichtlich des Zelldurchmessers, aufgeteilt nach Einwirkzeit und Konzentration, aufgeführt.

Tabelle 37: Mediane des Zelldurchmessers $(\mu \mathrm{m})$ : Konzentrationsvergleich der mittleren Konzentration der Immunsuppressiva

\begin{tabular}{|l|c|c|c|c|c|}
\hline & \multicolumn{5}{|c|}{ Einwirkzeit } \\
Medikament & 0 Stunden & 6 Stunden & 24 Stunden & 48 Stunden & 72 Stunden \\
\hline Cyclosporin A & 17,4 & 16,9 & 17,7 & 16,7 & 16,2 \\
\hline Tacrolimus & 17,5 & 17,0 & 17,6 & 16,4 & 16,0 \\
\hline Sirolimus & 17,6 & 17,3 & 17,2 & 16,5 & 16,3 \\
\hline
\end{tabular}




\subsubsection{Ergebnisse: Prokollagen Typ I}

Im Folgenden werden die Mediane der gemessenen Menge an Prokollagen Typ I in grafischer Form, aufgeteilt nach den einzelnen Immunsuppresiva, dargelegt. Anschließend folgen die beiden Vergleichsauswertungen. Die Angabe der Menge erfolgt in der Maßeinheit $n g / m l$.

\section{Cyclosporin A}

Tabelle 38 gibt die Mediane des gebildeten Prokollagens, aufgeteilt nach Einwirkzeit und Konzentration, wieder.

Tabelle 38: Mediane der Menge an Prokollagen Typ I (ng/ml): Behandlung mit CSA

\begin{tabular}{|l|c|c|c|}
\hline & \multicolumn{3}{|c|}{ Einwirkzeit } \\
Konzentration & 0 Stunden & 6 Stunden & 48 Stunden \\
\hline DMSO-Kontrolle & 2,6 & 2,7 & 3,2 \\
\hline $15 \mathrm{ng} /$ Well & 2,6 & 3,2 & 4,3 \\
\hline $150 \mathrm{ng} /$ Well & 2,6 & 4,1 & 5,0 \\
\hline $750 \mathrm{ng} /$ Well & 2,6 & 3,6 & 4,5 \\
\hline
\end{tabular}

\section{Tacrolimus}

Tabelle 39 stellt die Mediane des gebildeten Prokollagen Typ I, aufgeteilt nach Einwirkzeit und Konzentration, dar.

Tabelle 39: Mediane der Menge an Prokollagen Typ I (ng/ml): Behandlung mit TCR

\begin{tabular}{|l|c|c|c|}
\hline & \multicolumn{3}{|c|}{ Einwirkzeit } \\
Konzentration & 0 Stunden & 6 Stunden & 48 Stunden \\
\hline DMSO-Kontrolle & 2,6 & 2,7 & 3,2 \\
\hline 10ng/Well & 2,6 & 3,9 & 2,4 \\
\hline 15ng/Well & 2,6 & 3,0 & 3,1 \\
\hline $20 \mathrm{ng} / \mathrm{Well}$ & 2,6 & 3,3 & 4,6 \\
\hline
\end{tabular}

\section{Sirolimus}

Die Mediane des gebildeten Prokollagen Typ I, aufgeteilt nach Einwirkzeit und Konzentration, sind in Tabelle 40 aufgeführt.

Tabelle 40: Mediane der Menge an Prokollagen Typ I (ng/ml): Behandlung mit SIR

\begin{tabular}{|l|c|c|c|}
\hline & \multicolumn{3}{|c|}{ Einwirkzeit } \\
Konzentration & 0 Stunden & 6 Stunden & 48 Stunden \\
\hline DMSO Kontrolle & 2,6 & 2,7 & 3,2 \\
\hline $10 \mathrm{ng} /$ Well & 2,6 & 3,6 & 4,4 \\
\hline $15 \mathrm{ng} /$ Well & 2,6 & 3,0 & 2,5 \\
\hline $20 \mathrm{ng} /$ Well & 2,6 & 2,8 & 4,9 \\
\hline
\end{tabular}


Konzentrationsvergleich der Konzentration $15 \mathrm{ng} /$ Well der Immunsuppressiva

In Tabelle 41 sind die Mediane der Menge an Prokollagen Typ I, aufgeteilt nach Einwirkzeit und Konzentration, angegeben.

Tabelle 41: Mediane der Prokollagen Typ I Menge (ng/ml): Konzentrationsvergleich $15 \mathrm{ng} /$ Well der Immunsuppressiva

\begin{tabular}{|l|c|c|c|}
\hline & \multicolumn{3}{|c|}{ Einwirkzeit } \\
Medikament & 0 Stunden & 6 Stunden & 48 Stunden \\
\hline Cyclosporin A & 2,6 & 3,2 & 4,3 \\
\hline Tacrolimus & 2,6 & 3,0 & 3,1 \\
\hline Sirolimus & 2,6 & 3,0 & 2,5 \\
\hline
\end{tabular}

Konzentrationsvergleich der mittleren Konzentration der Immunsuppressiva

Tabelle 42 gibt die Mediane des Vergleiches der mittleren Konzentration aller Immunsuppressiva hinsichtlich der Prokollagen Typ I Menge, aufgeteilt nach Einwirkzeit und Konzentration, angegeben.

Tabelle 42: Mediane der Prokollagen Typ I Menge (ng/ml):

Konzentrationsvergleich der mittleren Konzentration der Immunsuppressiva

\begin{tabular}{|l|c|c|c|}
\hline & \multicolumn{3}{|c|}{ Einwirkzeit } \\
Medikament & 0 Stunden & 6 Stunden & 48 Stunden \\
\hline Cyclosporin A & 2,6 & 4,1 & 5,0 \\
\hline Tacrolimus & 2,6 & 3,0 & 3,1 \\
\hline Sirolimus & 2,6 & 3,0 & 2,5 \\
\hline
\end{tabular}

\subsubsection{Angabe der Ergebnisse der allgemeinen statistischen Auswertung aller Parame-} ter

Tabelle 43 gibt einen Gesamtüberblick über die globale multifaktorielle Varianzanalyse der gewonnen Ergebnisse aller Immunsuppressiva, aufgeteilt nach den einzelnen Parametern. Aufgrund einiger, signifikanter Effekte der einzelen Parameter wurden die jedes Immunsuppressiva für sich statitisch ausgewertet. Hierbei wurde ein Signifikanzniveau von $5 \%$ festgelegt.

Tabelle 43: $\mathrm{p}$-Werte der globalen statistischen Auswertung der einzelnen Parameter aller Immunsuppressiva, Signifikanz bei $\mathrm{p}<0,05$

\begin{tabular}{|l|c|c|c|c|}
\hline Analysierte Faktoren & Gesamtzellzahl & Lebendzellzahl & $\begin{array}{l}\text { Zelldurch- } \\
\text { messer }\end{array}$ & Prokollagen \\
\hline Konzentration & $<0,0001$ & $<0,0001$ & 0,0059 & 0,4899 \\
\hline Zeit & $<0,0001$ & $<0,0001$ & $<0,0001$ & 0,6242 \\
\hline Konzentration*Zeit & 0,0157 & 0,0326 & 0,6648 & 0,8166 \\
\hline Medikament & $<0,0001$ & $<0,0001$ & 0,1327 & 0,7510 \\
\hline Konzentration*Medikament & $<0,0001$ & $<0,0001$ & 0,6909 & 0,9982 \\
\hline Zeit*Medikament & $<0,0001$ & $<0,0001$ & 0,0453 & 0,9904 \\
\hline Konzenra*Zeit*Medikament & 0,0589 & 0,0121 & 0,5465 & 1,0000 \\
\hline
\end{tabular}




\section{$9 \quad$ Literaturverzeichnis}

Abraham RT, Wiederrecht GJ (1996):

Immunopharmacology of rapamycin.

Annu Rev Immunol 14, 483-510

Adams D, Davies G (1984):

Gingival hyperplasia associated with cyclosporin A. A report of two cases.

Br Dent J 157(3), 89-90

Addy V, McElnay JC, Eyre DG, Campbell N, D'Arcy PF (1983):

Risk factors in phenytoin-induced gingival hyperplasia.

J Periodontol 54(6), 373-377

Aimetti M, Romano F, Debernardi C (2005):

Effectiveness of periodontal therapy on the severity of cyclosporin A-induced gingival overgrowth.

J Clin Periodontol 32(8), 846-850

Allison AC (2000):

Immunosuppressive drugs: the first 50 years and a glance forward.

Immunopharmacology $\underline{47}(2-3), 63-83$

Allman SD, McWhorter AG, Seale NS (1994):

Evaluation of cyclosporin-induced gingival overgrowth in the pediatric patient.

Pediatr Dent 16(1), 36-40

Angelopoulos AP, Goaz PW (1972):

Incidence of diphenylhydantoin gingival hyperplasia.

Oral Surg Oral Med Oral Pathol 34(6), 898-906

Armitage GC (1999):

Developement of a classification system for periodontal diseases and conditions.

Ann Periodontol 4(1), 1-6

Assmann T, Homey B, Ruzicka T (2000):

Applications of tacrolimus for the treatment of skin disorders.

Immunopharmacology 47(2-3), 203-213

Baker H, Sidorowicz A, Sehgal SN, Vézina C (1978):

Rapamycin (AY-22,989), a new antifungal antibiotic. III. In vitro an in vivo evaluation. J Antibiot (Tokyo) 31(6), 539-545

Barber MT, Savage NW, Seymour GJ (1992):

The effect of cyclosporin and lipopolysaccharide on fibroblasts: implications for cyclosporin-induced gingival overgrowth.

J Periodontol 63(5), 397-404

Barclay S, Thomason JM, Idle JR, Seymour RA (1992):

The incidence and severity of nifedipine-induced gingival overgrowth.

J Clin Periodontol 19(5), 311-314 
Bejarano V, Conaghan PG, Proudman SM, Buch MH, Brown AK, Emery P (2009): Long-term efficacy and toxicity of ciclosporin A in combination with methotrexate in poor prognosis rheumatoid arthritis.

Ann Rheum Dis 68(5), 761-763

Bökenkamp A, Bohnhorst B, Beier C, Albers N, Offner G, Brodehl J (1994):

Nifedipine aggravates cyclosporine A-induced gingival hyperplasia.

Pediatr Nephrol $\underline{8}(2), 181-185$

Bolzani G, Della Coletta R, Martelli Júnior H, De Almeida OP, Graner E (2000):

Cyclosporin A inhibits production and activity of matrix metalloproteinases by gingival fibroblasts.

J Periodontol Res 35(1), 51-58

Bonnaure-Mallet M, Tricot-Doleux S, Godeau GJ (1995):

Changes in extracellular matrix macromolecules in human gingiva after treatment with drugs inducing gingival overgrowth.

Arch Oral Biol 40(5), 393-400

Border WA, Noble NA (1994):

Transforming growth factor beta in tissue fibrosis.

N Engl J Med 331(19), 1286-1292

Borel JF (1981):

Cyclosporin-A--present experimental status.

Transplant Proc 13(1 Pt 1), 344-348

Borel JF, Feurer C, Gubler HU, Stähelin H (1976):

Biological effects of cyclosporin A: a new antilymphocytic agent.

Agents Actions 6(4), 468-475

Bowman JM, Levy BA, Grubb RV (1988):

Gingival overgrowth induced by diltiazem. A case report.

Oral Surg Oral Med Oral Pathol 65(2), 183-185

Calne RY, White DJ, Rolles K, Smith DP, Herbertson BM (1978):

Prolonged survival of pig orthotopic heart grafts treated with cyclosporin A.

Lancet $1(8075), 1183-1185$

\section{Cakir L:}

Mundhygieneverhalten und Gebisszustand von organtransplantierten Patienten.

Med. Diss. Göttingen 1999

Camargo PM, Melnick PR, Pirih FQ, Lagos R, Takei HH (2001):

Treatment of drug-induced gingival enlargement: aesthetic and functional considerations. Periodontol 2000 27, 131-138

Castronovo G, Liani G, Fedon A, De Iudicibus S, Decorti G, Costantinides F, Bevilacqua L (2014):

The effect of nonsurgical periodontal treatment on the severity of drug-induced gingival overgrowth in transplant patients.

Quintessence Int $\underline{45}(2), 115-124$ 
Chan S, Scheulen ME, Johnston S, Mross K, Cardoso F, Dittrich C, Eiermann W, Hess D, Morant R, Semiglazov V (2005):

Phase II study of temsirolimus (CCI-779), a novel inhibitor of mTOR, in heavily pretreated patients with locally advanced or metastatic breast cancer.

J Clin Oncol 23(23), 5314-5322

Chen SY, Yu HT, Kao JP, Yang CC, Chiang SS, Mishchuk DO, Mau JL, Slupsky

CM (2014):

An NMR metabolic study on the effect of alendronate in ovariectomized mice.

PloS One 9(9), eCollection 2014

Ciancio SG (1996):

Medications as risk factors for periodontal disease.

J Periodontol 67(10 Suppl), 1055-1059

Costa LC, Costa FO, Cortelli SC, Cortelli JR, Cota LO (2013):

Gingival overgrowth in renal transplant subjects: a 44-month follow-up study.

Transplantation 96(10), 890-896

Cota LO, Oliveira AP, Costa JE, Cortelli SC, Costa FO (2008):

Gingival status of Brazilian renal transplant recipients under sirolimus-based regimes.

J Periodontol 79(11), 2060-2068

Cota LO, Aquino DR, Franco GC, Cortelli JR, Cortelli SC, Costa FO (2010):

Gingival overgrowth in subjects under immunosuppressive regimes based on cyclosporine, tacrolimus, or sirolimus.

J Clin Periodontol 37(10), 894-902

Csiszar A, Wiebe C, Larjava H, Häkkinen L (2007):

Distinctive molecular composition of human gingival interdental papilla.

J Periodontol 78(2), 304-314

Daley TD, Wysocki GP (1984):

Cyclosporine therapy. Its significance to the periodontist.

J Periodontol 55(12), 708-712

Daley TD, Wysocki GP, Day C (1986):

Clinical and pharmacologic correlations in cyclosporine-induced gingival hyperplasia.

Oral Surg Oral Med Oral Pathol 62(4), 417-421

Dannewitz B (2012):

Gingivawucherungen

Dental Magazin $\underline{4}(2012), 44-46$

Dannewitz B, Eickholz P (2002a):

Gingivawucherungen 1. Ätiologie.

Parodontol 13(2), 179-184

Dannewitz B, Eickholz P (2002b):

Gingivawucherungen 2. Therapie.

Parodontol 13(4), 393-398 


\section{Dannewitz B, Edrich C, Tomakidi P, Kohl A, Gabbert O, Eickholz P, Steinberg T (2006):}

Elevated gene expression of MMP-1, MMP-10, and TIMP-1 reveal changes of molecules involved in turn-over of extracellular matrix in cyclosporine-induced gingival overgrowth. Cell Tissue Res 325(3), 513-522

Dannewitz B, Tomakidi P, Syagailo Y, Kohl A, Staehle HJ, Eickholz P, Komposch G, Steinberg T (2009):

Elevation of collagen type I in fibroblast-keratinocyte cocultures emphasizes the decisive role of fibroblasts in the manifestation of the phenotype of cyclosporin A-induced gingival overgrowth.

J Periodontal Res 44(1), 62-72

Dannewitz B, Krieger JK, Simon I, Dreyhaupt J, Staehle HJ, Eickholz P (2010): Full-mouth disinfection as a nonsurgical treatment approach for drug-induced gingival overgrowth: a series of 11 cases.

Int J Periodontics Restorative Dent 30(1), 63-71

Dannewitz B, Kruck EM, Staehle HJ, Eickholz P, Giese T, Meuer S, Kaever V, Zeier M, Sommerer C (2011):

Cyclosporine-induced gingival overgrowth correlates with NFAT-regulated gene expression: a pilot study.

J Clin Periodontol 38(11), 948-991

Darbar UR, Hopper C, Speight PM, Newman HN (1996):

Combined treatment approach to gingival overgrowth due to drug therapy.

J Clin Periodontol 23(10), 941-944

Dodge IL, Demicri G, Strom TB, Li XC (2000):

Rapamycin induces transforming growth factor-beta production by lymphocytes.

Transplant 70(7), 1104-1106

Dongari A, McDonnell HT, Langlais RP (1993):

Drug-induced gingival overgrowth.

Oral Surg Oral Med Oral Pathol 76(4), 543-548

Dongari-Bagtzoglou A, Kashleva H (2006):

Development of a highly reproducible three-dimensional organotypic model of the oral mucosa.

Nat Protoc 1(4), 2012-2018

Dumont FJ, Staruch MJ, Koprak SL, Melino MR, Sigal NH (1990):

Distinct mechanisms of suppression of murine T cell activation by the related macrolides FK-506 and rapamycin.

J Immunol 144(1), 251-258

Dunnett CW (1955):

A multiple comparison procedure for comparing several treatments with a control.

J Amer Statist Assoc 50(272), 1096-1121

Ellis JS, Seymour RA, Steele JG, Robertson P, Butler TJ, Thomason JM (1999): Prevalence of gingival overgrowth induced by calcium channel blockers: a communitybased study.

J Periodontol 70(1), 63-67 
Ellis JS, Seymour RA, Taylor JJ, Thomason JM (2004):

Prevalence of gingival overgrowth in transplant patients immunosuppressed with tacrolimus.

J Clin Periodontol 31(2), 126-131

Esposito C, Fornoni A, Cornacchia F, Bellotti N, Fasoli G, Foschi A, Mazzucchelli I, Mazzullo T, Semeraro L, Dal Canton A (2000):

Cyclosporine induces different responses in human epithelial, endothelial and fibroblast cell cultures.

Kidney Int 58(1), 123-130

\section{European FK506 Mulitcentre Liver Study Group (1994):}

Randomised trial comparing tarcolimus (FK506) and cyclosporin in prevention of liver allograft rejection. European FK506 Multicentre Liver Study Group.

Lancet 344(8920), 423-428

\section{Fattore L, Stablein M, Bredfeldt G, Semla T, Moran M, Doherty-Greenberg JM} (1991):

Gingival hyperplasia: a side effect $\mathrm{f}$ nifedipine and diltiazem.

Spec Care Dentist 11(3), 107-109

Flanagan WM, Corthésy B, Bram RJ, Crabtree GR (1991):

Nuclear association of T-cell transcription factor blocked by FK-506 and cyclosporin A. Nature 352(6338), 803-807

Fruman DA, Klee CB, Bierer BE, Burakoff SJ (1992):

Calcineurin phosphatase activity in T lymphocytes is inhibited by FK 506 and cyclosporin A.

Proc Natl Acad Sci USA 89(9), 3686-3690

Fu E, Nieh S, Chang HL, Wang SL (1995):

Dose-dependent gingval overgrowth induced by cyclosporin in rats.

J Periodontol 66(7), 594-598

\section{Gagliano N, Moscheni C, Dellavia C, Torri C, Stabellini G, Ferrario VF, Gioia M} (2004):

Effect of cyclosporin A on human gingival fibroblast collagen turnover in relation to the development of gingival overgrowth: an in vitro study.

Biomed Pharmacother 58(4), 231-238

Gagliano N, Moscheni C, Dellavia C, Stabellini G, Ferrario VF, Gioia M (2005a):

Immunosuppression and gingival overgrowth: gene and protein expression profiles of collagen turnover in FK506-treated human gingival fibroblasts.

J Clin Periodontol 32(2), 167-173

Gagliano N, Moscheni C, Torri C, Dellavia C, Stabellini G, Ferrario VF, Gioia M (2005b):

Differential effect of Cyclosporin A and FK506 on SPARC mRNA expression by human gingival fibroblasts.

Biomed Pharmacother 59(5), 249-252 
Gagliano N, Moscheni C, Tartaglia GM, Selleri S, Chiriva-Internati M, Cobos E, Torri C, Costa F, Pettinari L, Gioia M (2008):

A therapeutic dose of FK506 does not affect collagen turnover pathways in healthy human gingival fibroblasts.

Transplant Proc 40(5), 1419-1424

Ghafari A, Poorabbas R, Takieh JA, Sepehrvand N, Kargar C, Hatami S (2010):

Gingival enlargement and its risk factors in kidney transplant patients receiving cyclosporine A.

Iran J Kidney Dis $\underline{4}(1), 66-70$

Götze G, Walther G, Löwinger K (1990):

Effect of Cyclosporin-A on gingiva.

Stomatol DDR $\underline{40}(1), 15-16$

Granelli-Piperno A (1988):

In situ hybridazation for interleukin 2 and interleukin 2 receptor mRNA in T cells activated in the presence or absence of cyclosporin A.

J Exp Med 168(5), 1649-1658

Greenberg KV, Armitage GC, Shiboski CH (2008):

Gingival enlargement among renal transplant recipients in the era of new-generation immunosuppressants.

J Periodontol 79(3), 453-460

Gressmann G, Cakir L, Hornecker E, Mausberg RF (2007):

Oraler Zustand organtransplantierter Patienten unter immunsuppressiver Therapie.

Parodontologie 58(11), 1201-1210

Groth CG, Bäckman L, Morales JM, Calne R, Kreis H, Lang P, Touraine JL, Claesson K, Campistol JM, Durand D (1999):

Sirolimus (rapamycin)-based therapy in human renal transplantation: similar efficacy and different toxicity compared with cyclosporine. Sirolimus European Renal Transplant Study Group.

Transplantation 67(7), 1036-1042

Guggenheimer J, Mayher D, Eghtesad B (2005):

A survey of dental care protocols among US organ transplant centers.

Clin Transplant 19(1), 15-18

Günay H, Evers BG (1990):

Treatment-effect on cyclosporin A-induced gingival hyperplasia in patients with organ transplantation: a longitudinal study.

Parodontologie 1(4), 329-342

Gürkan A, Emingil G, Afacan B, Berdeli A, Atilla G (2014):

Alpha 2 integrin gene (ITGA2) polymorphism in renal transplant recipients with and without drug induced gingival overgrowth.

Arch Oral Biol 59(3), 283-288

Halle W (1998):

Toxizitätsprüfung in Zellkulturen für eine Vorhersage der akuten Toxizität (LD 50) zur

Einsparung von Tierversuchen.

Life Sciences 1,94 
Handschumacher RE, Harding MW, Rice J, Drugge RJ, Speicher DW (1984):

Cyclophilin: a specific cytosolic binding protein for cyclosporin A.

Science 226(4674), 544-547

Hannak V, Hermann D (1992):

Histologischer Vergleich der Cyclosporin-A und der Diphenylhydantion

Gingivahyperplasie.

Dtsch Zahnärtztl Z 47, 381-384

Hassell TM (1981):

Epilepsy and the oral manifestations of phenytoin therapy.

Monogr Oral Sci $\underline{9}, 1-205$

Hassell TM, Jacoway JR (1980a):

Clinical and scientific approaches to gingival enlargement (I).

Quintessence Int Dent Dig 11(10), 53-60

Hassell TM, Jacoway JR (1980b):

Clinical and scientific approaches to gingival enlargement (II).

Quintessence Int Dent Dig 11(11), 51-59

Hassell TM, Hefti AF (1991):

Drug-induced gingival overgrowth: old problem, new problem.

Crit Rev Oral Biol Med 2(1), 103-137

He Z, Deng Y, Li W, Chen Y, Xing S, Zhao X, Ding J, Gao Y, Wang X (2014):

Overexpression of PTEN suppresses lipopolysaccharide-induced lung fibroblast proliferation, differentiation and collagen secretion through inhibition of the PI3-K-Akt-GSK3beta pathway.

Cell Biosci 4(1), 3701-3704

Hefti AF, Eshenaur AE, Hassell TM, Stone C (1994):

Gingival overgrowth in cyclosporine A treated multiple sclerosis patients.

J Periodontol 65(8), 744-749

Herold KC, Lancki DW, Moldwin RL, Fitch FW (1986):

Immunosuppressive effects of cyclosporin A on cloned T cells.

J Immunol 136(4), 1315-1321

Hess AD, Esa AH, Colombani PM (1988):

Mechanisms of action of cyclosporine: effect on cells of the immune system and on subcellular events in T cell activation.

Transplant Proc 20(2 Suppl 2), 29-40

Hinke C:

Zum Einfluss der Generik von Cyclosporin-A auf die Wirkstoffkonzentration in Mischspeichel und Plaque.

Med. Diss. Göttingen 1994

Hornecker E (2001):

Langzeitkasuistik eines Patienten mit Nierentransplantat.

Parodontologie 12(3), 249-258 


\section{Hraský V:}

Klinische Studie zum Mundhygieneverhalten und zur zahnärztlichen Aufklärung von Patienten vor und nach Transplantation.

Med. Diss. Göttingen 2010

Hudes G, Carducci M, Tomczak P, Dutcher J, Figlin R, Kapoor A, Staroslawska E, Sosman J, McDermott D, Bodrogi I (2007):

Temsirolimus, interferon alfa, or both for advanced renal-cell carcinoma.

N Engl J Med 356(22), 2271-2281

Hyland PL, Traynor PS, Myrillas TT, Marley JJ, Linden GJ, Winter P, Leadbetter N, Cawston TE, Irwin CR (2003):

The effects of cyclosporin on the collagenolytic activity of gingival fibroblasts.

J Periodontol 74(4), 437-445

\section{Ilgenli T, Atilla G, Baylas H (1999):}

Effectiveness of periodontal therapy in patients with drug-induced gingival overgrowth.

Long-term results.

J Periodontol 70(9), 967-972

\section{Jahn S, Ender D:}

Gingivahyperplasie unter immunsuppressiver Therapie bei nierentransplantierten Patienten: ein Vergleich zwischen Cyclosporin A und Tacrolimus.

Med. Diss. Jena 2002

James JA, Irwin CR, Linden GJ (1995):

The effects of culture environment on the response of human gingival fibroblasts to cyclosporin A.

J Periodontol 66(5), 339-344

James JA, Jamal S, Hull PS, Macfarlane TV, Campbell BA, Johnson RW, Short CD (2001):

Tacrolimus is not associated with gingival overgrowth in renal transplant patients.

J Clin Periodontol 28(9), 848-852

Jorgensen MG (1997):

Prevalence of amlodipine-related gingival hyperplasia.

J Periodontol 68(7), 676-678

Kantarci A, Cebeci I, Tuncer O, Carin M, Firatli E (1999):

Clinical effects of periodontal therapy on the severity of cyclosporine A-induced gingival hyperplasia.

J Periodontol 70(6), 587-593

Kapturczak MH, Meier-Kriesche HU, Kaplan B (2004):

Pharmacology of calcineurin antagonists.

Transplant Proc 36(2 Suppl), 25S-32S

Karnik R, Bhat KM, Bhat GS (2012):

Prevalence of gingival overgrowth among elderly patients under amlodipine therapy at a large Indian teaching hospital.

Gerodontology 29(3), 209-213 
Keller U, Mohr W (1988):

Cyclosporin-induced gingival hyperplasia. Morphology and pathogenetic considerations.

Dtsch Z Mund Kiefer Gesichtschir 12(4), 267-271

Khanna A, Cairns V, Hosenpud JD (1999):

Tacrolimus induces increased expression of transforming growth factor-betal in mammalian lymphoid as well as nonlymphoid cells.

Transplantation 67(4), 614-619

Khoori AH, Einollahi B, Ansari G, Moozeh MB (2003):

The effect of cyclosporine with and without nifedipine on gingival overgrowth in renal transplant patients.

J Can Dent Assoc 69(4), 236-241

Kino T, Hatanaka H, Miyata S, Inamura N, Nishiyama M, Yajima T, Goto T, Okuhara M, Kohsaka M, Aoki H (1987):

FK-506, a novel immunosuppressant isolated from a Streptomyces. II. Immunosuppressive effect of FK-506 in vitro.

J Antibiot (Tokyo) 40(9), 1256-1265

Kowal A, Warmińska J, Krasowska D (2003):

Immunosuppressive drugs in dermatology--benefits and threats.

Ann Univ Mariae Curie Sklodowska Med 58(2), 14-21

Krönke M, Leonard WJ, Depper JM, Arya SK, Wong-Staal F, Gallo RC, Waldmann TA, Greene WC (1984):

Cyclosporin A inhibits T-cell growth factor gene expression at the level of mRNA transcription.

Proc Natl Acad Sci USA $\underline{81}(16), 5214-5218$

Krüger M, Schwaninger M, Blume R, Oetjen E, Knepel W (1997):

Inhibition of CREB- and cAMP response element-mediated gene transcription by the immunosuppressive drugs cyclosporin A and FK506 in T cells.

Naunyn Schmiedebergs Arch Pharmacol 356(4), 433-440

Lang NP (Hrsg.):

Parodontalerkrankungen. Klassifikation und Charakterisierung.

Quintessenz Verlag, Berlin 2003

Lauerma AI, Maibach HI (1994):

Topical FK506--clinical potential or laboratory curiosity?

Dermatology 188(3), 173-176

Lederman D, Lumerman H, Reuben S, Freedman PD (1984):

Gingival hyperplasia associated with nifedipine therapy. Report of a case.

Oral Surg Oral Med Oral Pathol 57(6), 620-622

Lemkamp V, Schlagenhauf U (2008):

Nichtchirurgische Therapie einer chronischen Parodontitis mit einer überlagerten medikamenteninduzierten Gingivawucherung.

Parodontologie 19(3), 243-254

Lindl T, Gstraunthaler G:

Zell- und Gewebekultur. 7. Auflage;

Springer Spektrum Verlag, Berlin 2013 


\section{Lin YT, Yang FT (2010):}

Gingival enlargement in children administered cyclosporine after liver transplantation. J Periodontol 81(9), 1250-1255

\section{Little JW, Falace DA:}

Zahnärztliche Behandlung von Risikopatienten.

Deutsche Lizenzausgabe; Deutscher Ärzte-Verlag GmbH, Köln 1991

Liu J, Farmer JD Jr, Lane WS, Friedman J, Weissman I, Schreiber SL (1991):

Calcineurin is a common target of cyclophilin-cyclosporin A and FKBP-FK506 complexes. Cell $\underline{66}(4), 807-815$

Loh C, Shaw KT, Carew J, Viola JP, Luo C, Perrino BA, Rao A (1996):

Calcineurin binds the transcription factor NFAT1 and reversibly regulates its activity. J Biol Chem 271(18), 10884-10891

López-Pintor RM, Hernández G, de Arriba L, Morales JM, Jiménez C, de Andrés A (2009):

Amlodipine and nifedipine used with cyclosporine induce different effects on gingival enlargement.

Transplant Proc 41(6), 2351-2353

Ma S, Liu P, Li Y, Hou L, Chen L, Qin C (2014):

Cyclosporine a inhibits apoptosis of rat gingival epithelium.

J Periodontol 85(8), 1126-1134

\section{Marcus R, Peritz E, Gabriel KR (1976):}

On closed testing procedures with special reference to ordered analysis of variance.

Biometrika 63(3), 655-660

Mariani G, Calastrini C, Carinci F, Marzola R, Calura G (1993):

Ultrastructural features of cyclosporine A-induced gingival hyperplasia.

J Periodontol 64(11), 1092-1097

\section{Marshall RI, Bartold PM (1999):}

A clinical review of drug-induced gingival overgrowths.

Aust Dent J 44(4), 219-232

Martel RR, Klicius J, Galet S (1977):

Inhibition of the immune response by rapamycin, a new antifungal antibiotic.

Can J Physiol Pharmacol 55(1), 48-51

Massagué J (1990):

The transforming growth factor-beta family.

Annu Rev Cell Biol 6, 597-641

\section{Matsuda S, Koyasu S (2000):}

Mechanisms of action of cyclosporine.

Immunopharmacology 47(2-3), 119-125

Matsuda S, Moriguchi T, Koyasu S, Nishida E (1998):

T lymphocyte activation signals for interleukin-2 production involve activation of MKK6p38 and MKK7-SAPK/JNK signaling pathways sensitive to cyclosporin A.

J Biol Chem 273(20), 12378-12382 
Mausberg R, Hornecker E, Visser H (1991):

Clinical applications of HF-surgery.

ZWR 100(4), 233-239

Mavrogiannis M, Ellis JS, Thomason JM, Seymour RA (2006a):

The management of drug-induced gingival overgrowth.

J Clin Periodontol 33(6), 434-439

Mavrogiannis M, Ellis JS, Seymour RA, Thomason JM (2006b):

The efficacy of three different surgical techniques in the management of drug-induced gingival overgrowth.

J Clin Periodontol 33(9), 677-682

McGaw WT, Porter H (1988):

Cyclosporine-induced gingival overgrowth: an ultrastructural stereologic study.

Oral Surg Oral Med Oral Pathol 65(2), 186-190

Mesa FL, Osuna A, Aneiros J, Gonzalez-Jaranay M, Bravo J, Junco P, Del Moral RG, O'Valle F (2003):

Antibiotic treatment of incipient drug-induced gingival overgrowth in adult renal transplant patients.

J Periodontal Res $\underline{38}(2), 141-146$

Michel G, Auer H, Kemény L, Böcking A, Ruzicka T (1996):

Antioncogene P53 and mitogenic cytokine interleukin-8 aberrantly expressed in psoriatic skin are inversely regulated by antipsoriatic drug tacrolimus (FK506).

Biochem Pharmacol 51(10), 1315-1320

Morris RE (1991):

In vivo immunopharmacology of the macrolides FK 506 and rapamycin: toward the era of rational immunosuppressive drug discovery, development, and use.

Transplant Proc 23(6), 2722-2724

Napoli KL, Taylor PJ (2001):

From beach to bedside: history of the development of sirolimus.

Ther Drug Monit 23(5), 559-586

Nassar CA, Nassar PO, Andia DC, Guimarães MR, Spolidorio LC (2008):

The effects of up to 240 days of tacrolimus therapy on the gingival tissues of rats--a morphological evaluation.

Oral Dis 14(1), 67-72

Niimi A, Tohnai I, Kaneda T, Takeuchi M, Nagura H (1990):

Immunohistochemical analysis of effects of cyclosporin A on gingival epithelium.

J Oral Pathol Med 19(9), 397-403

Paixão CG, Sekiguchi RT, Saraiva L, Pannuti CM, Silva HT, Medina-Pestana J, Romito GA (2011):

Gingival overgrowth among patients medicated with cyclosporin A and tacrolimus undergoing renal transplantation: a prospective study.

J Periodontol $\underline{82}(2), 251-258$ 
Pamuk F, Cetinkaya BO, Gulbahar MY, Gacar A, Keles GC, Erisgin Z, Arik N (2013):

Effects of tacrolimus and nifedipine, alone or in combination, on gingival tissues.

J Periodontol 84(11), 1673-1682

Pamuk F, Cetinkaya BO, Ayas B, Keles GC, Gacar A (2015):

Evaluation of gingival alterations in rats medicated with cyclosporine A, tacrolimus and sirolimus: a stereological study.

J Periodontal Res 50(5), 629-636

\section{Pernu HE, Oikarinen K, Hietanen J, Knuuttila M (1989):}

Verapamil-induced gingival overgrowth: a clinical, histologic, and biochemic approach. J Oral Pathol Med 18(7), 422-425

Pernu HE, Pernu LM, Huttunen KR, Nieminen PA, Knuuttila ML (1992):

Gingival overgrowth among renal transplant recipients related to immunosuppressive medication and possible local background factors.

J Periodontol 63(6), 548-553

Pistorius A, Willershausen B, Callaway A (2003):

Effects of selected immunosuppressive drugs on prostaglandin release, protein synthesis and cell proliferation in human gingival fibroblasts and on the growth of plaque bacteria. Eur J Med Res $\underline{8}(1), 25-32$

\section{Plagmann HC:}

Lehrbuch der Parodontologie.

Hanser Verlag, München 1998

Purschwitz R, Wesiger U, Schmidt H, Jentsch H (2007):

Cyclosporin-A-induzierte Gingivawucherungen- Eine Darstellung von 10 Patientenfällen. Parodontol 18(4), 387-395

Rateitschak-Plüss EM, Hefti A, Lörtscher R, Thiel G (1983):

Initial observation that cyclosporin-A induces gingival enlargement in man.

J Clin Periodontol 10(3), 237-246

Reichenspurner H, Soni V, Nitschke M, Berry GJ, Brazelton TR, Shorthouse R, Huang X, Reitz BA, Morris RE (1997):

Obliterative airway disease after heterotopic tracheal xenotransplantation: pathogenesis and prevention using new immunosuppressive agents.

Transplantation $\underline{64(3), 373-383}$

\section{Renz-Polster H, Krautzig S:}

Basislehrbuch Innere Medizin. 5. Auflage;

Urban \& Fischer Verlag/ Elsevier GmbH, München 2012

Rostock MH, Fry HR, Turner JE (1986):

Severe gingival overgrowth associated with cyclosporine therapy.

J Periodontol 57(5), 294-299

Rote Liste

Rote Liste ${ }^{\circledR}$ Service GmbH, Frankfurt 2015 
Sabers CJ, Martin MM, Brunn GJ, William JM, Dumont FJ, Wiederrecht G, Abraham RT (1995):

Isolation of a protein target of the FKBP12-rapamycin complex in mammalian cells.

J Biol Chem 270(2), 815-822

Salman BN, Vahabi S, Movaghar SE, Mahjour F (2013):

Proliferative and inductive effects of Cyclosporine a on gingival fibroblast of child and adult.

Dent Res J (Isfahan) 10(1), 52-58

Sawada S, Suzuki G, Kawase Y, Takaku F (1987):

Novel immunosuppressive agent, FK506. In vitro effects on the cloned T cell activation. J Immunol 139(6), 1797-1803

\section{Schalaikin N:}

Wirkung von zwei verschieden konzentrierten alkoholfreien CHX-Mundspüllösungen auf die Regenerationsfähigkeit von humanen Gingivafibroblasten.

Med. Diss. Göttingen 2013

Schincaglia GP, Forniti F, Cavallini R, Piva R, Calura G, del Senno L (1992):

Cyclosporin-A increases type I procollagen production and mRNA level in human gingival fibroblasts in vitro.

J Oral Pathol Med 21(4), 181-185

Schreier MH, Baumann G, Zenke G (1993):

Inhibition of T-cell signaling pathways by immunophilin drug complexes: are side effects inherent to immunosuppressive properties?

Transplant Proc 25(1 Pt 1), 502-507

Schrem H, Barg-Hock H, Strassburg CP, Schwarz A, Klempnauer J (2009):

Nachsorge bei Organtransplantierten.

Dtsch Arztebl Int 106(9), 148-155

Schroeder HE (1986):

The Periodontium.

in: Oksche A, Vollrath L (Hrsg.):

Handbook of Microscopic Anatomy.

Springer-Verlag, Berlin/Heidelberg 1986

Schulz A, Lange DE, Hassell TM, Stone CE, Lison AE (1990):

Cyclosporine-induced gingival hyperplasia in renal transplant patients.

Dtsch Zahnarztl Z 45(7), 414-416

Sehgal SN, Baker H, Vézina C (1975):

Rapamycin (AY-22,989), a new antifungal antibiotic. II. Fermantation, isolation and characterization.

J Antibiot (Tokyo) 28(10), 727-732

\section{Sehgal SN (1998):}

Rapamune (RAPA, rapamycin, sirolimus): mechanism of action immunosuppressive effect results from blockade of signal transduction and inhibition of cell cycle progression.

Clin Biochem 31(5), 335-340 
Seibel W, Yahia NA, McCleary LB, Lesko LJ, Hassell TM (1989):

Cyclosporine-induced gingival overgrowth in beagle dogs.

J Oral Pathol Med 18(4), 240-245

Seymour RA (2003):

Dentistry and the medically compromised patient.

Surgeon 1(4), 207-214

Seymour RA, Smith DG (1991):

The effect of plaque control programme on the incidence and severity of cyclosporininduced gingival changes.

J Clin Periodontol 18(2), 107-110

Seymour RA, Jacobs DJ (1992):

Cyclosporin and the gingival tissues.

J Clin Periodontol 19(1), 1-11

Seymour RA, Thomason JM, Ellis JS (1996):

The pathogenesis of drug-induced gingival overgrowth.

J Clin Periodontol 23(3 Pt 1), 165-175

Seymour RA, Ellis JS, Thomason JM (2000):

Risk factors for drug-induced gingival overgrowth.

J Clin Periodontol 27(4), 217-223

Shihab FS, Andoh TF, Tanner AM, Noble NA, Border WA, Franceschini N, Bennett WM (1996):

Role of transforming growth factor-beta 1 in experimental chronic cyclosporine nephropathy.

Kidney Int 49(4), 1141-1151

Shin GT, Khanna A, Ding R, Sharma VK, Lagman M, Li B, Suthanthiran M (1998): In vivo expression of transforming growth factor-betal in humans: stimulation by cyclosporine.

Transplantation $\underline{65(3), 313-318}$

Slavin J, Taylor J (1987):

Cyclosporin, nifedipine, and gingival hyperplasia.

Lancet 2(8561), 739

Socransky SS, Haffajee AD, Ximenez-Fyvie LA, Feres M, Mager D (1999):

Ecological considerations in the treatment of Actinobacillus actinomycetemcomitans and Porphyromonas gingivalis periodontal infections.

Periodontol 2000 20, 341-362

Somacarrera ML, Hernández G, Acero J, Moskow BS (1994):

Factors related to the incidence and severity of cyclosporin-induced gingival overgrowth in transplant patients. A longitudinal study.

J Periodontol 65(7), 671-675

Somacarrera ML, Lucas M, Scully C, Barrios C (1997):

Effectiveness of periodontal treatments on cyclosporine-induced gingival overgrowth in transplant patients.

Br Dent J 183(3), 89-94 
Starzl TE, Iwatsuki S, Malatack JJ, Zitelli BJ, Gartner JC Jr, Hakala TR, Rosenthal JT, Shaw BW Jr (1982):

Liver and kidney transplantation in children receiving cyclosporin A and steroids.

J Pediatr 100(5), 681-686

Starzl TE, Todo S, Fung J, Demetris AJ, Venkataramman R, Jain A (1989):

FK 506 for liver, kidney, and pancreas transplantation.

Lancet 2(8670), 1000-1004

Staudinger LA, Spano SJ, Lee WS, Coelho N, Moriarty TJ, McCulloch CA (2015):

Role of discoidin domain receptor 1 in dysregulation of collagen remodeling by cyclosporin A.

Int J Biochem Cell Biol 62, 80-87

Su B, Jacinto E, Hibi M, Kallunki T, Karin M, Ben-Neriah Y (1994):

$\mathrm{JNK}$ is involved in signal integration during costimulation of T lymphocytes.

Cell 77(5), 727-736

Subramani T, Sakkarai A, Senthilkumar K, Periasamy S, Abraham G, Rao S (2007): Expression of insulin like growth factor binding protein-5 in drug induced human gingival overgrowth.

Indian J Med Res 125(1), 43-48

Süss R, al-Ayoubi M, Ruzicka T (1993):

Cyclosporine therapy in Behçet's disease.

J Am Acad Dermatol 29(1), 101-112

\section{Szilinski K:}

Hauttumoren im Kopf-Halsbereich bei Patienten nach Organtransplantation unter besonderer Berücksichtigung der aktuellen immunsuppressiven Regime.

Med. Diss. München 2009

Terada N, Patel HR, Takase K, Kohno K, Nairn AC, Gelfand EW (1994):

Rapamycin selectively inhibits translation of mRNAs encoding elongation factors and ribosomal proteins.

Proc Natl Acad Sci U S A 91(24), 11477-11481

\section{Thomas L:}

Labor und Diagnose. 6. Auflage;

TH-Books Verlagsgesellschaft GmbH, Frankfurt/Main 2005

Thomason JM, Seymour RA, Rawlins MD (1992):

Incidence and severity of phenytoin-induced gingival overgrowth in epileptic patients in general medical practice.

Community Dent Oral Epidemiol 20(5), 288-291

Tipton DA, Stricklin GP, Dabbous MK (1991):

Fibroblast heterogeneity in collagenolytic response to cyclosporine.

J Cell Biochem 46(2),152-165

Todaro GJ, Green H (1963):

Quantitative studies of the growth of mouse embryo cells in culture and their development into established lines.

J Cell Biol 17, 299-313 
Todorova L, Bjermer L, Miller-Larsson A, Westergren-Thorsson G (2010):

Relationship between matrix production by bronchial fibroblasts and lung function and AHR in asthma.

Respir Med 104(2), 1799-1808

Tyldesley WR, Rotter E (1984):

Gingival hyperplasia induced by cyclosporin-A.

Br Dent J 157(9), 305-309

Tyler B, Wadsworth S, Recinos V, Mehta V, Vellimana A, Li K, Rosenblatt J, Do H, Gallia GL, Siu IM (2011):

Local delivery of rapamycin: a toxicity and efficacy study in an experimental malignant glioma model in rats.

Neuro Oncol 13(7), 700-709

Vasanthan A, Dallal N (2007):

Periodontal treatment considerations for cell transplant and organ transplant patients.

Periodontol $2000 \underline{44}, 82-102$

Velich N, Remport A, Szabó G (2002):

Dental screening of patients after organ transplantation.

Orv Hetil 143(10), 505-508

Vézina C, Kudelski A, Sehgal SN (1975):

Rapamycin (AY-22,989), a new antifungal antibiotic. I. Taxonomy of the producing streptomycete and isolation of the active principle.

J Antiobiot (Tokyo) 28(10), 721-726

Vogel C, Köhler I, Lauchart W, Reichart P (1984):

Cyclosporin-A induced oral mucosal changes.

Dtsch Z Mund Kiefer Gesichtschir $\underline{8}(3), 168-171$

Walker RG, Cottrell S, Sharp K, Tripodi R, Nicholls KM, Fraser I, Varigos GA, Butcher BE (2007):

Conversion of cyclosporine to tacrolimus in stable renal allograft recipients: quantification of effects on the severity of gingival enlargement and hirsutism and patient-reported outcomes.

Nephrology (Carlton) 12(6), 607-614

Wentz LA, Oliveira SC, Moreira CH, Rösing CK (2012):

Low prevalence of gingival overgrowth associated to new immunosuppressive protocols with cyclosporin.

Braz Oral Res 26(1), 64-70

Willershausen-Zönnchen B, Lemmen C, Hamm G (1991):

The effect of cyclosporin A (Cya) on the growth and metabolic activity of gingival fibroblasts.

Schweiz Monatsschr Zahnmed 101(1), 18-23

Wysocki GP, Gretzinger HA, Laupacis A, Ulan RA, Stiller CR (1983):

Fibrous hyperplasia of the gingiva: a side effect of cyclosporin A therapy.

Oral Surg Oral Med Oral Pathol 55(3), 274-278 
Yamasaki A, Rose GG, Pinero GJ, Mahan CJ (1987):

Ultrastructure of fibroblasts in cyclosporin A-induced gingival hyperplasia.

J Oral Pathol 16(3), 129-134

Zyba V:

Wirkung von antiseptischen Mundspüllösungen auf die menschlichen Zellen der Mundschleimhaut.

Med. Diss. Göttingen 2010

\section{Internetquellen:}

AAOM (2015):

http://www.aaom.com/index.php\%3Foption\%3Dcom_content\%26view\%3Darticle\%26id \%3D132:gingival-enlargement $\% 26$ catid $\% 3 \mathrm{D} 22$ :patient-condition-

information\%26Itemid\%3D120; Zugriff am 05.06.2016

DSO Jahresbericht 2015:

http://www.dso.de/uploads/tx_dsodl/DSO_JB_2015_Web_2.pdf; Zugriff am 06.06.2016

Merck, Millipore:

CSA: http://www.merckmillipore.com/DE/de/product/Cyclosporin-A\%2C-

Tolypocladium-inflatum---CAS-59865-13-3---Calbiochem,EMD_BIO-

239835\#anchor_Description; Zugriff am 10.06.2016

TCR: http://www.merckmillipore.com/INTL/es/product/FK-506,-Streptomyces-sp.--CAS-104987-11-3---Calbiochem,EMD_BIO-342500; Zugriff am 10.06.2016

SIR: https://www.merckmillipore.com/INTL/en/product/InSolution ${ }^{\text {TM}-R a p a m y c i n---~}$ Calbiochem,EMD_BIO-553211; Zugriff am 10.06.2016

Roche Diagnostics Corporation (2010):

https://lifescience.roche.com/wcsstore/RASCatalogAssetStore/Articles/05955653001_04.1

0 US.pdf ;Zugriff am: 05.06.2016 


\section{Danksagung}

\section{Mein ganz besonderer Dank gilt:}

Herrn PD Dr. med. dent. Dirk Ziebolz für die Herausgabe dieses interessanten zahnmedizinisch-medizinisch interdisziplinären Themas wie auch die hervorragende Betreuung und Unterstützung;

Frau Monika Hoch für ihre ausgezeichnete Unterstützung in allen experimentellen Belangen;

Herrn Markus Harden aus der Abteilung Medizinische Statistik für die hervorragende statistische Beratung.

Meiner Familie für ihre kontinuierliche Unterstützung. 


\section{Lebenslauf}

Am 13.09.1987 wurde ich als Tochter von Jutta Meyl-Sievers und Arnd Sievers in Kassel geboren.

Von 1994 bis 1998 besuchte ich die Grundschule (Bilsteinschule) in Edermünde-Besse. 1998 wechselte ich auf das Gymnasium (König-Heinrich-Schule) in Fritzlar. Die elfte Klasse absolvierte ich im Jahr 2004/2005 in den Vereinigten Staaten (Marietta, Georgia). Anschließend wechselte ich 2005 auf das Gymnasium Herderschule in Kassel und erlangte dort im Jahr 2007 mein Abitur (Note: 1,9).

Zum Wintersemester 2007/2008 nahm ich das Studium der Zahnmedizin an der GeorgAugust-Universität Göttingen auf. Meine Approbation erhielt ich im Dezember 2012 (Note: 1$)$.

Anschließend arbeitete ich bis August 2013 an den experimentellen Versuchen meiner Dissertation.

Von September 2013 bis August 2014 war ich als Vorbereitungsassistentin in der allgemeinzahnärztlichen Praxis Dres. V. Schardt und S. Vogel in München tätig. Anschließend wechselte ich meine Arbeitsstätte und arbeitete von September 2014 bis Dezember 2014 als Vorbereitungsassistentin in der kieferorthopädischen Facharztpraxis Dr. S. Müller in Puchheim. Seit Januar 2015 absolviere ich meine Facharztausbildung und das bayrische Curriculum in der kieferorthopädischen Facharztpraxis Prof. Dr. R. Koch in Bamberg. 